Spectral Measurements in Critical Assemblies: MCNP Specifications and Calculated Results

Stephanie C. Frankle

Judith F. Briesmeister 



\section{DISCLAIMER}

This report was prepared as an account of work sponsored by an agency of the United States Government. Neither the United States Government nor any agency thereof, nor any of their employees, make any warranty, express or implied, or assumes any legal liability or responsibility for the accuracy, completeness, or usefulness of any information, apparatus, product, or process disclosed, or represents that its use would not infringe privately owned rights. Reference herein to any specific commercial product, process, or service by trade name, trademark, manufacturer, or otherwise does not necessarily constitute or imply its endorsement, recommendation, or favoring by the United States Government or any agency thereof. The views and opinions of authors expressed herein do not necessarily state or reflect those of the United States Government or any agency thereof. 


\section{DISCLAIMER}

Portions of this document may be illegible in electronic image products. Images are produced from the best available original document. 


\section{Table of Contents}

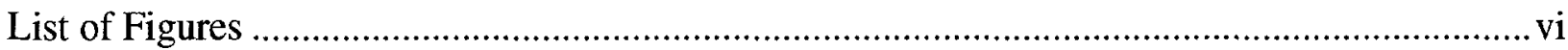

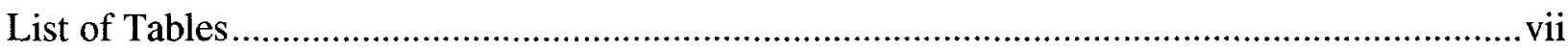

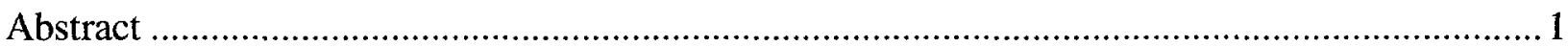

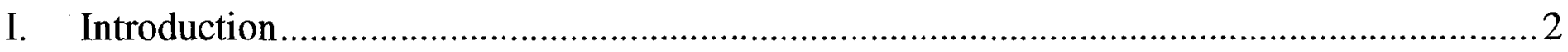

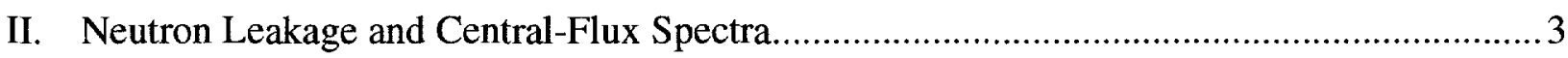

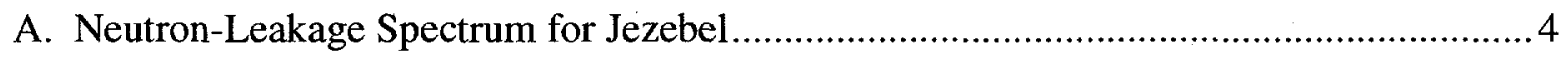

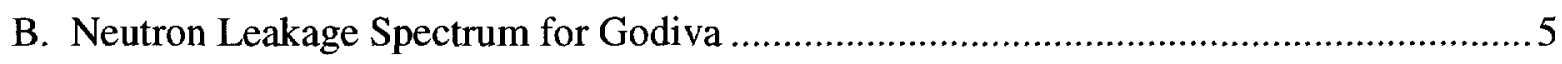

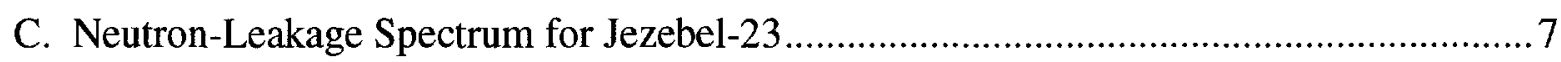

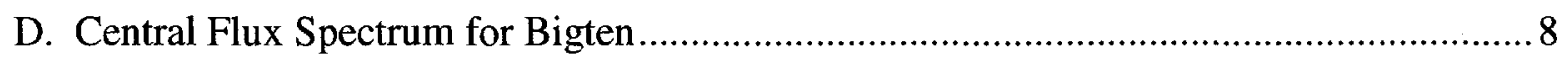

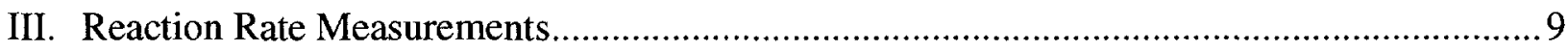

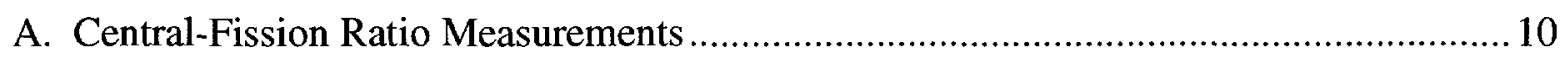

1. Central-fission Ratios for ${ }^{232} \mathrm{Th}$........................................................................ 14

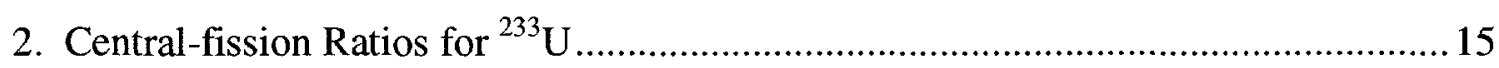

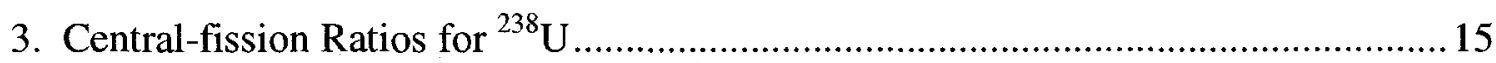

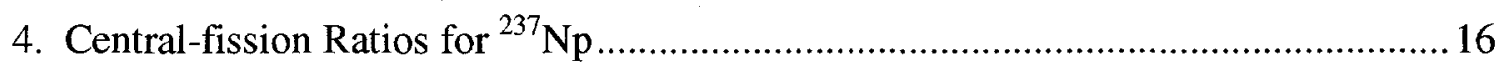

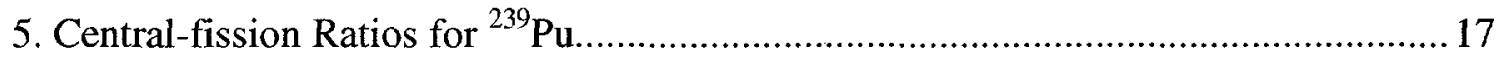

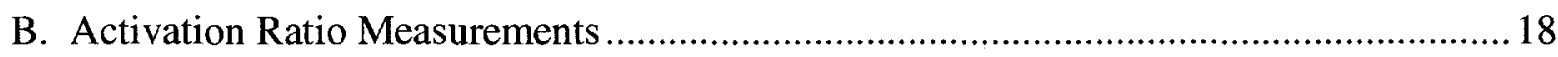

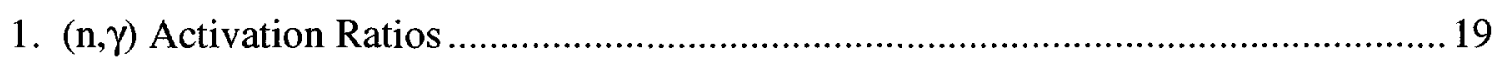

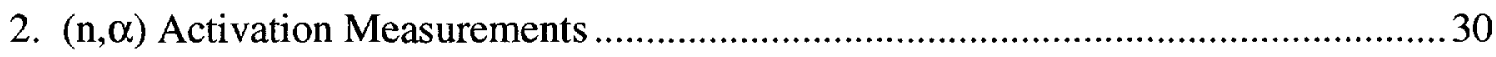

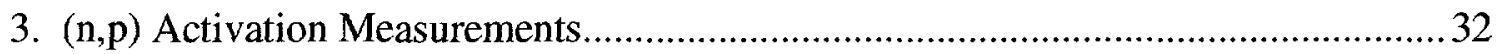

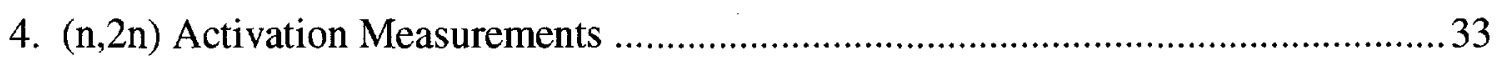

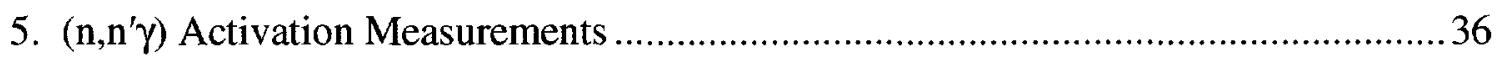

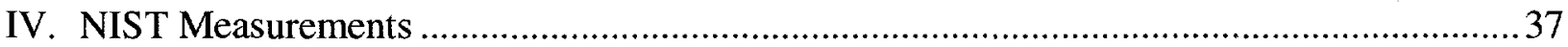

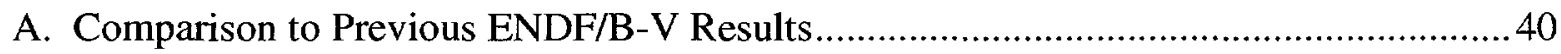

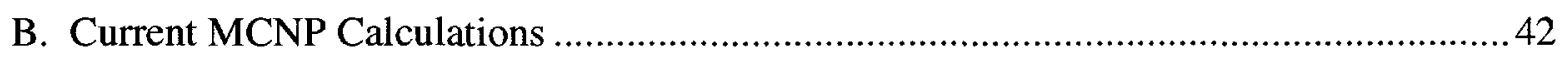

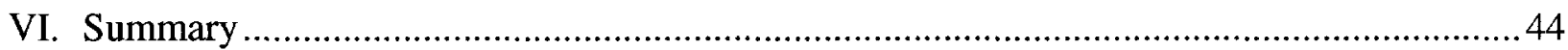

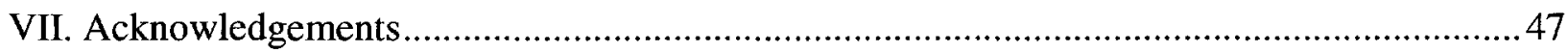

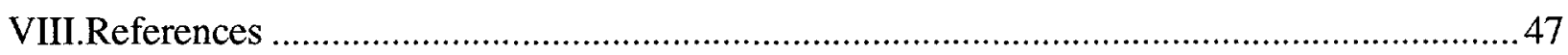

Appendix A: Plots of Fission Cross Sections......................................................................

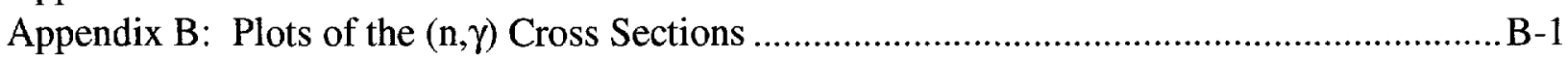

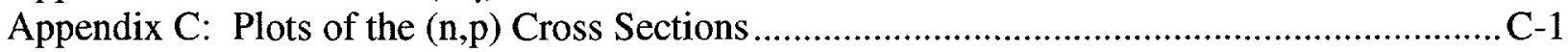

Appendix D: Plots of the $(\mathrm{n}, 2 \mathrm{n})$ Cross Sections.......................................................................

Appendix E: Plots of Other Cross Sections ....................................................................... E-1 


\section{List of Figures}

Figure 1. Comparison of the Jezebel neutron-leakage spectrum/CSEWG group structure. 4

Figure 2. Comparison of the Jezebel neutron-leakage spectrum/Stewart group structure. .5

Figure 3. Comparison of the Godiva neutron-leakage spectrum/CSEWG group structure. 6

Figure 4. Comparison of the Godiva neutron-leakage spectrum/Stewart group structure. 6

Figure 5. Comparison of the Jezebel-23 neutron-leakage spectrum/CSEWG group structure....... 7

Figure 6. Comparison of the Bigten central-flux spectrum/CSEWG group structure. 8

Figure 7. Central-neutron flux spectra for Jezebel (pumet1), Jezebel-Pu (pumet2), Godiva (umet1ss), and Jezebel-23 (23umt1) assemblies.

Figure 8. Central-neutron flux spectra for Jezebel (pumet1), Flattop-25 (umet28), Flattop-Pu

(pumet6), and Flattop-23 (flat23) assemblies.

Figure 9. Central-neutron flux spectra for Jezebel (pumet1), Thor (pumet8a), and Bigten (bigten 1) assemblies.

Figure 10. Comparison of ${ }^{232} \mathrm{Th}$ fission cross sections from $1-20 \mathrm{MeV}$.

Figure 11. Comparison of the fission cross section for ${ }^{239} \mathrm{Pu}$.

Figure 12 The ENDF/B-V cross sections for the $(n, \alpha)$ activation ratio.

Figure 13. NIST experimental geometry for the $5.08 \mathrm{~cm}\left(2^{\prime \prime}\right)$ sphere. 38

Figure 14. Neutron flux spectra for the $5.08 \mathrm{~cm} \mathrm{(2")} \mathrm{sphere} \mathrm{experiments} \mathrm{at} \mathrm{the} \mathrm{foil} \mathrm{locations....39}$

Figure 15. Total absorption cross section for Cadmium from ENDF/B-V. 39 


\section{List of Tables}

Table 1. Data Used for the Central-Fission Ratio Calculations in MCNP................................. 12

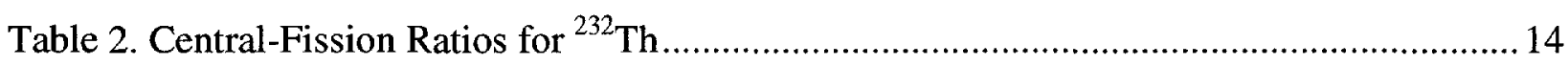

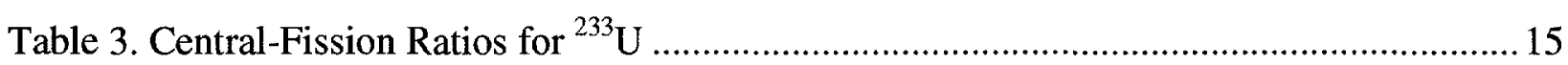

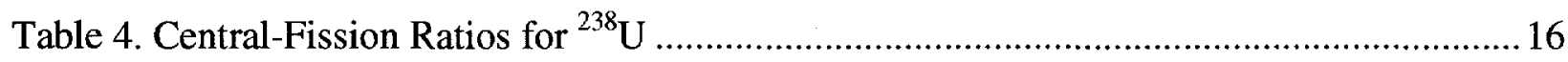

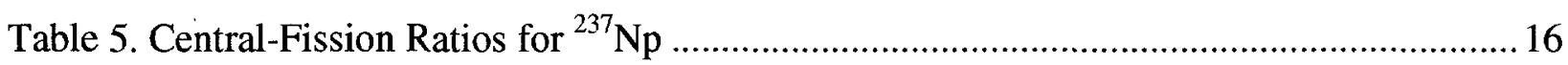

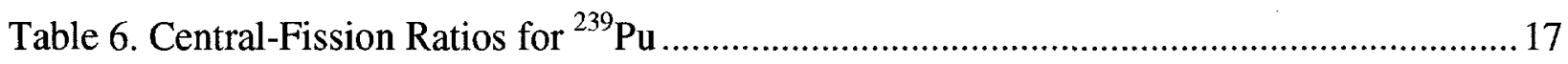

Table 7. Experimental Data for the $(\mathrm{n}, \gamma)$ Activation Ratio Measurements ................................20

Table 8. Data Used in the MCNP Calculations for the (n, $\gamma$ ) Activation Ratios ..........................222

Table 9. Comparison of MCNP Calculations to Experiment for the $(\mathrm{n}, \gamma)$ Activation Ratios.......23

Table 10. Experimental Data for the $(n, \alpha)$ Activation Ratio Measurements ...............................30

Table 11. Data Used in the MCNP Calculations for the $(n, \alpha)$ Activation Ratios ........................ 31

Table 12. Comparison of MCNP Calculations to Experiment for the $(n, \alpha)$ Activation Ratios .... 31

Table 13. Experimental Data for the (n,p) Activation Ratio Measurements...............................32

Table 14. Data Used in the MCNP Calculations for the $(n, p)$ Activation Ratios ..................... 32

Table 15. Comparison of MCNP Calculations to Experiment for the $(n, p)$ Activation Ratios .... 33

Table 16. Experimental Data for the (n,2n) Activation Ratio Measurements..............................34

Table 17. Data Used in the MCNP Calculations for the (n,2n) Activation Ratios .....................34

Table 18. Comparison of MCNP Calculations to Experiment for the (n,2n) Activation Ratios .. 35

Table 19. Experimental Data for the (n,n' $\gamma)$ Activation Ratio Measurements ............................36

Table 20. Data Used in the MCNP Calculations for the $\left(\mathbf{n}, \mathbf{n}^{\prime} \gamma\right)$ Activation Ratios .....................36

Table 21. Comparison of MCNP Calculations to Experiment for the (n,n' $\gamma$ ) Activation Ratios .. 36

Table 22. Data Used for the Fission Rate Calculations in MCNP ............................................38

Table 23. Comparison of Original (ENDF/B-V) and Current (ENDF/B-VI) Transport Calculations with Experiment for the ENDF/B-V Fission Rates

Table 24. Comparison of MCNP Calculations to NIST Experimental Measurements for ${ }^{235} \mathrm{U} \ldots 42$

Table 25. Comparison of MCNP Calculations to NIST Experimental Measurements for ${ }^{238} \mathrm{U}$...43

Table 26. Comparison of MCNP Calculations to NIST Experimental Measurements for ${ }^{237} \mathrm{~Np} .43$

Table 27. Comparison of MCNP Calculations to NIST Experimental Measurements for ${ }^{239} \mathrm{Pu} . .44$ 


\title{
SPECTRAL MEASUREMENTS IN CRITICAL ASSEMBLIES: MCNP SPECIFICATIONS AND CALCULATED RESULTS
}

\author{
by
}

Stephanie C. Frankle and Judith F. Briesmeister

\begin{abstract}
Recently, a suite of 86 criticality benchmarks for the Monte Carlo N-Particle (MCNP) transport code was developed, and the results of testing the ENDF/B-V and ENDF/B-VI data (through Release 2) were published. In addition to the standard $\mathrm{k}_{\mathrm{eff}}$ measurements, other experimental measurements were performed on a number of these benchmark assemblies. In particular, the Cross Section Evaluation Working Group (CSEWG) specifications contain experimental data for neutron leakage and central-flux measurements, central-fission ratio measurements, and activation ratio measurements. Additionally, there exists another set of fission reaction-rate measurements performed at the National Institute of Standards and Technology (NIST) utilizing $a^{252} \mathrm{Cf}$ source. This report will describe the leakage and central-flux measurements and show a comparison of experimental data to MCNP simulations performed using the ENDF/B-V and BVI (Release 2) data libraries. Central-fission and activation reaction-rate measurements will be described, and the comparison of experimental data to MCNP simulations using available data libraries for each reaction of interest will be presented. Finally, the NIST fission reaction-rate measurements will be described. A comparison of MCNP results published previously with the current MCNP simulations will be presented for the NIST measurements, and a comparison of the current MCNP simulations to the experimental measurements will be presented.
\end{abstract}




\section{Introduction}

Recently, a suite of 86 criticality benchmarks for the Monte Carlo N-Particle (MCNP ${ }^{*}$ ) transport code $^{1,2}$ was developed, and the results of testing the ENDF/B-V and ENDF/B-VI data (through Release $2^{\ddagger}$ ) were published. ${ }^{3}$ This suite of criticality $\left(\mathrm{k}_{\mathrm{eff}}\right)$ benchmarks was developed using two primary sources of information: the Cross Section Evaluation Working Group (CSEWG) specifications ${ }^{4}$ and the International Criticality Safety Benchmark Evaluation Project (ICSBEP) specifications. ${ }^{5}$ In addition to the standard $\mathrm{k}_{\mathrm{eff}}$ measurements, other experimental measurements were performed on a number of these benchmark assemblies. In particular, the CSEWG specifications contain experimental data for neutron leakage and central-flux measurements, central-fission ratio measurements, and activation ratio measurements. Additionally, there exists another set of fission reaction-rate measurements performed at the National Institute of Standards and Technology (NIST) utilizing a ${ }^{252} \mathrm{Cf}$ source. ${ }^{6,7}$ This report will first describe the leakage and central-flux measurements and will show a comparison of experimental data to MCNP simulations performed using the ENDF/B-V and B-VI data libraries. In Section III, centralfission and activation reaction-rate measurements will be described, and the comparison of experimental data to MCNP simulations using available data libraries for each reaction of interest will be presented. Finally, the NIST fission reaction-rate measurements will be described in Section IV. A comparison of MCNP results published previously with the current MCNP simulations will be presented, and a comparison of the current MCNP simulations to the experimental measurements will be presented.

Additionally, central-worth and transverse fission and activation measurements have been performed with critical assemblies that are not included in this report, and these measurements should be considered for future validation efforts. Central-worth measurements for a variety of materials are discussed in the CSEWG specifications. Transverse fission and activation measurements, where measurements are made at different radial positions in the assembly, have been performed using the Godiva, Jezebel-23, Topsy, Flattop-25, Flattop-Pu, and Thor assemblies. $^{8,9,10,11,12,13,14}$

\footnotetext{
${ }^{*}$ MCNP is a trademark of the Regents of the University of California, Los Alamos National Laboratory.

${ }^{\dagger}$ Evaluated Nuclear Data File.

ENDF/B-VI data is through Release 2 throughout this report.
} 


\section{Neutron Leakage and Central-Flux Spectra}

The CSEWG specifications include neutron-leakage spectra for the Jezebel, Godiva, and Jezebel-23 critical assemblies. The Jezebel assembly is a bare sphere of ${ }^{239} \mathrm{Pu}$, the Godiva assembly is a bare sphere of highly-enriched uranium, and the Jezebel-23 assembly is a bare sphere of ${ }^{233} \mathrm{U}$. A central-flux spectrum is provided for the Bigten assembly. The onedimensional representation of the Bigten assembly is a normal (natural) uranium-reflected sphere of enriched uranium (10.06 wt\%). The one-dimensional model for each of these assemblies was used in these calculations.

The neutron spectra for the Jezebel, Godiva, Jezebel-23, and Bigten assemblies were calculated with the MCNP geometries (pumet1, umet1ss, 23umt1, and bigten 1, respectively) given in Reference 2. For each assembly, the MCNP calculations performed with ENDF/B-V and ENDF/B-VI data are compared with the measured data. The ENDF/B-V data are those referenced by the ZAID (see Appendix G of Reference 1) ending of ".50c" or ".55c," while the ENDF/B-VI data are referenced by the ZAID ending of ".60c" and are contained in the ENDF60 library. ${ }^{15}$ The leakage spectra were calculated using an F2 tally over the outer surface of the assembly, and the central-flux spectrum of Bigten was calculated using an F4 tally in a 1-cm radius sphere at the center of the assembly.

The CSEWG neutron spectra are given in half-lethargy groups with a reference energy of $10 \mathrm{MeV}$. The half-lethargy group structure is defined by the following formula:

$$
\operatorname{In}\left(\frac{E_{\text {ref }}}{E}\right)=0.5,1.0,1.5, \ldots .
$$

where $E$ represents the lower energy limit of the groups and $E_{\mathrm{ref}}$ is the reference energy. In addition to the CSEWG specifications, we have the original publication of the experimental data in a finer group structure reported by Stewart ${ }^{16}$ for the Jezebel and Godiva assemblies. Neutronenergy spectra are generally measured in critical assemblies using proton-recoil detectors that are able to measure neutrons with energies greater than $\sim 20 \mathrm{keV}$. For each spectrum in the figures, the total flux has been normalized to 1.0 over equivalent energy ranges for comparison purposes. Error bars are given for all of the MCNP results and for all of the experimental data, except for the central-flux spectrum of Bigten, for which no experimental error bars were reported. 


\section{A. Neutron-Leakage Spectrum for Jezebel}

Figures 1 and 2 show a comparison of the MCNP calculations with the CSEWG and Stewart data, respectively, with little difference between the ENDF/B-V and B-VI calculations. The MCNP data libraries slightly underpredict the flux in the lowest energy bins and overpredict the flux near $1 \mathrm{MeV}$, but show good overall agreement with experiment.

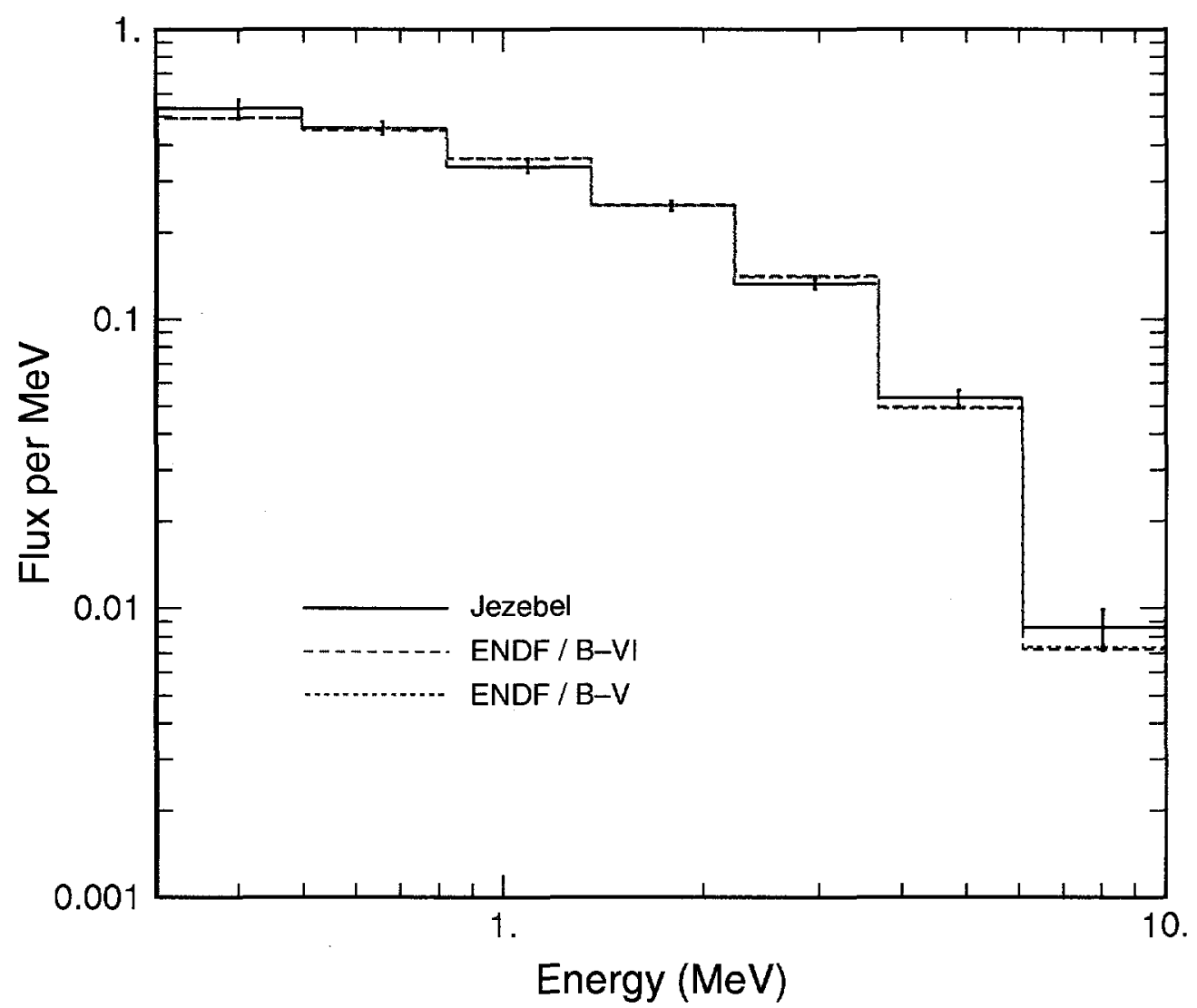

Figure 1. Comparison of the Jezebel neutron-leakage spectrum using the CSEWG group structure. 


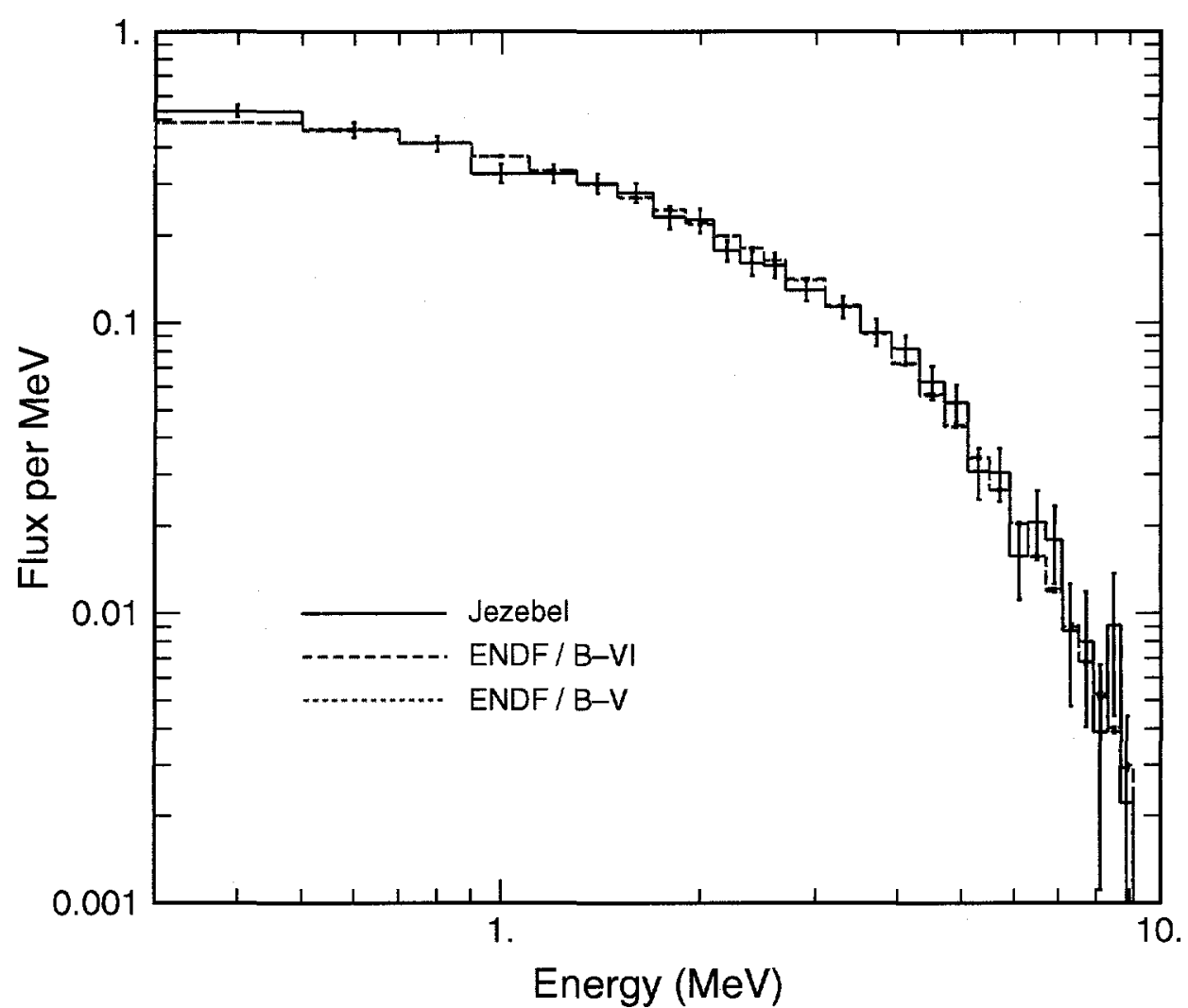

Figure 2. Comparison of the Jezebel neutron-leakage spectrum using the Stewart group structure.

\section{B. Neutron Leakage Spectrum for Godiva}

Figures 3 and 4 show a comparison of the MCNP calculations with the CSEWG and Stewart data, respectively, with better agreement between the ENDF/B-VI data and experiment than with the ENDF/B-V data. In the lowest energy regions the ENDF/B-VI flux is higher than ENDF/B$\mathrm{V}$, and in the intermediate and higher energy regions the ENDF/B-VI spectra is lower than ENDF/B-V. 


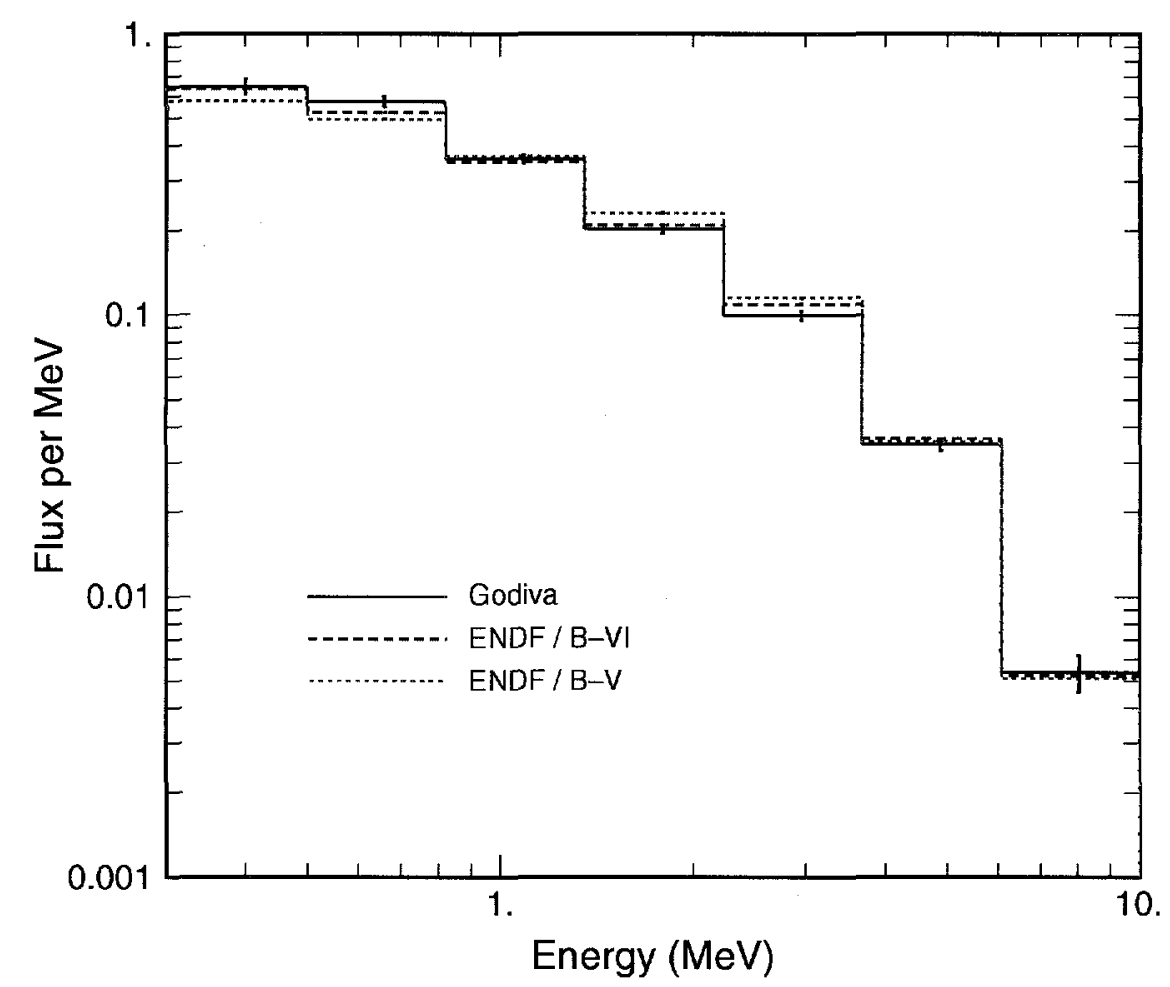

Figure 3. Comparison of the Godiva neutron-leakage spectrum using the CSEWG group structure.

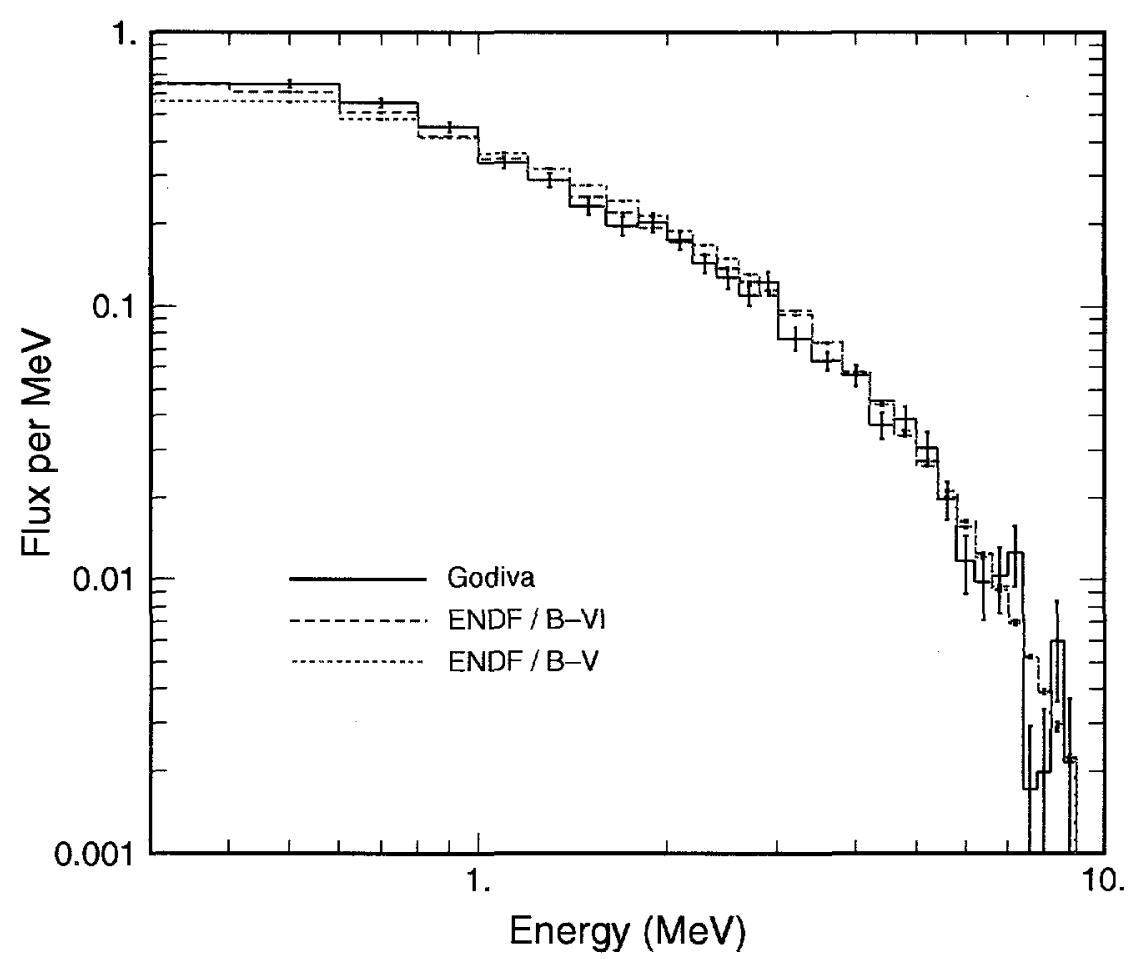

Figure 4. Comparison of the Godiva neutron-leakage spectrum using the Stewart group structure. 


\section{Neutron-Leakage Spectrum for Jezebel-23}

Figure 5 compares the MCNP calculations with the CSEWG data, showing little difference between the ENDF/B-V and B-VI calculations, as expected. The ENDF/B-VI evaluation for ${ }^{233} \mathrm{U}$ is equivalent to the ENDF/B-V evaluation except for the addition of photon-production data. The addition of photon-production data will not affect the neutron transport, so small differences in the results for ${ }^{233} \mathrm{U}$ are because of small differences in the processing of the ENDF evaluation into an MCNP data library. The ENDF data underpredict the flux in the lowest energy bin $(<0.5$ $\mathrm{MeV})$, but do an adequate job in the higher energy regions. In an attempt to understand the underestimate of the flux in the lowest energy bin, we ran the calculation using data from the ENDL92 ${ }^{17}$ and JENDL3.2 ${ }^{18}$ libraries. The $\mathrm{k}_{\text {eff }}$ results were quite different among the ENDF (0.9929 \pm 0.0002$)$, ENDL92 (0.9978 \pm 0.0002$)$, and JENDL3.2 (1.0129 \pm 0.0002$)$ libraries, but the neutron-leakage spectrum was underpredicted by the same amount in the lowest energy bin by all libraries.

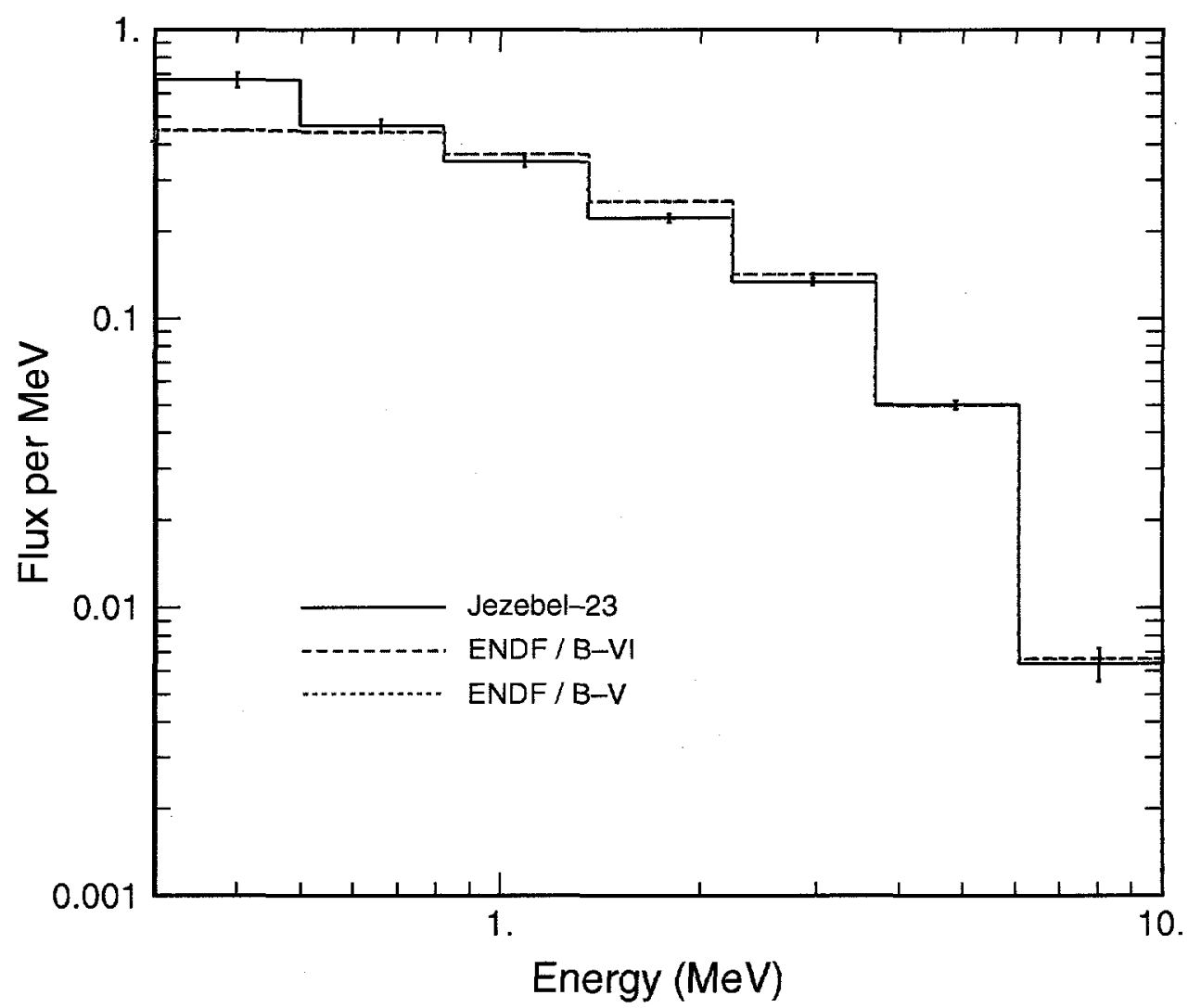

Figure 5. Comparison of the Jezebel-23 neutron-leakage spectrum using the CSEWG group structure. 


\section{Central Flux Spectrum for Bigten}

Figure 6 compares the MCNP calculations with the CSEWG data for the central-flux spectrum in Bigten, showing a substantial improvement in predicting the neutron flux in the lowest energy groups when using ENDF/B-VI. Both ENDF/B-VI and B-V data underpredict the flux below $\sim 0.02 \mathrm{MeV}$, and appear to overpredict the flux from $0.04-0.08 \mathrm{MeV}$. As there are no error bars given for the CSEWG spectrum, it is difficult to assess the degree of disagreement with experiment. There is agreement between the MCNP data and experiment for the higher energy regions ( $>0.1 \mathrm{MeV}$ ). The CSEWG specifications do not give a measured value for the highest energy group, therefore no definitive comparison is possible. Sensitivity studies were performed and determined that the increase in the neutron-energy spectrum in the lowest energy bins is mostly from the improvements in the ENDF/B-VI evaluation for ${ }^{238} \mathrm{U}$. The balance between elastic and total inelastic cross sections changed significantly in the new ENDF/B-VI evaluation for ${ }^{235} \mathrm{U}$, but this change had a much smaller effect on the neutron-energy spectrum for Bigten.

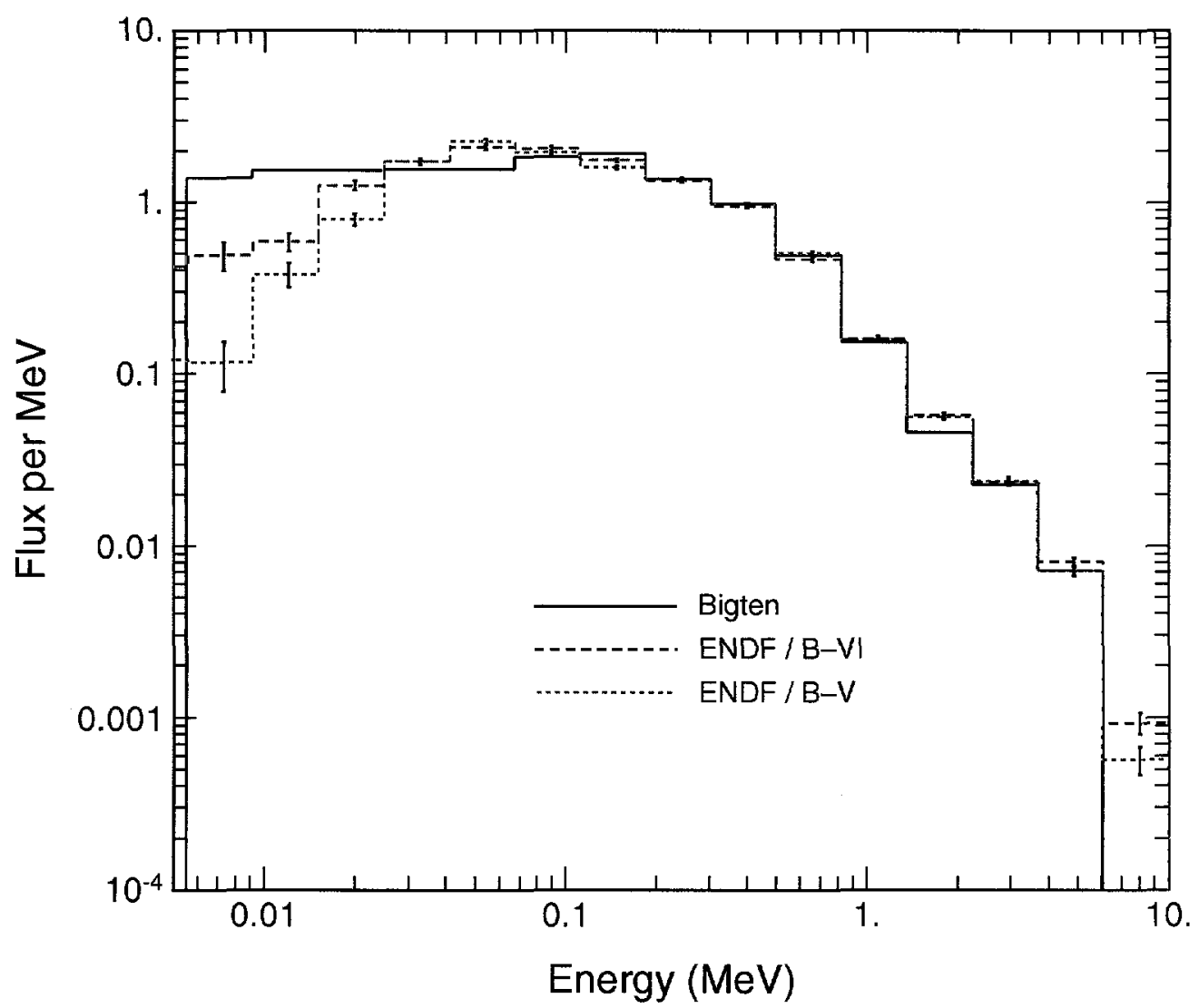

Figure 6. Comparison of the Bigten central-flux spectrum using the CSEWG group structure. 


\section{Reaction Rate Measurements}

Reaction rates are measured in critical assemblies by placing a foil of the isotope of interest in a critical assembly and irradiating the foil for a specified length of time. Following the irradiation, the foils are then placed in a gamma-ray counting facility where the gamma-ray spectrum is measured at a standard source-to-detector distance. The emission rate of gamma-ray(s) corresponding to the specific reaction of interest is then measured. Most counting facilities use HPGe or NaI gamma-ray detectors. The reaction rate can be determined by an expression similar to the following: ${ }^{19,20}$

$$
R=\left(\frac{A}{\varepsilon B}\right)\left(\frac{a}{m p N_{0}}\right)\left(\frac{\lambda e^{\lambda \tau}}{f\left(1-e^{-\lambda \top^{\prime}}\right)\left(1-e^{-\lambda t}\right)}\right)\left(\frac{\delta_{1}}{\delta_{2} \delta_{3} \delta_{4} \delta_{5} \delta_{6}}\right)
$$

where

$A$ is the measured peak area,

$\varepsilon$ is the detector efficiency for point source at the gamma-ray energy of interest,

$\mathrm{B}$ is the absolute gamma-ray intensity or branching ratio,

$\mathrm{a}$ is the atomic mass of the isotope of interest,

$m$ is the mass of the foil,

$\mathrm{p}$ is the weight abundance of the mass of interest,

$\mathrm{N}_{\mathrm{o}}$ is equal to $6.023 \times 10^{23}$,

$\lambda$ is equal to $\left(\ln 2 / T_{1 / 2}\right)$, where $T_{1 / 2}$ is the half-life,

$\mathrm{T}$ is the counting time (live),

$\mathrm{T}^{\prime}$ is the counting time (clock),

$f$ is equal to $T / T^{\prime}$,

$t$ is the irradiation time,

$\tau$ is the decay time from end of irradiation to start of counting,

$\delta_{1}$ is the correction for finite sample,

$\delta_{2}$ is the parent/daughter activity ratio,

$\delta_{3}$ is the correction for coincidence sampling,

$\delta_{4}$ is the correction for random summing, 
$\delta_{5}$ is the correction for gamma-ray absorption in the sample, and $\delta_{6}$ is the correction for external gamma-ray absorbers.

For many of the irradiations using the Bigten assembly, multiple irradiations of individual foil sets were performed. Neutron flux monitors provided run-to-run normalization. The individual foil packets then were sent to multiple laboratories for analysis. The high degree of consistency between reaction rates obtained by each laboratory $(\leq 2 \%)$ lends confidence to the measured values. Additional experiments typically are performed to ensure that the reaction rates are insensitive to the placement of the foil packets in the assembly cavity and to the presence of multiple foils in each packet (neutron scattering and absorption effects with the foil packet). For fissionable nuclides of interest, experiments utilizing a fission chamber in place of the foils also can be performed..$^{21,22}$ The holder assembly for the foil packets is often designed like a fission chamber to ensure that neutron scattering and absorption for both the activation foils and fissionchamber measurements are the same.

For a given reaction, such as ${ }^{45} \mathrm{Sc}(\mathrm{n}, \gamma)$, multiple final states may be populated. For the ${ }^{45} \mathrm{Sc}(\mathrm{n}, \gamma)$ reaction, the first metastable state of ${ }^{46} \mathrm{Sc}$ with a half-life of 18.75 seconds and the ground state of ${ }^{46} \mathrm{Sc}$ with a half-life of 83.79 days are populated. It is assumed that the published results are given for the total reaction-rate for such situations, unless otherwise explicitly stated in the publication. For cross-section data that give separate cross sections for each process, such as population of the metastable and ground states of ${ }^{46} \mathrm{Sc}$, the sum of the cross sections must be used in the MCNP calculations. Often publications are not explicit about the specific reaction of interest in their tables of results, so care must be taken to search the text of a publication for this information. Additionally, the half-lives and branching ratios used by the experimentalists in computing the reaction rate may change over time. No attempt has been made to correct for differences between the values used by the experimentalists and the values accepted today. ${ }^{23,24}$

\section{A. Central-Fission Ratio Measurements}

The CSEWG specifications have central-fission ratio measurements for nine assemblies: Jezebel, Jezebel-Pu, Jezebel-23, Godiva, Flattop-Pu, Flattop-25, Flattop-23, Bigten, and Thor. The Jezebel, Jezebel-23, Godiva, and Bigten assemblies were described in Section II. Jezebel-Pu is a sphere of ${ }^{239} \mathrm{Pu}$ with a higher concentration of ${ }^{240} \mathrm{Pu}(20 \mathrm{wt} \%)$ than Jezebel, which has $4.5 \mathrm{wt} \%$ 
${ }^{240} \mathrm{Pu}$. Flattop-Pu, Flattop-25, and Flattop-23 are assemblies with a highly-enriched uranium core and are reflected by ${ }^{239} \mathrm{Pu}$, normal uranium, and ${ }^{233} \mathrm{U}$, respectively. Thor is an assembly with a ${ }^{239} \mathrm{Pu}\left(5.1 \mathrm{wt} \%\right.$ ) core reflected by ${ }^{232} \mathrm{Th}$. The one-dimensional (spherical) model for each of these assemblies was used in these calculations.

In addition to the CSEWG specifications, a smaller set of measurements were available from the Chemical Science and Technology (CST) Division at Los Alamos National Laboratory (LANL). ${ }^{25}$ No experimental errors were given for the CST-LANL measurements. Each of the measurements in the CSEWG and CST-LANL specifications gives the ratio of the fission rate of a nuclide with respect to the ${ }^{235} \mathrm{U}$ fission rate for a foil situated in the center of the assembly. Nuclides for which experimental data exist include ${ }^{232} \mathrm{Th},{ }^{233,238} \mathrm{U},{ }^{237} \mathrm{~Np}$, and ${ }^{239} \mathrm{Pu}$.

The fission reaction rates were calculated in MCNP by using an FM tally multiplier of the appropriate fission cross section (as specified by the MT value) for an F4 tally in a 1-cm radius sphere in the center of each assembly. Previous studies have shown that this method gives equivalent results to using a point-detector tally at the center of the assembly. ${ }^{26}$ The centralfission ratio was then calculated by dividing the fission reaction rate for the nuclide of interest by the ${ }^{235} \mathrm{U}$ fission rate, propagating the MCNP statistical error. ${ }^{27}$ For every ratio, the ENDF/B-VIbased data from the ENDF60 library were used for producing the neutron spectrum in the assembly and for calculating the ${ }^{235} \mathrm{U}$ fission reaction rate. Four sets of data were tested for each nuclide of interest and are detailed in Table 1 . The fission cross sections from each data library used in the calculations are shown in Appendix A for ${ }^{232} \mathrm{Th},{ }^{233,238} \mathrm{U},{ }^{237} \mathrm{~Np}$, and ${ }^{239} \mathrm{Pu}$. The ENDL92 data library ${ }^{11}$ and the LLLDOS dosimetry library ${ }^{28,29}$ are based on evaluations performed at Lawrence Livermore National Laboratory (LLNL). To make the comparison of calculation to experiment easier, the calculated-to-experimental ratio (C/E) was computed for each reaction of interest, along with its associated relative error (RE). Relative errors are quoted at the $1 \sigma$ level.

The nine assemblies have a fairly fast neutron-energy spectrum in the center of each assembly, as shown in Figures 7-9. The neutron spectrum from each assembly has been normalized to a total flux of 1.0 for comparison purposes. The central flux spectrum for Jezebel (pumet1) is shown in all three figures for ease of comparison. Note that while error bars were not plotted in these figures, it is clear that the error bars on the neutron flux below $0.001 \mathrm{MeV}$ are large, but this energy region has little impact on the calculations. The Jezebel (pumet1), Jezebel- 
$\mathrm{Pu}$ (pumet2), Jezebel-23 (23umt1), Godiva (umet1ss), Flattop-Pu (pumet6), Flattop-25 (umet28), Flattop-23 (flat23), Bigten (bigten1), and Thor (pumet8a) assemblies are referenced by their MCNP filenames and are documented in Reference 2.

Table 1. Data Used for the Central-Fission Ratio Calculations in MCNP

\begin{tabular}{clccc}
\hline $\begin{array}{c}\text { Target } \\
\text { Nuclide }\end{array}$ & ENDF/B-V & $\begin{array}{c}\text { ENDF/B-VI } \\
\text { Release 2 }\end{array}$ & ENDL92 & $\begin{array}{c}\text { LLLDOS } \\
\text { (ACTL) }\end{array}$ \\
\hline${ }^{232} \mathrm{Th}$ & $90232.50 \mathrm{c}$ & $90232.60 \mathrm{c}$ & $90232.42 \mathrm{c}$ & $90232.30 \mathrm{y}$ \\
${ }^{233} \mathrm{U}$ & $92233.50 \mathrm{c}$ & $92233.60 \mathrm{c}$ & $92233.42 \mathrm{c}$ & $92233.30 \mathrm{y}$ \\
${ }^{238} \mathrm{U}$ & $92238.50 \mathrm{c}$ & $92238.60 \mathrm{c}$ & $92238.42 \mathrm{c}$ & $92238.30 \mathrm{y}$ \\
${ }^{237} \mathrm{~Np}$ & $93237.55 \mathrm{c}(\mathrm{a})$ & $93237.60 \mathrm{c}$ & $93237.42 \mathrm{c}$ & $93237.30 \mathrm{y}$ \\
${ }^{239} \mathrm{Pu}$ & $94239.55 \mathrm{c}$ & $94239.60 \mathrm{c}$ & $94239.42 \mathrm{c}$ & $94239.30 \mathrm{y}$
\end{tabular}

(a) LANL evaluation and not ENDF/B-V.

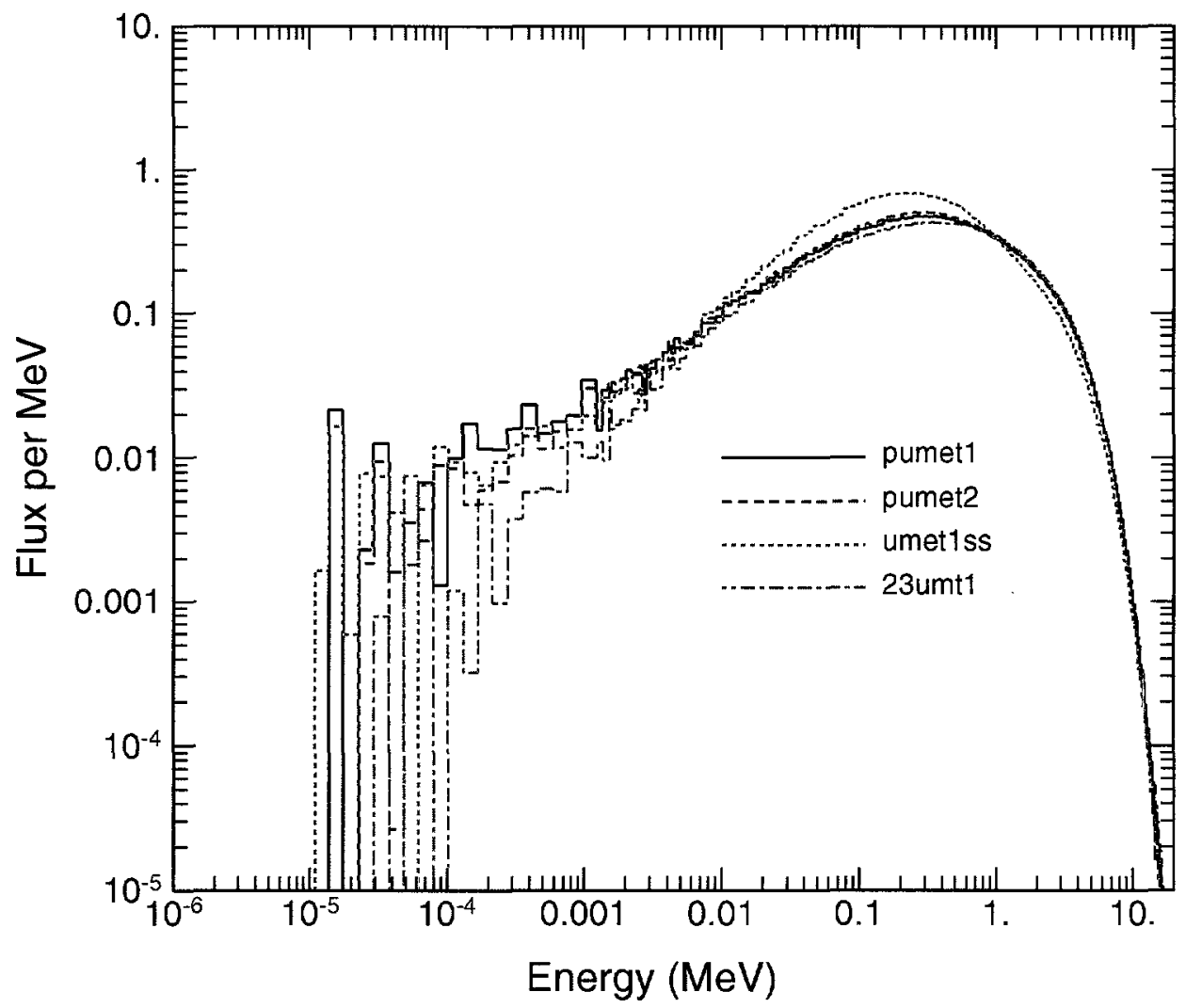

Figure 7. Central-neutron flux spectra for Jezebel (pumet1), Jezebel-Pu (pumet2), Godiva (umet1ss), and Jezebel-23 (23umt1) assemblies. 


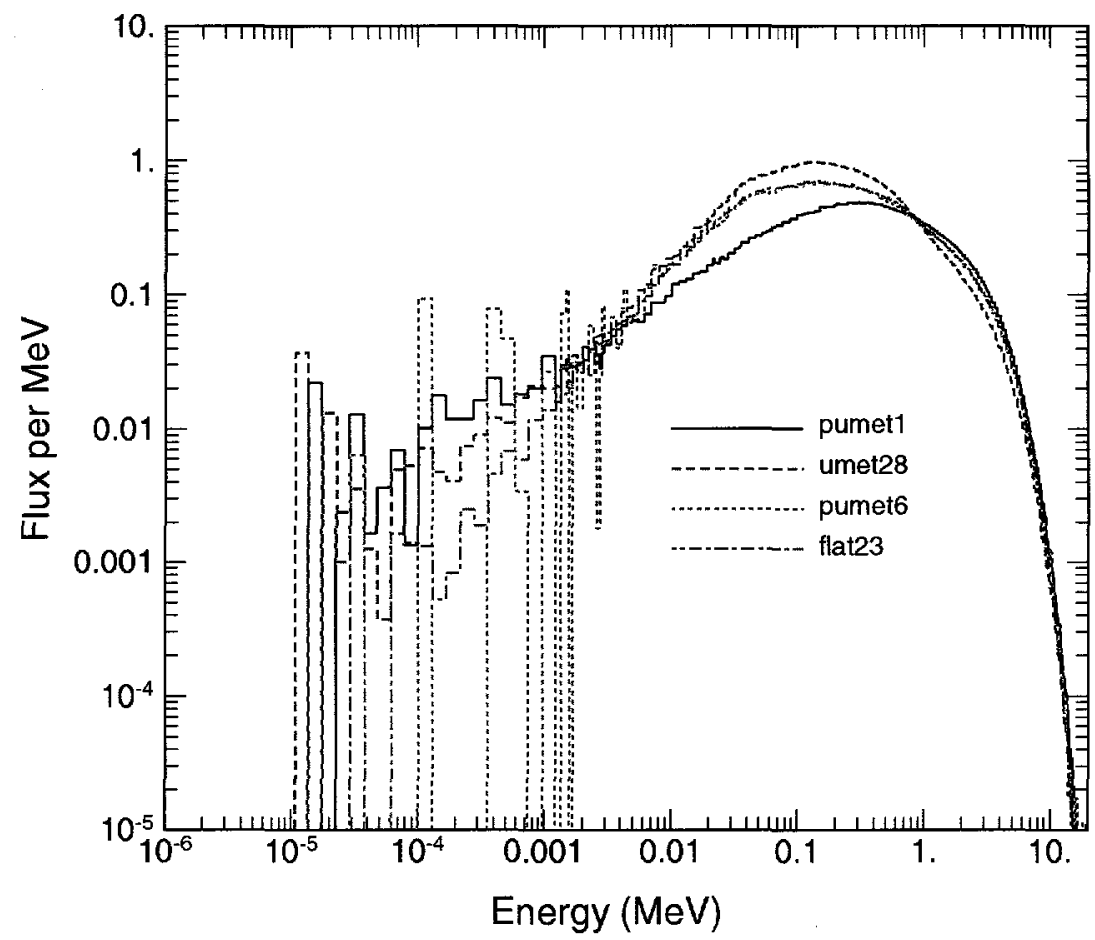

Figure 8. Central-neutron flux spectra for Jezebel (pumet1), Flattop-25 (umet28), Flattop-Pu (pumet6), and Flattop-23 (flat23) assemblies.

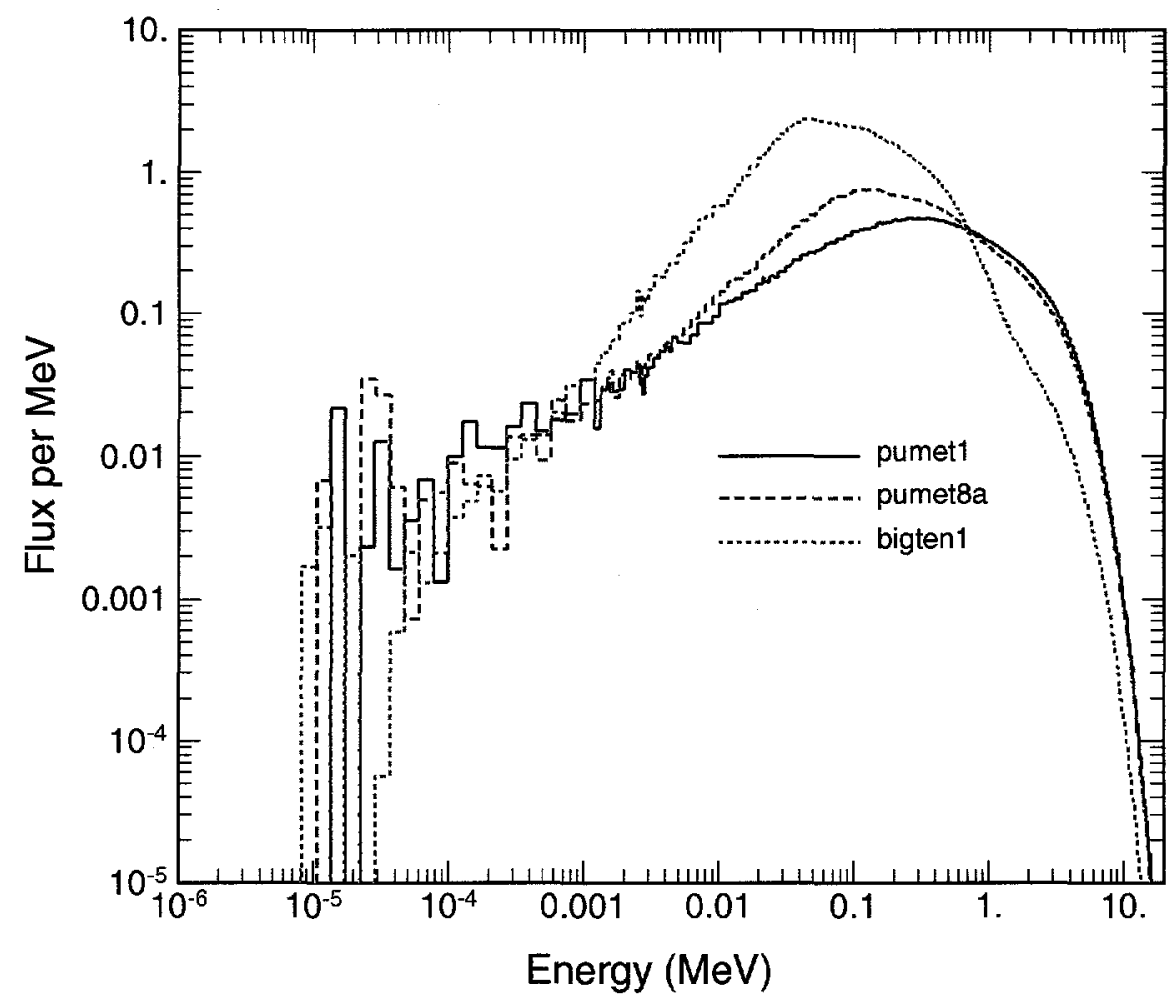

Figure 9. Central-neutron flux spectra for Jezebel (pumet1), Thor (pumet8a), and Bigten (bigten1) assemblies. 


\section{Central-fission Ratios for ${ }^{232} \mathrm{Th}$}

Unlike the other central-fission measurements, the fission rate for ${ }^{232} \mathrm{Th}$ was compared to the fission rate for ${ }^{238} \mathrm{U}$ in the Thor assembly. Therefore, ENDF/B-VI data were used for the ${ }^{238} \mathrm{U}$ fission reaction rate for all the results given in Table 2 . The ${ }^{232} \mathrm{Th}$ evaluation did not change from ENDF/B-V to B-VI, hence the results are equivalent for this reaction rate. ENDF underpredicts the fission rate for ${ }^{232} \mathrm{Th}$, while the LLNL data come much closer. This is because of the slight overall increase in the fission cross section between 1-6 MeV in the LLNL data relative to the ENDF data, as shown in Figure 10. The increase in the fission cross section from 6-10 MeV is less important. Eighty-eight percent of the reaction rate is from neutrons having an energy of 1-6 $\mathrm{MeV}, 12 \%$ is from neutrons between $6-10 \mathrm{MeV}$, less than $0.1 \%$ is from neutrons below $1 \mathrm{MeV}$, and less than $1 \%$ is from neutrons above $10 \mathrm{MeV}$.

Table 2. Central-Fission Ratios for ${ }^{232} \mathrm{Th}$

\begin{tabular}{cccccccccccc}
\hline Assembly & \multicolumn{2}{c}{ CSEWG } & \multicolumn{2}{c}{ ENDF/B-V } & \multicolumn{2}{c}{$\begin{array}{c}\text { ENDF/B-VI } \\
\text { Release 2 }\end{array}$} & & ENDL92 & $\begin{array}{c}\text { LLLDOS } \\
\text { (ACTL) }\end{array}$ \\
\hline & Expt. & RE & C/E & RE & C/E & RE & C/E & RE & C/E & RE \\
Thor & 0.26 & 0.038 & 0.951 & 0.039 & 0.951 & 0.039 & 0.988 & 0.039 & 0.988 & 0.039 \\
\hline
\end{tabular}

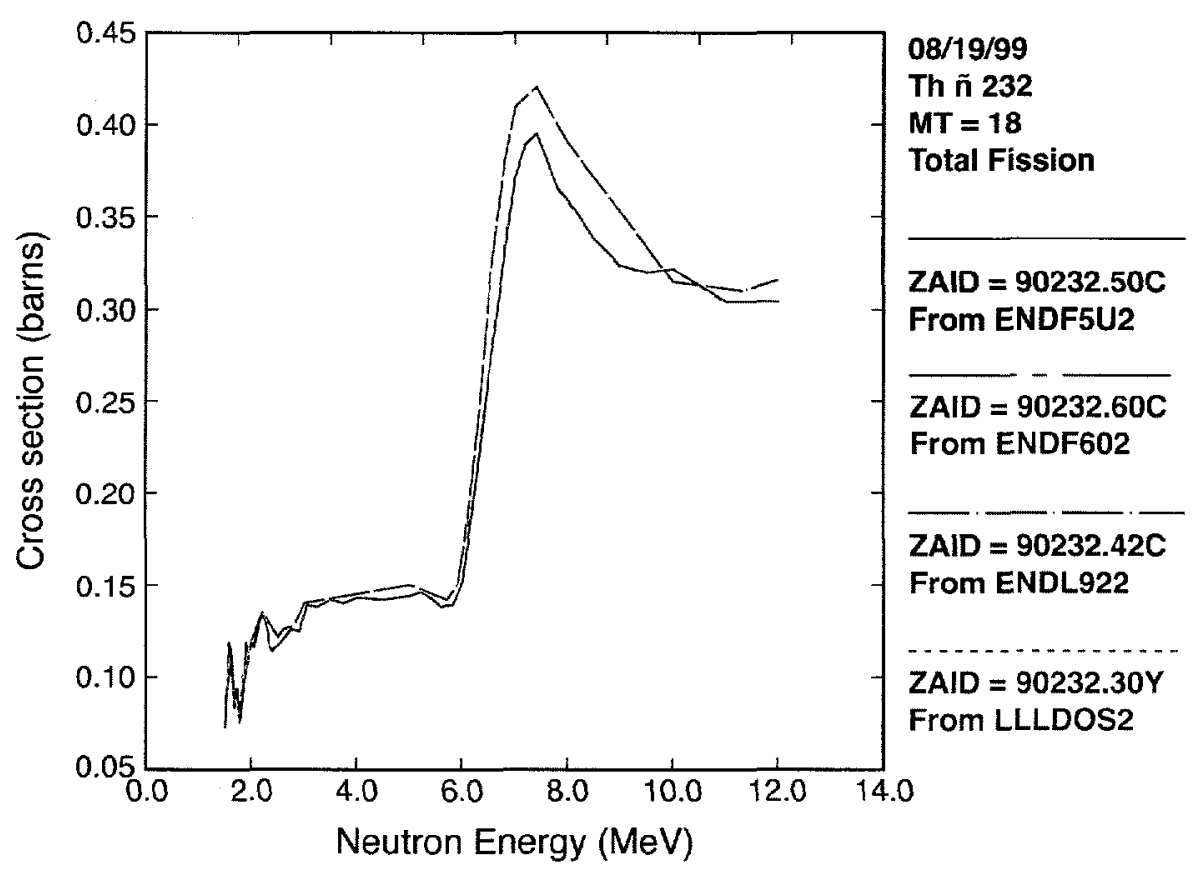

Figure 10. Comparison of ${ }^{232}$ Th fission cross sections from 1-20 MeV. 


\section{Central-fission Ratios for $^{233} U$}

There are central-fission ratio measurements for ${ }^{233} \mathrm{U}$ for four assemblies. As with ${ }^{232} \mathrm{Th}$, the evaluation for ${ }^{233} \mathrm{U}$ did not change from ENDF/B-V to B-VI, except for the addition of photon production data that will not affect these calculations. The results for the four assemblies are given in Table 3. We have good agreement with experiment for the Jezebel, Godiva, and Bigten assemblies from all cross-section libraries. There is slightly poorer agreement with the Flattop-25 assembly. The experimental error for the Flattop- 25 measurements is noticeably smaller than for the other three assemblies for this nuclide. If the experimental error for the Flattop-25 measurement was comparable to the others, the relative error for the $\mathrm{C} / \mathrm{E}$ ratios would be $\sim 0.019$.

Table 3. Central-Fission Ratios for ${ }^{233} U$

\begin{tabular}{|c|c|c|c|c|c|c|c|c|c|c|}
\hline \multirow[t]{2}{*}{ Assembly } & \multicolumn{2}{|c|}{ CSEWG } & \multicolumn{2}{|c|}{ ENDF/B-V } & \multicolumn{2}{|c|}{$\begin{array}{c}\text { ENDF/B-VI } \\
\text { Release } 2\end{array}$} & \multicolumn{2}{|c|}{ ENDL92 } & \multicolumn{2}{|c|}{$\begin{array}{c}\text { LLLDOS } \\
\text { (ACTL) }\end{array}$} \\
\hline & Expt. & RE & $\mathrm{C} / \mathrm{E}$ & $\mathbf{R E}$ & $\mathrm{C} / \mathrm{E}$ & RE & $\mathrm{C} / \mathrm{E}$ & $\mathbf{R E}$ & C/E & RE \\
\hline Jezebel & 1.578 & 0.017 & 1.000 & 0.017 & 1.000 & 0.017 & 1.002 & 0.017 & 1.000 & 0.017 \\
\hline Godiva & 1.59 & 0.019 & 1.001 & 0.019 & 1.001 & 0.019 & 1.006 & 0.019 & 1.005 & 0.019 \\
\hline Bigten & 1.58 & 0.019 & 0.997 & 0.022 & 0.997 & 0.022 & 1.021 & 0.022 & 1.020 & 0.022 \\
\hline Flattop-25 & 1.608 & 0.002 & 0.989 & 0.004 & 0.989 & 0.004 & 0.996 & 0.004 & 0.995 & 0.004 \\
\hline
\end{tabular}

\section{Central-fission Ratios for ${ }^{238} \mathrm{U}$}

There are central-fission ratio measurements for ${ }^{238} \mathrm{U}$ for each of the nine assemblies. The results for these assemblies are given in Table $4 .{ }^{238} \mathrm{U}$ was completely reevaluated for ENDF/B-VI, but we see little difference for this reaction rate between B-V and B-VI data. The ENDF-based data underpredict the reaction rate for the Jezebel, Jezebel-Pu, Godiva, and Thor assemblies. The LLNL-based data of ENDL92 and LLLDOS overpredict the reaction rate for the Jezebel-23 and Flattop-23 assemblies. All four libraries overpredict the reaction rate for the Bigten assembly. 
Table 4. Central-Fission Ratios for ${ }^{238} \mathrm{U}$

\begin{tabular}{llccccccccc}
\hline Assembly & \multicolumn{2}{c}{ CSEWG } & \multicolumn{3}{c}{ ENDF/B-V } & \multicolumn{2}{c}{$\begin{array}{c}\text { ENDF/B-VI } \\
\text { Release 2 }\end{array}$} & & ENDL92 & \multicolumn{2}{c}{$\begin{array}{c}\text { LLDOS } \\
\text { (ACTL) }\end{array}$} \\
\hline & Expt. & RE & C/E & RE & C/E & RE & C/E & RE & C/E & RE \\
Jezebel & 0.2133 & 0.011 & 0.975 & 0.012 & 0.975 & 0.012 & 1.003 & 0.012 & 1.003 & 0.012 \\
Jezebel-Pu & 0.2071 & 0.010 & 0.970 & 0.011 & 0.971 & 0.011 & 0.998 & 0.011 & 0.998 & 0.011 \\
Jezebel-23 & 0.2133 & 0.012 & 1.015 & 0.013 & 1.016 & 0.013 & 1.044 & 0.013 & 1.044 & 0.013 \\
Godiva & 0.1643 & 0.011 & 0.974 & 0.012 & 0.974 & 0.012 & 1.002 & 0.012 & 1.001 & 0.012 \\
Bigten & 0.03739 (a) & 0.009 & 1.107 & 0.029 & 1.107 & 0.029 & 1.138 & 0.029 & 1.138 & 0.029 \\
Flattop-25 & 0.1492 & 0.011 & 0.986 & 0.012 & 0.987 & 0.012 & 1.014 & 0.012 & 1.014 & 0.012 \\
Flattop-Pu & 0.1799 & 0.011 & 0.983 & 0.012 & 0.984 & 0.012 & 1.011 & 0.012 & 1.011 & 0.012 \\
Flattop-23 & 0.1916 & 0.011 & 1.008 & 0.012 & 1.009 & 0.012 & 1.037 & 0.012 & 1.037 & 0.012 \\
Thor & 0.1962 & 0.011 & 0.968 & 0.012 & 0.969 & 0.012 & 0.996 & 0.012 & 0.996 & 0.012 \\
\hline
\end{tabular}

(a) CST-LANL gives a value of 0.0372 for this ratio.

\section{Central-fission Ratios for ${ }^{237} \mathrm{~Np}$}

There are central-fission ratio measurements for ${ }^{237} \mathrm{~Np}$ for each of the nine assemblies, and the results are given in Table $5 .{ }^{237} \mathrm{~Np}$ was reevaluated for ENDF/B-VI, and the ENDF/B-VI results are consistently lower than the ENDF/B-V results. As with ${ }^{238} \mathrm{U}$, the fission rate is overpredicted by all libraries for the Bigten assembly and underpredicted for the Thor assembly. In general, the LLNL-based data consistently underpredict the fission rate and are farther from measurement than the ENDF-based data.

Table 5. Central-Fission Ratios for ${ }^{237} \mathrm{~Np}$

\begin{tabular}{|c|c|c|c|c|c|c|c|c|c|c|}
\hline \multirow[t]{2}{*}{ Assembly } & \multicolumn{2}{|c|}{ CSEWG } & \multicolumn{2}{|c|}{ ENDF/B-V } & \multicolumn{2}{|c|}{$\begin{array}{c}\text { ENDF/B-VI } \\
\text { Release } 2\end{array}$} & \multicolumn{2}{|c|}{ ENDL92 } & \multicolumn{2}{|c|}{$\begin{array}{c}\text { LLLDOS } \\
\text { (ACTL) }\end{array}$} \\
\hline & Expt. & RE & $\mathrm{C} / \mathrm{E}$ & RE & $\mathrm{C} / \mathrm{E}$ & $\mathbf{R E}$ & $\mathrm{C} / \mathrm{E}$ & $\mathbf{R E}$ & $\mathrm{C} / \mathrm{E}$ & RE \\
\hline Jezebel & 0.9835 & 0.014 & 0.984 & 0.015 & 0.971 & 0.015 & 0.953 & 0.015 & 0.954 & 0.015 \\
\hline Jezebel-Pu & 0.9365 & 0.014 & 1.014 & 0.014 & 1.000 & 0.014 & 0.982 & 0.014 & 0.983 & 0.014 \\
\hline Jezebel-23 & 0.997 & 0.015 & 1.006 & 0.015 & 0.992 & 0.015 & 0.974 & 0.015 & 0.976 & 0.015 \\
\hline Godiva & 0.8516 & 0.014 & 0.980 & 0.015 & 0.966 & 0.015 & 0.950 & 0.015 & 0.951 & 0.015 \\
\hline Bigten & $0.3223(\mathrm{a})$ & 0.012 & 1.082 & 0.021 & 1.068 & 0.021 & 1.057 & 0.021 & 1.058 & 0.021 \\
\hline Flattop-25 & 0.7804 & 0.013 & 1.000 & 0.013 & 0.986 & 0.013 & 0.970 & 0.013 & 0.971 & 0.013 \\
\hline Flattop-Pu & 0.8561 & 0.014 & 1.004 & 0.014 & 0.990 & 0.014 & 0.972 & 0.014 & 0.974 & 0.014 \\
\hline Flattop-23 & 0.9103 & 0.014 & 1.013 & 0.015 & 0.999 & 0.015 & 0.982 & 0.015 & 0.983 & 0.014 \\
\hline Thor & 0.9419 & 0.011 & 0.955 & 0.011 & 0.942 & 0.011 & 0.925 & 0.011 & 0.927 & 0.011 \\
\hline
\end{tabular}




\section{Central-fission Ratios for ${ }^{239} \mathrm{Pu}$}

Central-fission ratios have been measured for ${ }^{239} \mathrm{Pu}$ in the Jezebel, Godiva, Bigten, Flattop-25, and Flattop-Pu assemblies. The results for these five assemblies are given in Table $6 .{ }^{239} \mathrm{Pu}$ was reevaluated for $\mathrm{ENDF} / \mathrm{B}-\mathrm{VI}$ and gives slightly lower fission rates than $\mathrm{ENDF} / \mathrm{B}-\mathrm{V}$. As we have seen with the other nuclides, the reaction rates for Bigten are consistently higher than those for other assemblies, but are nowhere near as drastically different as those for other isotopes. For ${ }^{239} \mathrm{Pu}$, the higher reaction rates bring the Bigten results closer to agreement with measured values than the other assemblies. As with most integral measurements, reaction rates are quite insensitive to the details of the cross sections used in the calculation and are only sensitive to the average cross section as a function of incident neutron energy. As shown in Figure 11, although the ENDF/B-VI-based data of the ENDF60 library have far more detail than the data of the LLLDOS library through the resonance region, the two sets of results are very similar.

Table 6. Central-Fission Ratios for ${ }^{239} \mathrm{Pu}$

\begin{tabular}{|c|c|c|c|c|c|c|c|c|c|c|c|}
\hline \multirow[t]{2}{*}{ Assembly } & \multicolumn{2}{|c|}{ CSEWG } & \multirow{2}{*}{$\begin{array}{c}\begin{array}{c}\text { CST- } \\
\text { LANL }\end{array} \\
\text { Expt. }\end{array}$} & \multicolumn{2}{|c|}{ ENDF/B-V } & \multicolumn{2}{|c|}{$\begin{array}{c}\text { ENDF/B-VI } \\
\text { Release } 2\end{array}$} & \multicolumn{2}{|c|}{ ENDL92 } & \multicolumn{2}{|c|}{$\begin{array}{l}\text { LLLDOS } \\
\text { (ACTL) }\end{array}$} \\
\hline & Expt. & RE & & $\mathbf{C} / \mathbf{E}$ & RE & $\mathrm{C} / \mathrm{E}$ & $\mathbf{R E}$ & $\mathrm{C} / \mathrm{E}$ & $\mathbf{R E}$ & $\mathbf{C} / \mathbf{E}$ & $\mathbf{R E}$ \\
\hline Jezebel & 1.4609 & 0.009 & 1.417 & 0.980 & 0.010 & 0.975 & 0.010 & 0.968 & 0.010 & 0.973 & 0.010 \\
\hline Godiva & 1.4152 & 0.010 & - & 0.984 & 0.011 & 0.978 & 0.011 & 0.973 & 0.011 & 0.978 & 0.011 \\
\hline Bigten & 1.1936 & 0.007 & 1.177 & 1.006 & 0.014 & 0.992 & 0.014 & 0.992 & 0.014 & 0.996 & 0,014 \\
\hline Flattop-25 & 1.3847 & 0.009 & 1.355 & 0.991 & 0.009 & 0.985 & 0.009 & 0.980 & 0.009 & 0.984 & 0.009 \\
\hline Flattop-Pu & - & - & 1.396 & 0.997 & 0.003 & 0.992 & 0.003 & 0.986 & 0.003 & 0.990 & 0.003 \\
\hline
\end{tabular}




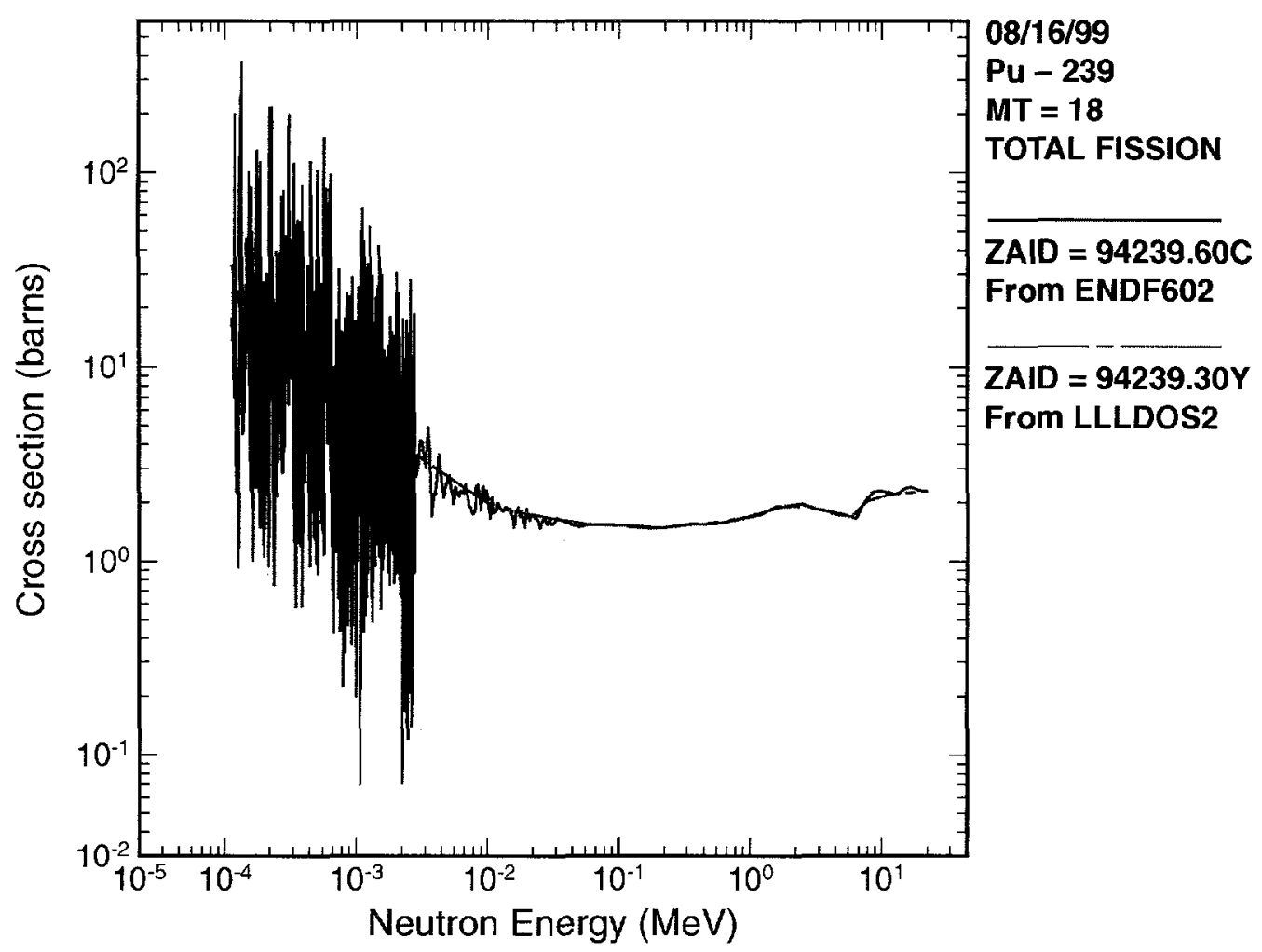

Figure 11. Comparison of the fission cross section for ${ }^{239} \mathrm{Pu}$.

\section{B. Activation Ratio Measurements}

There are a wide variety of activation ratio measurements for six critical assemblies: Jezebel, Godiva, Bigten, Flattop-Pu, Flattop-25 and Thor. These assemblies are briefly described in the introductions to Sections II and III.A. The activation ratio measurements were performed for a number of nuclides using the $(\mathrm{n}, \gamma),(\mathrm{n}, \alpha),(\mathrm{n}, \mathrm{p}),(\mathrm{n}, 2 \mathrm{n})$, and $\left(\mathrm{n}, \mathrm{n}^{\prime} \gamma\right)$ reactions. For each ratio, the reaction rate for the reaction and nuclide of interest was measured in the center of the critical assembly. The rate was then divided by the fission rate for ${ }^{235} \mathrm{U}$ at the same position in the assembly to form the activation ratio quoted in the publications. Activation ratios are available from the CSEWG specifications, from CST-LANL, and from Byers. ${ }^{30}$ As stated previously, the CST-LANL data do not have experimental errors included. The activation data from Byers are given as a reaction rate in barns. The ratio is then computed by using the value of 1.25 barns for the ${ }^{235} \mathrm{U}$ fission rate given in the reference for the Jezebel and Godiva assemblies. The Byers data give experimental errors for the Godiva measurements, but not for the Jezebel measurements. There is no experimental error given for the ${ }^{235} \mathrm{U}$ fission rate by Byers. The CSEWG specifications are based on the measurements of Byers, and it is not clear why many of the 
activation ratios were not included by CSEWG. Additionally, CSEWG used a slightly different fission rate for ${ }^{235} \mathrm{U}$ than Byers in calculating the activation ratios.

As for the central-fission ratio calculations, the ENDF/B-VI-based data of ENDF60 were used to calculate the central-neutron flux and the ${ }^{235} \mathrm{U}$ fission rate for each assembly. The reaction rates were calculated in MCNP by using an FM tally multiplier of the appropriate reaction cross section for an F4 tally in a 1-cm radius sphere at the center of each assembly. The reaction rate for the nuclide of interest was then divided by the calculated ${ }^{235} \mathrm{U}$ fission rate, propagating the MCNP statistical error. Each calculated activation ratio is then divided by the experimental measurement to make the comparison easier. The relative error (RE) in the calculated-to-experimental ratio $(\mathrm{C} / \mathrm{E})$ is propagated when an experimental error estimate is available. In the absence of an experimental error estimate, the MCNP relative error for the activation ratio of interest is given instead, allowing the reader to have an estimate of the validity of the calculation for that reaction.

Figures 7-9 in Section III.A show the central-neutron flux spectra for the assemblies of interest. Recall that the Jezebel, Godiva, Bigten, Flattop-Pu, Flattop-25, and Thor assemblies are referenced by their associated MCNP filenames of pumet1, umet1ss, bigten 1, pumet6, umet28, and pumet8a, respectively. Six sets of data were available for testing the activation cross sections: ENDF/B-V, ENDF/B-VI ${ }^{8}$ ENDL92, ${ }^{18}$ ENDF/B-V dosimetry, ${ }^{19}$ LLLDOS, ${ }^{19,20}$ and SUPER. ${ }^{31}$ SUPER is a continuous-energy dosimetry library made available at Los Alamos National Laboratory in the mid-1980s.

\section{1. (n, 久) Activation Ratios}

The largest set of activation data is for the $(\mathrm{n}, \gamma)$ reaction. Table 7 lists the available experimental data from the three sources, and Table 8 lists the relevant MCNP data that can be used for each calculation. Table 9 gives the results of the calculated-to-experiment $(\mathrm{C} / \mathrm{E})$ ratio for each nuclide and assembly and the associated relative error (RE). As we have noted previously, the Thor measurements were performed with respect to the ${ }^{238} \mathrm{U}$ fission rate. The ENDF/B-VI data from ENDF60 were used for the ${ }^{238} \mathrm{U}$ fission rate for the Thor calculations. The radiative capture cross sections from each data library used in the calculations are shown in Appendix B. The activation ratio results are insensitive to the details of the cross sections through the resonance region for the calculations, as was seen with the central-fission ratios for ${ }^{239} \mathrm{Pu}$. It is the average value of the 
reaction cross section as a function of neutron energy that is important for these benchmarks. Examples of this behavior can be seen for ${ }^{65} \mathrm{Cu}$ and ${ }^{197} \mathrm{Au}$ for the $(\mathrm{n}, \gamma)$ reaction.

There are seven reactions for which a partial reaction rate was measured instead of the total. The production of the metastable state was measured for the $(\mathrm{n}, \gamma)$ reaction on ${ }^{79} \mathrm{Br},{ }^{103} \mathrm{Rh}$, ${ }^{109} \mathrm{Ag},{ }^{113} \mathrm{In}$, and ${ }^{115} \mathrm{In}$. The production of the ground state plus the first metastable state, but not the second metastable state, was measured for ${ }^{192} \operatorname{Ir}$ in the ${ }^{191} \operatorname{Ir}(\mathrm{n}, \gamma)$ reaction. At an incident neutron energy of $1 \mathrm{MeV}$, the production of the second metastable state of ${ }^{192}$ Ir only accounts for $-3.5 \%$ of the total $(n, \gamma)$ cross section. ${ }^{32}$ Hence, the total cross section will be used for this reaction in the MCNP calculations. The total reaction rate for ${ }^{59} \operatorname{Co}(\mathrm{n}, \gamma)$ was measured for the Bigten assembly, but the reaction rate for the metastable state was measured for the Godiva assembly. The reaction rate for the ground state was measured for the ${ }^{15 t} \operatorname{Eu}(n, \gamma)$ reaction in the Bigten assembly. We currently do not have the appropriate reaction cross section data necessary to calculate the reaction rates for ${ }^{79} \mathrm{Br}(\mathrm{n}, \gamma){ }^{80 \mathrm{~m}} \mathrm{Br}$ and ${ }^{103} \mathrm{Rh}(\mathrm{n}, \gamma){ }^{104 \mathrm{~m}} \mathrm{Rh}$.

Table 7. Experimental Data for the (n, $\gamma)$ Activation Ratio Measurements

\begin{tabular}{|c|c|c|c|c|}
\hline Target Nuclide & Assembly & CSEWG & Byers & CST-LANL \\
\hline${ }^{45} \mathrm{Sc}$ & Bigten & $0.0132 \pm 0.0003$ & - & 0.0127 \\
\hline \multirow[t]{2}{*}{${ }^{51} \mathrm{~V}$} & Jezebel & $0.0023 \pm 0.0003$ & 0.0023 & - \\
\hline & Godiva & - & $0.0023 \pm 0.0002$ & - \\
\hline \multirow[t]{3}{*}{${ }^{55} \mathrm{Mn}$} & Jezebel & $0.0024 \pm 0.0003$ & 0.0023 & - \\
\hline & Godiva & $0.0027 \pm 0.0002$ & $0.0026 \pm 0.0002$ & - \\
\hline & Bigten & - & - & 0.00537 \\
\hline${ }^{58} \mathrm{Fe}$ & Bigten & $0.0031 \pm 0.0001$ & - & 0.00291 \\
\hline${ }^{59} \mathrm{Co}$ & Bigten & $0.0095 \pm 0.0002$ & - & 0.0093 \\
\hline \multirow[t]{3}{*}{${ }^{63} \mathrm{Cu}$} & Jezebel & $0.0100 \pm 0.0006$ & 0.0098 & - \\
\hline & Godiva & $0.0117 \pm 0.0006$ & $0.0115 \pm 0.0005$ & - \\
\hline & Bigten & $0.0164 \pm 0.0010$ & - & 0.0173 \\
\hline${ }^{65} \mathrm{Cu}$ & Godiva & 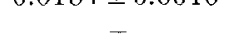 & $0.0070 \pm 0.0004$ & - \\
\hline${ }^{75} \mathrm{As}$ & Godiva & - & $0.0450 \pm 0.0032$ & - \\
\hline${ }^{81} \mathrm{Br}$ & Godiva & - & $0.0360 \pm 0.0032$ & - \\
\hline${ }^{85} \mathrm{Rb}$ & Godiva & - & $0.0495 \pm 0.0024$ & - \\
\hline${ }^{87} \mathrm{Rb}$ & Godiva & - & $0.0033 \pm 0.0006$ & - \\
\hline \multirow[t]{2}{*}{${ }^{89} \mathrm{Y}$} & Bigten & - & $\begin{array}{c}-000-0.000 \\
-\end{array}$ & 0.00639 \\
\hline & Godiva & - & $0.0069 \pm 0.0006$ & $\frac{1}{10003}$ \\
\hline \multirow[t]{3}{*}{${ }^{93} \mathrm{Nb}$} & Jezebel & $0.023 \pm 0.002$ & 0.0221 & - \\
\hline & Godiva & $0.030 \pm 0.003$ & $0.0297 \pm 0.0024$ & - \\
\hline & Jezebel & - & 0.0124 & - \\
\hline \multirow[t]{2}{*}{${ }^{107} \mathrm{Ag}$} & Godiva & - & $0.1440 \pm 0.0144$ & - \\
\hline & Jezebel & - & 0.1224 & - \\
\hline \multirow[t]{2}{*}{${ }^{121} \mathrm{Sb}$} & Godiva & - & $0.0848 \pm 0.0064$ & - \\
\hline & Jezebel & - & 0.0744 & - \\
\hline${ }^{127} \mathrm{I}$ & Godiva & - & $0.0832 \pm 0.0080$ & - \\
\hline \multirow[t]{2}{*}{${ }^{139} \mathrm{La}$} & Godiva & - & $0.0073 \pm 0.0006$ & - \\
\hline & Jezebel & - & 0.0066 & - \\
\hline${ }^{153} \mathrm{Eu}$ & Bigten & - & - & 0.578 \\
\hline
\end{tabular}


Table 7, continued

\begin{tabular}{|c|c|c|c|c|}
\hline Target Nuclide & Assembly & CSEWG & Byers & CST-LANL \\
\hline \multirow{4}{*}{${ }^{169} \mathrm{Tm}$} & Jezebel & - & - & 0.0931 \\
\hline & Bigten & - & - & 0.219 \\
\hline & Flattop-25 & - & - & 0.137 \\
\hline & Flattop-Pu & _ & - & 0.118 \\
\hline \multirow[t]{3}{*}{${ }^{176} \mathrm{Lu}$} & Bigten & - & - & 0.54 \\
\hline & Flattop-25 & - & - & 0.306 \\
\hline & Flattop- $\mathrm{Pu}$ & - & - & 0.29 \\
\hline \multirow[t]{2}{*}{${ }^{181} \mathrm{Ta}$} & Bigten & - & - & 0.216 \\
\hline & Godiva & - & $0.1230 \pm 0.0120$ & - \\
\hline${ }^{180} \mathrm{~W}$ & Bigten & - & - & 0.245 \\
\hline${ }^{184} \mathrm{~W}$ & Bigten & - & - & 0.0684 \\
\hline${ }^{186} \mathrm{~W}$ & Bigten & - & $\ldots$ & 0.05688 \\
\hline${ }^{185} \mathrm{Re}$ & Godiva & - & $0.1856 \pm 0.0080$ & - \\
\hline${ }^{187} \mathrm{Re}$ & Godiva & - & $0.1432 \pm 0.0120$ & - \\
\hline \multirow[t]{3}{*}{${ }^{193} \mathrm{Ir}$} & Bigten & - & - & 0.246 \\
\hline & Godiva & - & $0.1064 \pm 0.0064$ & - \\
\hline & Jezebel & - & 0.0848 & - \\
\hline \multirow[t]{4}{*}{${ }^{197} \mathrm{Au}$} & Jezebel & $0.083 \pm 0.002$ & 0.0810 & - \\
\hline & Bigten & $0.167 \pm 0.003$ & - & 0.17 \\
\hline & Godiva & $0.100 \pm 0.002$ & $0.0984 \pm 0.0020$ & - \\
\hline & Flattop-25 & - & - & 0.0996 \\
\hline \multirow[t]{2}{*}{${ }^{203} \mathrm{Tl}$} & Flattop-25 & - & - & 0.0341 \\
\hline & Flattop-Pu & - & - & 0.031 \\
\hline${ }^{205} \mathrm{Tl}$ & Godiva & - & $0.0087 \pm 0.0012$ & - \\
\hline${ }^{209} \mathrm{Bi}$ & Godiva & - & $0.0011 \pm 0.0001$ & - \\
\hline${ }^{232} \mathrm{Th}$ & Thor* & $1.20 \pm 0.06$ & - & - \\
\hline \multirow[t]{2}{*}{${ }^{238} \mathrm{U}$} & Bigten & $0.110 \pm 0.003$ & - & 0.106 \\
\hline & Thor & $0.083 \pm 0.003$ & - & - \\
\hline \multirow{2}{*}{${ }^{241} \mathrm{Am}$} & Bigten & - & - & 0.521 \\
\hline & Flattop-Pu & - & - & 0.2514 \\
\hline \multicolumn{5}{|c|}{ * This reaction ratio is given with respect to the ${ }^{238} \mathrm{U}(\mathrm{n}, \gamma)$ rate. } \\
\hline${ }^{59} \mathrm{Co}(\mathrm{n}, \gamma){ }^{60 \mathrm{~m}} \mathrm{Co}$ & Godiva & $0.038 \pm 0.003$ & $0.297 \pm 0.0024$ & - \\
\hline${ }^{79} \mathrm{Br}(\mathrm{n}, \gamma){ }^{80 \mathrm{~m}} \mathrm{Br}$ & Godiva & - & $0.0706 \pm 0.0043$ & - \\
\hline${ }^{103} \mathrm{Rh}(\mathrm{n}, \gamma){ }^{104 \mathrm{~m}} \mathrm{Rh}$ & Godiva & - & $0.0152 \pm 0.0012$ & - \\
\hline \multirow[t]{2}{*}{${ }^{109} \mathrm{Ag}(\mathrm{n}, \gamma){ }^{110 \mathrm{~m}} \mathrm{Ag}$} & Flattop-25 & - & - & 0.0107 \\
\hline & Flattop-Pu & - & - & 0.0099 \\
\hline${ }^{113} \mathrm{In}(\mathrm{n}, \gamma){ }^{114 m} \mathrm{In}$ & Bigten & - & - & 0.422 \\
\hline \multirow[t]{3}{*}{${ }^{115} \operatorname{In}(\mathrm{n}, \gamma){ }^{116 \mathrm{~m}} \mathrm{In}$} & Bigten & - & - & 0.146 \\
\hline & Godiva & - & $0.1168 \pm 0.0080$ & - \\
\hline & Jezebel & - & 0.1112 & - \\
\hline${ }^{151} \mathrm{Eu}(\mathrm{n}, \gamma){ }^{152 \mathrm{~s}} \mathrm{Eu}$ & Bigten & - & - & 0.699 \\
\hline \multirow{4}{*}{${ }^{191} \operatorname{Ir}(\mathrm{n}, \gamma){ }^{192 \mathrm{~m} 1+\mathrm{gs}} \operatorname{Ir}$} & Jezebel & - & - & 0.1671 \\
\hline & Bigten & - & - & 0.341 \\
\hline & Flattop-25 & - & - & 0.209 \\
\hline & Flattop-Pu & - & - & 0.191 \\
\hline
\end{tabular}


Table 8. Data Used in the MCNP Calculations for the (n, $\gamma$ ) Activation Ratios

\begin{tabular}{|c|c|c|c|c|c|c|}
\hline $\begin{array}{c}\text { Target } \\
\text { Nuclide }\end{array}$ & ENDF/B-V & $\begin{array}{c}\text { ENDF/B-VI } \\
\text { Release } 2\end{array}$ & ENDL92 & $\begin{array}{c}\text { ENDF/B-V } \\
\text { Dosimetry }\end{array}$ & $\begin{array}{c}\text { LLLDOS } \\
\text { (ACTL) }\end{array}$ & SUPER \\
\hline${ }^{45} \mathrm{Sc}$ & - & $21045.60 \mathrm{c}$ & - & $21045.26 y$ & $21045.30 y(a)$ & - \\
\hline${ }^{51} \mathrm{~V}$ & $23000.50 \mathrm{c}$ & $23000.60 \mathrm{c}$ & $23051.42 \mathrm{c}$ & - & $23051.30 \mathrm{y}$ & - \\
\hline${ }^{55} \mathrm{Mn}$ & $25055.50 \mathrm{c}$ & $25055.60 \mathrm{c}$ & $25055.42 \mathrm{c}$ & - & $25055.30 y$ & - \\
\hline${ }^{58} \mathrm{Fe}$ & - & $26058.60 \mathrm{c}$ & - & $26058.26 y$ & $26058.30 \mathrm{y}$ & - \\
\hline${ }^{59} \mathrm{Co}$ & $27059.50 \mathrm{c}$ & $27059.60 \mathrm{c}$ & $27059.42 c$ & - & $27059.30 y(a)$ & - \\
\hline${ }^{63} \mathrm{Cu}$ & - & $29063.60 \mathrm{c}$ & - & $29063.26 y$ & $29063.30 y$ & - \\
\hline${ }^{65} \mathrm{Cu}$ & - & $29065.60 \mathrm{c}$ & - & - & $29065.30 y$ & - \\
\hline${ }^{75} \mathrm{As}$ & - & - & $33075.42 \mathrm{c}$ & - & $33075.30 y$ & - \\
\hline${ }^{81} \mathrm{Br}$ & $35081.55 \mathrm{c}$ & - & - & - & $35081.30 y$ & - \\
\hline${ }^{85} \mathrm{Rb}$ & $37085.55 \mathrm{c}$ & - & - & - & - & - \\
\hline${ }^{87} \mathrm{Rb}$ & $37087.55 \mathrm{c}$ & - & - & - & - & - \\
\hline${ }^{89} \mathrm{Y}$ & $39089.50 \mathrm{c}$ & $39089.60 \mathrm{c}$ & $39089.42 c$ & - & $39089.30 y$ & $39089.71 \mathrm{y}(\mathrm{b})$ \\
\hline${ }^{93} \mathrm{Nb}$ & $41093.50 \mathrm{c}$ & $41093.60 \mathrm{c}$ & - & - & $41093.30 \mathrm{y}$ & - \\
\hline${ }^{107} \mathrm{Ag}$ & $47107.50 \mathrm{c}$ & $47107.60 \mathrm{c}$ & $47107.42 c$ & - & $47107.30 y$ (a) & - \\
\hline${ }^{121} \mathrm{Sb}$ & - & - & - & $\ldots$ & $51121.30 y(a)$ & - \\
\hline${ }^{127} \mathrm{I}$ & $53127.55 \mathrm{c}$ & $53127.60 \mathrm{c}$ & $53127.42 c$ & $53127.26 y$ & - & - \\
\hline${ }^{139} \mathrm{La}$ & - & - & - & $57139.26 y$ & - & - \\
\hline${ }^{153} \mathrm{Eu}$ & $63153.55 \mathrm{c}(\mathrm{c})$ & $63153.60 \mathrm{c}$ & - & - & $63153.30 \mathrm{y}$ & - \\
\hline${ }^{169} \mathrm{Tm}$ & $69169.55 \mathrm{c}(\mathrm{c})$ & - & - & - & $69169.30 y$ & $69169.70 y$ \\
\hline${ }^{176} \mathrm{Lu}$ & - & - & - & - & $71176.30 y(a)$ & - \\
\hline${ }^{181} \mathrm{Ta}$ & $73181.50 \mathrm{c}$ & $73181.60 \mathrm{c}$ & $73181.42 \mathrm{c}$ & - & $73181.30 y(a)$ & - \\
\hline${ }^{180} \mathrm{~W}$ & - & - & - & - & $74180.30 \mathrm{y}$ & - \\
\hline${ }^{184} \mathrm{~W}$ & $74184.55 \mathrm{c}$ & $74184.60 \mathrm{c}$ & - & - & $74184.30 y$ & - \\
\hline${ }^{186} \mathrm{~W}$ & $74186.55 \mathrm{c}$ & $74186.60 \mathrm{c}$ & - & - & $74186.30 y$ & - \\
\hline${ }^{185} \mathrm{Re}$ & $75185.50 \mathrm{c}$ & $75185.60 \mathrm{c}$ & $75185.42 \mathrm{c}$ & - & $75185.30 y$ & - \\
\hline${ }^{187} \mathrm{Re}$ & $75187.50 \mathrm{c}$ & $75187.60 \mathrm{c}$ & $75187.42 \mathrm{c}$ & - & $75187.30 y(a)$ & - \\
\hline${ }^{193} \mathrm{Ir}$ & - & - & - & - & - & $77193.71 \mathrm{y}$ \\
\hline${ }^{197} \mathrm{Au}$ & $79197.55 \mathrm{c}(\mathrm{c})$ & $79197.60 \mathrm{c}$ & - & - & $79197.30 y$ & - \\
\hline${ }^{203} \mathrm{Tl}$ & - & - & - & - & $81203.30 y$ & - \\
\hline${ }^{205} \mathrm{Tl}$ & - & - & - & - & $81205.30 y$ & $\ldots$ \\
\hline${ }^{209} \mathrm{Bi}$ & $83209.50 c$ & $83209.60 \mathrm{c}$ & $83209.42 c$ & - & $83209.30 y(a)$ & - \\
\hline${ }^{232} \mathrm{Th}$ & $90232.50 \mathrm{c}$ & $90232.60 \mathrm{c}$ & $90232.42 c$ & - & $90232.30 y$ & - \\
\hline${ }^{238} \mathrm{U}$ & $92238.50 \mathrm{c}$ & $92238.60 \mathrm{c}$ & $92238.42 c$ & - & $92238.30 y$ & - \\
\hline${ }^{241} \mathrm{Am}$ & $95241.50 \mathrm{c}$ & $95241.60 \mathrm{c}$ & $95241.42 \mathrm{c}$ & - & $95241.30 y(a)$ & -- \\
\hline${ }^{59} \mathrm{Co}(\mathrm{n}, \gamma){ }^{60 \mathrm{~m}} \mathrm{Co}$ & - & - & - & - & $27059.30 y$ & - \\
\hline${ }^{79} \mathrm{Br}(\mathrm{n}, \gamma){ }^{80 \mathrm{~m}} \mathrm{Br}$ & - & - & - & - & $\frac{1}{2103900}$ & - \\
\hline${ }^{103} \mathrm{Rh}(\mathrm{n}, \gamma){ }^{104 \mathrm{~m}} \mathrm{Rh}$ & - & - & - & - & - & - \\
\hline${ }^{109} \mathrm{Ag}(\mathrm{n}, \gamma){ }^{110 \mathrm{~m}} \mathrm{Ag}$ & - & - & - & - & $47109.30 y$ & - \\
\hline${ }^{113} \operatorname{In}(\mathrm{n}, \gamma){ }^{114 \mathrm{~m}} \mathrm{In}$ & - & - & - & - & $49113.30 y$ & - \\
\hline${ }^{115} \mathrm{In}(\mathrm{n}, \gamma){ }^{116 \mathrm{~m}} \mathrm{In}$ & - & - & - & $49115.26 y$ & $49115.30 y(a)$ & - \\
\hline${ }^{151} \mathrm{Eu}(\mathrm{n}, \gamma){ }^{152 \mathrm{~g}} \mathrm{Eu}$ & - & - & - & - & $63151.30 \mathrm{y}$ & - \\
\hline${ }^{191} \operatorname{Ir}(\mathrm{n}, \gamma){ }^{192 \mathrm{~g} 1+\mathrm{gs}} \operatorname{Ir}$ & - & - & - & - & - & $77191.70 y$ \\
\hline \multirow{2}{*}{\multicolumn{7}{|c|}{$\begin{array}{l}\text { (a) This reaction ratio is composed of more than one MT value. } \\
\text { (b) There is not a specific MT that corresponds to this reaction. The cross section information was obtained from the original } \\
\text { evaluation for the ZAID. }\end{array}$}} \\
\hline & & & & & & \\
\hline (c) These evaluati & are from LANI & and are not part & ENDF/B-V. & & & \\
\hline
\end{tabular}


Table 9. Comparison of MCNP Calculations to Experiment for the (n,y) Activation Ratios

\begin{tabular}{|c|c|c|c|c|c|c|c|c|c|c|c|c|c|}
\hline \multirow[t]{2}{*}{$\begin{array}{l}\text { Target } \\
\text { Nuclide }\end{array}$} & \multirow[t]{2}{*}{ Assembly } & \multicolumn{2}{|c|}{ ENDF/B-V } & \multicolumn{2}{|c|}{$\begin{array}{c}\text { ENDF/B-VI } \\
\text { Release } 2\end{array}$} & \multicolumn{2}{|c|}{ ENDL92 } & \multicolumn{2}{|c|}{$\begin{array}{l}\text { LLLDOS } \\
\text { (ACTL) }\end{array}$} & \multicolumn{2}{|c|}{$\begin{array}{c}\text { ENDF/B-V } \\
\text { Dosimetry }\end{array}$} & \multicolumn{2}{|c|}{ SUPER } \\
\hline & & $\mathbf{C} / \mathbf{E}$ & $\mathbf{R E}$ & $\mathbf{C} / \mathbf{E}$ & RE & $\mathrm{C} / \mathrm{E}$ & $\mathbf{R E}$ & C/E & $\mathbf{R E}$ & $\mathbf{C} / \mathbf{E}$ & RE & $\mathbf{C} / \mathbf{E}$ & RE \\
\hline${ }^{45} \mathrm{Sc}$ & Bigten & - & - & 1.066 & 0.034 & - & - & 1.045 & 0.026 & 1.061 & 0.034 & - & - \\
\hline \multirow[t]{3}{*}{${ }^{51} \mathrm{~V}$} & Jezebel & 0.785 & 0.131 & 0.835 & 0.131 & 0.838 & 0.131 & 0.754 & 0.131 & - & - & - & - \\
\hline & Jezebel:Byers & 0.799 & 0.006 & 0.828 & 0.009 & 0.831 & 0.009 & 0.747 & 0.005 & - & - & - & - \\
\hline & Godiva:Byers & 0.920 & 0.069 & 0.985 & 0.070 & 0.988 & 0.070 & 0.881 & 0.069 & - & - & - & - \\
\hline \multirow[t]{5}{*}{${ }^{55} \mathrm{Mn}$} & Jezebel & 1.214 & 0.127 & 1.223 & 0.126 & 1.461 & 0.125 & 1.490 & 0.125 & - & - & - & - \\
\hline & Jezebel:Byers & 1.256 & 0.020 & 1.265 & 0.014 & 1.512 & 0.005 & 1.541 & 0.010 & - & - & - & - \\
\hline & Godiva & 1.272 & 0.076 & 1.267 & 0.075 & 1.581 & 0.075 & 1.590 & 0.075 & - & - & - & - \\
\hline & Godiva:Byers & 1.301 & 0.062 & 1.296 & 0.062 & 1.617 & 0.061 & 1.626 & 0.061 & - & - & - & - \\
\hline & Bigten:CST & 1.028 & 0.025 & 1.098 & 0.021 & 1.628 & 0.015 & 1.647 & 0.016 & - & - & - & - \\
\hline${ }^{58} \mathrm{Fe}$ & Bigten & - & - & 1.437 & 0.053 & - & - & 0.631 & 0.035 & 0.790 & 0.059 & - & - \\
\hline${ }^{59} \mathrm{Co}$ & Bigten & 0.990 & 0.034 & 0.893 & 0.029 & 0.841 & 0.028 & 1.001 & 0.025 & - & - & - & - \\
\hline \multirow[t]{5}{*}{${ }^{63} \mathrm{Cu}$} & Jezebel & - & - & 1.016 & 0.061 & - & - & 1.005 & 0.060 & 0.948 & 0.062 & - & - \\
\hline & Jezebel:Byers & - & - & 1.041 & 0.011 & - & - & 1.029 & 0.004 & 0.972 & 0.014 & - & - \\
\hline & Godiva & - & - & 0.981 & 0.052 & - & - & 0.991 & 0.052 & 0.916 & 0.052 & - & - \\
\hline & Godiva:Byers & - & - & 0.996 & 0.043 & - & - & 1.006 & 0.042 & 0.930 & 0.043 & - & - \\
\hline & Bigten & - & - & 1.051 & 0.064 & - & - & 1.028 & 0.062 & 0.997 & 0.063 & - & - \\
\hline${ }^{65} \mathrm{Cu}$ & Godiva:Byers & - & - & 1.014 & 0.058 & - & - & 0.997 & 0.057 & - & - & - & - \\
\hline${ }^{75}$ As & Godiva:Byers & - & - & - & - & 1.310 & 0.072 & 1.298 & 0.072 & - & - & - & - \\
\hline${ }^{81} \mathrm{Br}$ & Godiva:Byers & 1.875 & 0.089 & - & - & - & - & 1.062 & 0.089 & - & - & - & - \\
\hline${ }^{85} \mathrm{Rb}$ & Godiva:Byers & 0.691 & 0.049 & - & - & - & - & - & - & - & - & - & - \\
\hline${ }^{87} \mathrm{Rb}$ & Godiva:Byers & 0.981 & 0.195 & - & - & - & - & - & - & - & - & - & - \\
\hline \multirow[t]{2}{*}{${ }^{89} \mathbf{Y}$} & Bigten:CST & 1.579 & 0.017 & 1.035 & 0.023 & 1.478 & 0.019 & 1.038 & 0.013 & - & - & 0.924 & 0.013 \\
\hline & Godiva:Byers & 1.143 & 0.082 & 0.685 & 0.082 & 0.864 & 0.082 & 0.775 & 0.082 & - & - & 0.656 & 0.082 \\
\hline \multirow[t]{4}{*}{${ }^{93} \mathrm{Nb}$} & Jezebel & 1.173 & 0.087 & 1.227 & 0.087 & 1.180 & 0.087 & 1.181 & 0.087 & - & - & - & - \\
\hline & Jezebel:Byers & 1.222 & 0.005 & 1.278 & 0.005 & 1.229 & 0.006 & 1.231 & 0.005 & - & - & - & - \\
\hline & Godiva & 1.099 & 0.100 & 1.139 & 0.100 & 1.105 & 0.100 & 1.105 & 0.100 & - & - & - & - \\
\hline & Godiva:Byers & 1.111 & 0.081 & 1.152 & 0.081 & 1.117 & 0.081 & 1.117 & 0.081 & - & - & - & - \\
\hline \multirow[t]{2}{*}{${ }^{107} \mathrm{Ag}$} & Godiva:Byers & 0.854 & 0.100 & 0.931 & 0.100 & 0.924 & 0.100 & 0.849 & 0.100 & - & - & - & - \\
\hline & Jezebel:Byers & 0.836 & 0.005 & 0.946 & 0.008 & 0.922 & 0.005 & 0.855 & 0.004 & - & - & - & - \\
\hline \multirow[t]{2}{*}{${ }^{121} \mathbf{S b}$} & Godiva:Byers & - & - & - & - & - & - & 1.465 & 0.076 & - & - & - & - \\
\hline & Jezebel:Byers & - & - & - & - & - & - & 1.429 & 0.004 & - & - & - & - \\
\hline${ }^{127} \mathrm{I}$ & Godiva:Byers & 1.079 & 0.096 & 1.092 & 0.096 & 1.207 & 0.096 & - & $\cdot-$ & 1.084 & 0.096 & - & - \\
\hline \multirow[t]{2}{*}{${ }^{139} \mathrm{La}$} & Godiva:Byers & - & - & - & - & - & - & - & - & 0.876 & 0.077 & - & - \\
\hline & Jezebel:Byers & - & - & - & - & - & - & - & - & 0.910 & 0.017 & - & - \\
\hline${ }^{153} \mathrm{Eu}$ & Bigten:CST & 0.975 & 0.014 & 1.000 & 0.014 & - & - & 1.174 & 0.014 & - & - & - & - \\
\hline \multirow[t]{4}{*}{${ }^{169} \mathrm{Tm}$} & Jezebel:CST & 1.420 & 0.005 & - & - & - & - & 1.263 & 0.005 & - & - & 1.254 & 0.005 \\
\hline & Bigten:CST & 1.311 & 0.014 & - & - & - & - & 1.052 & 0.013 & - & - & 1.342 & 0.014 \\
\hline & Flattop-25:CST & 1.260 & 0.004 & - & - & - & - & 1.082 & 0.004 & - & - & 1.173 & 0.005 \\
\hline & Flattop-Pu:CST & 1.342 & 0.004 & - & - & - & - & 1.160 & 0.004 & - & - & 1.240 & 0.004 \\
\hline${ }^{176} \mathrm{Lu}$ & Bigten:CST & - & - & - & - & - & - & 0.905 & 0.013 & - & -- & - & - \\
\hline & Flattop-25:CST & - & - & - & - & - & - & 1.007 & 0.004 & - & - & - & - \\
\hline & Flattop-Pu:CST & - & - & - & - & - & - & 0.956 & 0.003 & - & - & - & - \\
\hline${ }^{181} \mathrm{Ta}$ & Bigten:CST & 0.903 & 0.013 & 0.904 & 0.013 & 0.775 & 0.014 & 0.778 & 0.014 & - & - & - & - \\
\hline & Godiva:Byers & 0.995 & 0.098 & 0.995 & 0.098 & 0.838 & 0.098 & 0.844 & 0.098 & - & - & - & - \\
\hline${ }^{180} \mathrm{~W}$ & Bigten:CST & - & - & - & - & - & - & 0.344 & 0.013 & - & - & - & - \\
\hline${ }^{184} \mathrm{~W}$ & Bigten:CST & 0.850 & 0.013 & 0.850 & 0.013 & - & - & 0.948 & 0.013 & - & - & - & - \\
\hline${ }^{186} \mathrm{~W}$ & Bigten:CST & 1.000 & 0.013 & 1.001 & 0.013 & - & - & 0.977 & 0.013 & - & - & - & - \\
\hline${ }^{185} \mathrm{Re}$ & Godiva:Byers & 0.943 & 0.044 & 1.096 & 0.044 & 0.931 & 0.044 & 0.867 & 0.044 & - & - & - & - \\
\hline${ }^{187} \mathrm{Re}$ & Godiva:Byers & 1.039 & 0.084 & 1.023 & 0.084 & 1.297 & 0.084 & 1.332 & 0.084 & - & - & - & - \\
\hline
\end{tabular}


Table 9, continued

\begin{tabular}{|c|c|c|c|c|c|c|c|c|c|c|c|c|c|}
\hline \multirow[t]{2}{*}{$\begin{array}{l}\text { Target } \\
\text { Nuclide }\end{array}$} & \multirow[t]{2}{*}{ Assembly } & \multicolumn{2}{|c|}{ ENDF/B-V } & \multicolumn{2}{|c|}{$\begin{array}{c}\text { ENDF/B-VI } \\
\text { Release } 2\end{array}$} & \multicolumn{2}{|c|}{ ENDL92 } & \multicolumn{2}{|c|}{$\begin{array}{l}\text { LLLDOS } \\
\text { (ACTL) }\end{array}$} & \multicolumn{2}{|c|}{$\begin{array}{l}\text { ENDF/B-V } \\
\text { Dosimetry }\end{array}$} & \multicolumn{2}{|c|}{ SUPER } \\
\hline & & $\mathrm{C} / \mathrm{E}$ & RE & $\mathrm{C} / \mathrm{E}$ & $\mathbf{R E}$ & $\mathrm{C} / \mathrm{E}$ & $\mathbf{R E}$ & $\mathrm{C} / \mathrm{E}$ & RE & $\mathbf{C} / \mathbf{E}$ & RE & $\mathrm{C} / \mathrm{E}$ & RE \\
\hline \multirow[t]{3}{*}{${ }^{193} \mathrm{Ir}$} & Bigten:CST & - & - & - & - & - & - & - & - & - & - & 0.936 & 0.014 \\
\hline & Godiva:Byers & - & - & - & - & - & - & - & - & - & - & 1.100 & 0.061 \\
\hline & Jezebel:Byers & - & - & - & - & - & - & - & - & - & - & 1.108 & 0.005 \\
\hline \multirow[t]{6}{*}{${ }^{197} \mathrm{Au}$} & Jezebel & 0.953 & 0.024 & 0.938 & 0.024 & - & - & 1.006 & 0.025 & - & - & - & - \\
\hline & Jezebel:Byers & 0.977 & 0.004 & 0.961 & 0.004 & - & - & 1.032 & 0.004 & - & - & - & - \\
\hline & Bigten & 0.941 & 0.022 & 0.948 & 0.022 & - & - & 0.984 & 0.022 & - & - & - & - \\
\hline & Godiva & 0.948 & 0.021 & 0.939 & 0.021 & - & - & 0.992 & 0.021 & - & - & - & - \\
\hline & Godiva:Byers & 0.963 & 0.022 & 0.954 & 0.022 & - & - & 1.009 & 0.022 & - & - & - & - \\
\hline & Flattop-25:CST & 1.016 & 0.004 & 1.009 & 0.004 & - & - & 1.064 & 0.004 & - & - & - & - \\
\hline \multirow[t]{2}{*}{${ }^{203} \mathrm{Tl}$} & Flattop-25:CST & - & - & - & - & - & - & 0.344 & 0.004 & - & - & - & - \\
\hline & Flattop-Pu:CST & - & - & - & - & - & - & 0.348 & 0.004 & - & - & - & - \\
\hline${ }^{205} \mathrm{Tl}$ & Godiva:Byers & - & - & - & - & - & - & 0.115 & 0.138 & - & - & - & - \\
\hline${ }^{209} \mathrm{Bi}$ & Godiva:Byers & 1.232 & 0.072 & 2.045 & 0.072 & 1.232 & 0.072 & 1.223 & 0.072 & - & - & - & -- \\
\hline \multirow[t]{2}{*}{${ }^{238} \mathrm{U}$} & Bigten & 1.013 & 0.030 & 0.976 & 0.030 & 1.072 & 0.030 & 1.069 & 0.030 & - & - & - & - \\
\hline & Thor & 0.855 & 0.036 & 0.841 & 0.036 & 0.924 & 0.036 & 0.923 & 0.036 & - & - & - & - \\
\hline \multirow[t]{2}{*}{${ }^{241} \mathrm{Am}$} & Bigten:CST & 1.262 & 0.013 & 1.109 & 0.013 & 0.119 & 0.013 & 1.198 & 0.013 & - & - & - & - \\
\hline & Flattop-Pu:CST & 1.404 & 0.003 & 1.082 & 0.004 & 0.117 & 0.004 & 1.174 & 0.004 & - & - & - & - \\
\hline${ }^{232} \mathrm{Th}$ & Thor (a) & 1.082 & 0.050 & 1.083 & 0.050 & 1.146 & 0.050 & 1.173 & 0.050 & - & - & - & - \\
\hline \multirow[t]{2}{*}{${ }^{59} \mathrm{Co}$} & Godiva & - & - & - & - & - & - & 0.101 & 0.079 & - & - & - & - \\
\hline & Godiva:Byers & - & - & - & - & - & - & 0.130 & 0.081 & - & - & - & - \\
\hline \multirow[t]{2}{*}{${ }^{109} \mathrm{Ag}$} & Flattop-25:CST & - & - & - & - & - & - & 0.454 & 0.004 & - & - & - & - \\
\hline & Flattop-Pu:CST & - & - & - & - & - & - & 0.454 & 0.004 & - & - & - & - \\
\hline${ }^{113} \ln$ & Bigten: CST & - & - & - & - & - & - & 0.503 & 0.012 & - & - & - & - \\
\hline \multirow[t]{3}{*}{${ }^{115} \mathbf{I n}$} & Bigten:CST & - & - & - & - & - & - & 2.707 & 0.012 & 1.113 & 0.013 & - & - \\
\hline & Jezebel:Byers & - & - & - & - & - & - & 2.405 & 0.004 & 1.007 & 0.004 & - & - \\
\hline & Godiva:Byers & - & - & - & - & - & - & 2.553 & 0.069 & 1.049 & 0.069 & - & - \\
\hline${ }^{151} \mathrm{Eu}$ & Bigten:CST & - & - & - & - & - & - & 0.902 & 0.014 & - & - & - & - \\
\hline \multirow[t]{4}{*}{${ }^{191}$ Ir (b) } & Jezebel:CST & - & - & - & - & - & - & - & - & 1.088 & 0.005 & - & - \\
\hline & Bigten:CST & - & - & - & - & - & - & - & - & 1.098 & 0.013 & - & - \\
\hline & Flattop-25:CST & - & - & - & - & - & - & - & - & 1.122 & 0.004 & - & - \\
\hline & Flattop-Pu:CST & - & - & - & - & - & - & - & - & 1.125 & 0.004 & - & - \\
\hline
\end{tabular}

Italics indicate that no experimental error was given. The MCNP relative error for the reaction ratio is given instead.

(a) This reaction ratio is given with respect to the ${ }^{238} U(n, \gamma)$ rate.

(b) The total reaction was used for this calculation.

For the results given in Table 9, when experimental errors have not been available, the MCNP relative error for the reaction-rate ratio $\left[{ }^{51} \mathrm{~V}(\mathrm{n}, \gamma)\right.$ to ${ }^{235} \mathrm{U}$ fission] has been quoted in the table as noted by the italicized type. As can be seen from the CSEWG and Byers' results from the Jezebel assembly for ${ }^{51} \mathrm{~V}(\mathrm{n}, \gamma)$, neglecting the experimental error can seriously underestimate the error for the calculated-to-experimental $(\mathrm{C} / \mathrm{E})$ comparison. 
${ }^{45} \mathrm{Sc}$

For each of the data libraries considered for this reaction, the calculated result appears to overpredict the measured value, but is within two standard deviations of the measurement.

${ }^{51} \mathrm{~V}$

For each of the data libraries considered for this reaction, the calculated result is within two standard deviations of the measurement for each assembly. The experimental error for the Godiva assembly is much less than that of the Jezebel assembly. The more recent data from ENDF/B-VI and ENDL92 have improved the calculated result for this reaction.

${ }^{55} \mathrm{Mn}$

The reaction rate for this nuclide is consistently overpredicted for each assembly and data library. The ENDF-based data do better at matching the measured value than the LLNLbased data. There is a noticeable improvement for this reaction rate for the softer energy spectrum of the Bigten assembly with the ENDF-based data.

${ }^{58} \mathrm{Fe}$

The ENDF/B-VI data substantially overpredict the reaction rate, while the LLNL and ENDF/B-V dosimetry data substantially underpredict the reaction rate.

${ }^{59} \mathrm{Co}$

The ENDF/B-V and LLLDOS data correctly predict the measured reaction rate in the Bigten assembly, but the ENDF/B-VI and ENDL92 data significantly underpredict the measurement. The decrease in the radiative-capture cross section above $1 \mathrm{MeV}$ for the ENDF/B-VI and ENDL92 data relative to ENDF/B-V made the largest contribution to the calculational differences.

${ }^{63} \mathrm{Cu}$

The calculated reaction rate for this nuclide is well within the experimental error for all of the assemblies for the ENDF/B-VI and ENDL92 data libraries. The ENDF/B-V dosimetry data underpredict the measurement for the faster assemblies of Godiva and Jezebel, but match the measured value for the Bigten assembly.

${ }^{65} \mathrm{Cu}$

The calculated reaction rate matches the measured value for the Godiva assembly. 
${ }^{75} \mathrm{As}$

The calculated reaction rate overpredicts the measured values for the LLNL-based data.

${ }^{81} \mathrm{Br}$

The ENDF-based data substantially overpredict the reaction rate, while the LLNL-based data do an adequate job of matching the measurement.

${ }^{85} \mathrm{Rb}$

The calculated reaction rate underpredicts the measured value for the ENDF/B-V data.

${ }^{87} \mathrm{Rb}$

The calculated reaction rate matches the measured value for the ENDF/B-V data.

${ }^{89} \mathrm{Y}$

The ENDF/B-V and ENDL92 data for ${ }^{89} \mathrm{Y}$ overpredict the reaction rate for the Bigten assembly, while the SUPER data underpredict the reaction rate. The ENDF/B-VI and LLLDOS data give similar results and are much closer to the measured value. For the Godiva assembly, ENDF/B-V data overpredict the reaction rate, while the other data libraries substantially underpredict the reaction rate. From the plot in Appendix B, it is evident that the ENDF/B-V cross section is much greater on average above $\sim 0.02 \mathrm{MeV}$. This gives better agreement with the Godiva measurement, but poorer agreement with the softer energy spectrum of Bigten, where the ENDF/B-VI data give better agreement with measurement.

${ }^{93} \mathrm{Nb}$

The calculated reaction rate overpredicts the measured value for the Godiva and Jezebel assemblies. For the Godiva assembly, the calculated reaction rate is within two standard deviations of the measured value for all of the data libraries.

${ }^{107} \mathrm{Ag}$

The calculated reaction rate consistently underpredicts the measured value for the Godiva and Jezebel assemblies, but is within two standard deviations of the measured value.

${ }^{121} \mathrm{Sb}$

The LLNL-based dosimetry data overpredict the reaction rate.

The ENDF-based data libraries more closely match the measured value for this reaction than the ENDL92 data. 
${ }^{139} \mathrm{La}$

The ENDF-based data underpredict the reaction rate, though the calculated values are within two standard deviations of the measurement.

${ }^{153} \mathrm{Eu}$

The calculated reaction rate using the ENDF-based data matches the measured value, while the LLNL-based dosimetry data slightly overpredict the reaction rate.

${ }^{169} \mathrm{Tm}$

All of the data libraries overpredict the reaction rate, but the LLNL-based dosimetry data are a better match with the measured values than the ENDF/B-V or SUPER data.

${ }^{176} \mathrm{Lu}$

The calculated reaction rate for Bigten is $10 \%$ lower than measured for this nuclide. The calculated reaction rates for the Flattop assemblies are closer to the measured values.

${ }^{181} \mathrm{Ta}$

The calculated reaction rates are consistently lower than the measured values for this reaction. The calculations are within two standard deviations of the measured value, and the ENDF-based data more closely match experiment than the LLNL-based data.

${ }^{180} \mathrm{~W}$

The reaction rate is substantially underpredicted for the Bigten assembly, indicating that the $(n, \gamma)$ cross section in the LLLDOS library is low.

${ }^{184} \mathrm{~W}$

The calculated reaction rates for this nuclide are lower than the measured values. The LLNL-based dosimetry data of LLLDOS more closely match experiment than the ENDFbased data.

${ }^{186} \mathrm{~W}$

All of the calculated reaction rates match the measured values for this nuclide.

${ }^{185} \operatorname{Re}$

The ENDF/B-VI reaction rate for this nuclide is substantially greater than the ENDF/B-V rate. In both cases, the calculated value is within two standard deviations of the measured value. The ENDL92 data more closely match experiment than the earlier LLLDOS data. The ENDL92 reaction rate is also within two standard deviations of the measured value. 
${ }^{187} \mathrm{Re}$

The ENDF-based data match the measured reaction rate, while the LLNL-based data greatly overestimate the reaction rate for this nuclide.

${ }^{193} \mathrm{Ir}$

The SUPER dosimetry data do an adequate job of matching the measured reaction rates, coming within $\sim 10 \%$ for the various assemblies.

${ }^{197} \mathrm{Au}$

The ENDF-based data appear to slightly underestimate the reaction rate for this nuclide for the majority of the critical assemblies. The LLNL-based dosimetry data more closely match the measured values for all but the Flattop- 25 assembly.

${ }^{203} \mathrm{Tl},{ }^{205} \mathrm{Tl}$

The LLNL-based dosimetry data for these nuclides greatly underpredict the measured values for the critical assemblies.

${ }^{209} \mathrm{Bi}$

The new ENDF/B-VI data have greatly overestimated the $(n, \gamma)$ cross section for this nuclide. The ENDF/B-V and LLNL-based data all overpredict the measured value by $\sim 22 \%$.

${ }^{238} \mathrm{U}$

The ENDF-based data for this nuclide are a slightly better match with the measurement, though all are within two standard deviations of the measured value for the Bigten assembly. The LLNL-based data are a better match with the measured value for the Thor assembly.

${ }^{241} \mathrm{Am}$

The ENDF/B-VI data for this nuclide are a great improvement over ENDF/B-V in calculating the measured reaction rate. The ENDL92 data greatly underpredict the measured value, and the LLLDOS data overpredict the measurement.

${ }^{232} \mathrm{Th}$

This reaction rate was measured with respect to the ${ }^{238} U(n, \gamma)$ rate. The ENDF-based data are a slightly better match with the measurement than the LLNL-based data. 
${ }^{59} \mathrm{Co}(\mathrm{n}, \gamma){ }^{60 \mathrm{~m}} \mathrm{Co}$

This reaction cross section was only available from the LLLDOS library. The cross section appears to be underpredicted by a factor of 10 . It is interesting to note that the measured value given by Byers for this reaction is larger than the total reaction rates given by Byers for either ${ }^{55} \mathrm{Mn}$ or ${ }^{63} \mathrm{Cu}$. As the total $(\mathrm{n}, \gamma)$ cross section for ${ }^{59} \mathrm{Co}$ falls between the total $(\mathrm{n}, \gamma)$ cross section for ${ }^{55} \mathrm{Mn}$ and ${ }^{63} \mathrm{Cu}$, and the measured total reaction rates for ${ }^{55} \mathrm{Mn}$ and ${ }^{63} \mathrm{Cu}$ are reported by Byers to be $0.0026 \pm 0.0002$ and 0.0155 \pm 0.0005 , it appears that there is an error in the reported value for ${ }^{59} \mathrm{Co}$. The simplest explanation would be a typographical error in the published value, where the reported measured value of $0.0297 \pm 0.0024$ for ${ }^{59} \mathrm{Co}(\mathrm{n}, \gamma){ }^{60 \mathrm{~m}} \mathrm{Co}$ should be $0.00297 \pm 0.00024$. As the CSEWG specification is based on the Byers result, the CSEWG value would become $0.0038 \pm 0.0003$. If this were the case, the calculated-to-experiment ratio and relative error for the Byers data would be 1.297 and 0.081 , respectively. The C/E ratio and relative error for the CSEWG specification would become 1.093 and 0.079 , respectively. ${ }^{109} \mathrm{Ag}(\mathrm{n}, \gamma){ }^{110 \mathrm{~m}} \mathrm{Ag}$

The LLNL dosimetry data underestimate the reaction rate by a factor of 2 . This indicates that a larger percentage of the total reaction cross section should be to the metastable state, and less to the ground state of ${ }^{110} \mathrm{Ag}$.

${ }^{113} \operatorname{In}(\mathrm{n}, \gamma){ }^{114 \mathrm{~m}} \mathrm{In}$

The LLNL dosimetry data underestimate the reaction rate by a factor of 2 . As most of the total reaction cross section feeds into the metastable state, this implies that the total $(n, \gamma)$ cross section is too low.

${ }^{115} \operatorname{In}(\mathrm{n}, \gamma){ }^{1116 \mathrm{~m}} \mathrm{In}$

The calculated reaction rate using ENDF/B-V dosimetry data matches the measured value much more closely than the LLNL-based dosimetry data.

${ }^{151} \operatorname{Eu}(\mathrm{n}, \gamma){ }^{152 \mathrm{~g}} \mathrm{Eu}$

The calculated reaction rate underpredicts the measured value for the LLNL-based dosimetry data by $10 \%$. 
${ }^{191} \operatorname{Ir}(\mathrm{n}, \gamma)^{192(\mathrm{gs}+\mathrm{ml})} \operatorname{Ir}$

The total $(\mathrm{n}, \gamma)$ cross section was used for the calculation of the reaction rate. As noted previously, the production of the second metastable state in ${ }^{192}$ Ir is $\sim 3.5 \%$ of the total at an incident neutron energy of $1 \mathrm{MeV}$. Considering this effect, the calculated reaction rates are in fair agreement, $10 \%$, of the measured values.

\section{2. (n, $\alpha$ ) Activation Measurements}

Three $(\mathrm{n}, \alpha)$ measurements have been performed on the Bigten critical assembly. For ${ }^{6} \mathrm{Li}$ and ${ }^{10} \mathrm{~B}$, the total alpha production was measured, ${ }^{33}$ while only the $(n, \alpha)$ reaction was measured for ${ }^{27} \mathrm{Al}$. Table 10 lists the available experimental data for these measurements. Table 11 lists the MCNP data libraries available for these calculations, and Table 12 gives the results of the MCNP calculations. In general, total alpha production can be calculated by using MT $=207$ in MCNP. This is not the case for the ENDF60 data library as NJOY ${ }^{34}$ did not have the capability to produce the MT $=203-207$ cross sections when the library was created. Instead, the total alpha production was calculated by summing over all of the individual contributions with their corresponding multiplicities. ${ }^{35,36,37}$

In general, all data libraries underpredict the alpha production for these three nuclides by $10-15 \%$. The errors on the calculated-to-experimental ratios are greater for ${ }^{27} \mathrm{Al}$ as the $(\mathrm{n}, \alpha)$ reaction has a threshold of $3.25 \mathrm{MeV}$ and a much lower cross section, as illustrated in Figure 12. Hence, the calculated reaction rate has poorer statistics for ${ }^{27} \mathrm{Al}$ than for the total alphaproduction rate for ${ }^{6} \mathrm{Li}$ and ${ }^{10} \mathrm{~B}$.

Table 10. Experimental Data for the $(n, \alpha)$ Activation Ratio Measurements

\begin{tabular}{|c|c|c|c|}
\hline Reaction & Assembly & CSEWG & CST-LANL \\
\hline${ }^{6} \operatorname{Li}(\mathrm{n}, \alpha)(\mathrm{a})$ & Bigten & $0.71 \pm 0.01$ & - \\
\hline${ }^{10} \mathrm{~B}(\mathrm{n}, \alpha)(\mathrm{a})$ & Bigten & $1.011 \pm 0.014$ & - \\
\hline${ }^{27} \mathrm{Al}(\mathrm{n}, \alpha){ }^{24} \mathrm{Na}$ & Bigten & $0.000078 \pm 0.000002$ & 0.0000673 \\
\hline
\end{tabular}


Table 11. Data Used in the MCNP Calculations for the $(n, \alpha)$ Activation Ratios

\begin{tabular}{|c|c|c|c|c|}
\hline Reaction & ENDF/B-V & $\begin{array}{c}\text { ENDF/B-VI } \\
\text { Release } 2\end{array}$ & $\begin{array}{l}\text { LLLDOS } \\
\text { (ACTL) }\end{array}$ & $\begin{array}{l}\text { ENDF/B-V } \\
\text { Dosimetry }\end{array}$ \\
\hline${ }^{6} \mathrm{Li}(\mathrm{n}, \boldsymbol{\alpha})$ & $3006.50 \mathrm{c}$ & $3006.60 \mathrm{c}(\mathrm{a})$ & - & $3006.24 y$ \\
\hline${ }^{10} \mathrm{~B}(\mathrm{n}, \alpha)$ & $5010.50 c$ & $5010.60 c(a)$ & - & $5010.24 y$ \\
\hline${ }^{27} \mathrm{Al}(\mathrm{n}, \alpha){ }^{24} \mathrm{Na}$ & $13027.50 \mathrm{c}$ & $13027.60 \mathrm{c}$ & $13027.30 \mathrm{y}$ & $13027.26 y$ \\
\hline
\end{tabular}

Table 12. Comparison of MCNP Calculations to Experiment for the $(n, \alpha)$ Activation Ratios

\begin{tabular}{lcccccccc}
\hline Reaction & \multicolumn{2}{c}{ ENDF/B-V } & \multicolumn{2}{c}{$\begin{array}{c}\text { ENDF/B-VI } \\
\text { Release 2 }\end{array}$} & \multicolumn{2}{c}{$\begin{array}{c}\text { LLLDOS } \\
\text { (ACTL) }\end{array}$} & $\begin{array}{c}\text { ENDF/B-V } \\
\text { Dosimetry }\end{array}$ \\
\hline & C/E & RE & C/E & RE & C/E & RE & C/E & RE \\
${ }^{6} \mathrm{Li}(n, \alpha)$ & 0.903 & 0.020 & 0.908 & 0.020 & - & - & 0.903 & 0.020 \\
${ }^{10} \mathrm{~B}(\mathrm{n}, \alpha)$ & 0.873 & 0.019 & 0.895 & 0.066 & - & - & 0.873 & 0.019 \\
${ }^{27} \mathrm{Al}(\mathrm{n}, \alpha){ }^{24} \mathrm{Na}$ & 0.855 & 0.184 & 0.855 & 0.184 & 0.872 & 0.181 & 0.855 & 0.184 \\
\hline
\end{tabular}

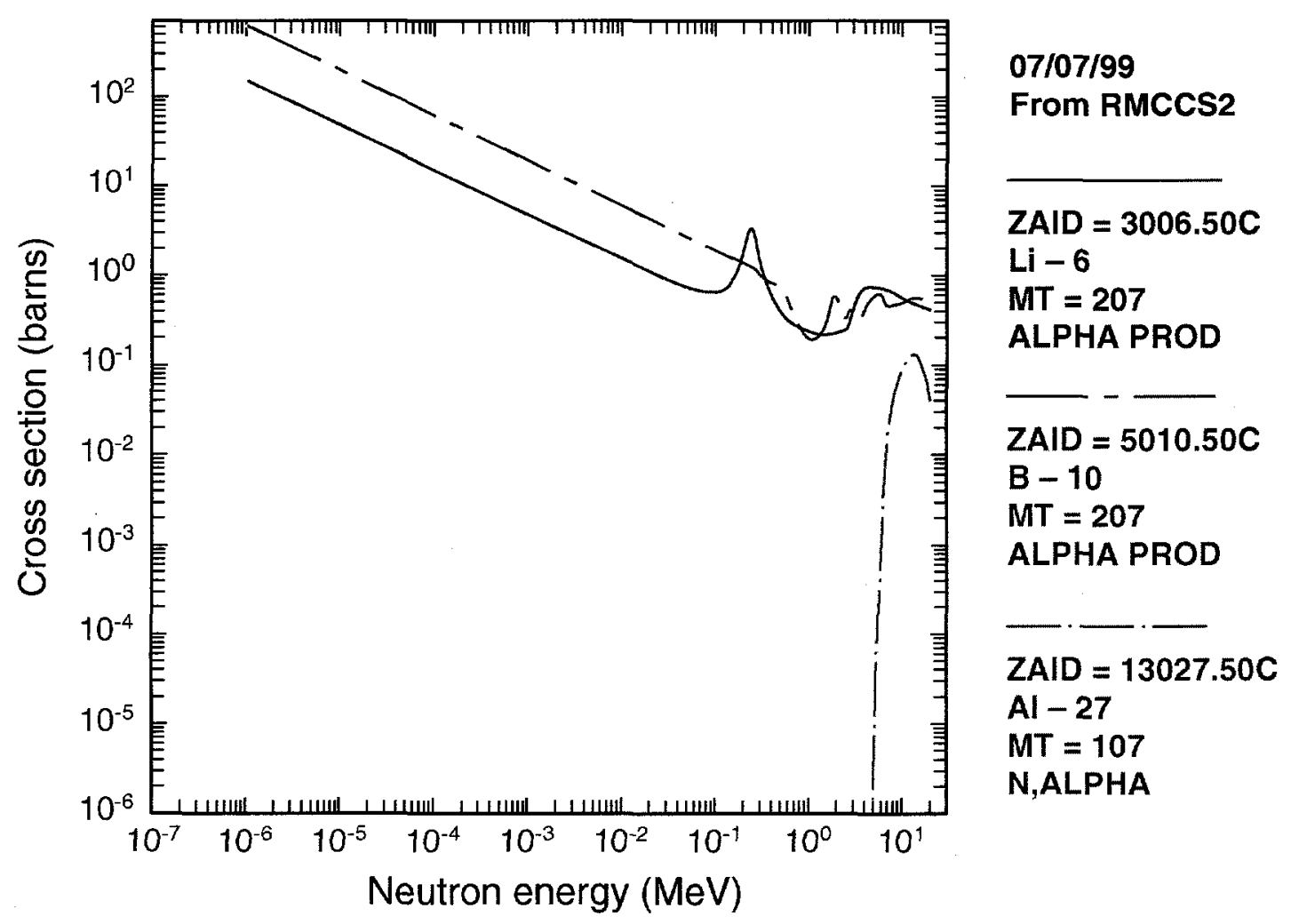

Figure 12. The ENDF/B-V cross sections for the $(n, \alpha)$ activation ratio. 


\section{3. (n,p) Activation Measurements}

All $(n, p)$ measurements were performed on the Bigten critical assembly. Table 13 lists the available experimental data for these measurements. Table 14 lists the MCNP data libraries available for these calculations, and Table 15 gives the results of the MCNP calculations. Table 14 also lists the reaction thresholds for the $(n, p)$ reaction for each nuclide. The $(n, p)$ cross sections for each data library used in the calculations are plotted in Appendix C.

The $(\mathrm{n}, \mathrm{p})$ reaction rate is overpredicted by $16-30 \%$ for ${ }^{27} \mathrm{Al},{ }^{47} \mathrm{Ti}$ and ${ }^{56} \mathrm{Fe}$ for all of the data libraries tested. The (n,p) reaction rate is overpredicted for the ${ }^{54} \mathrm{Fe}$ LLLDOS data and to a lesser extent by the ENDF/B-VI and ENDF/B-V dosimetry data. The ENDF/B-VI data improved the $(n, p)$ reaction rate for ${ }^{59} \mathrm{Co}$ over the previous ENDF/B-V and LLLDOS data. The ENDF/B-V dosimetry data do a good job of predicting the ${ }^{46} \mathrm{Ti}(\mathrm{n}, \mathrm{p})$ reaction rate, but seriously underestimate the reaction rate for ${ }^{48} \mathrm{Ti}$.

Table 13. Experimental Data for the (n,p) Activation Ratio Measurements

\begin{tabular}{cccc}
\hline Reaction & Threshold (MeV) & CSEWG & CST-LANL \\
\hline${ }^{27} \mathrm{Al}(\mathrm{n}, \mathrm{p}){ }^{27} \mathrm{Mg}$ & 1.896 & - & 0.000388 \\
${ }^{46} \mathrm{Ti}(\mathrm{n}, \mathrm{p}){ }^{46} \mathrm{Sc}$ & 1.619 & $0.00130 \pm 0.00003$ & 0.00125 \\
${ }^{47} \mathrm{Ti}(\mathrm{n}, \mathrm{p}){ }^{47} \mathrm{Sc}$ & 0.000 & $0.00215 \pm 0.00009$ & 0.00202 \\
${ }^{48} \mathrm{Ti}(\mathrm{n}, \mathrm{p}){ }^{48} \mathrm{Sc}$ & 3.279 & $0.000036 \pm 0.000001$ & 0.0000338 \\
${ }^{54} \mathrm{Fe}(\mathrm{n}, \mathrm{p}){ }^{54} \mathrm{Mn}$ & 0.000 & $0.0090 \pm 0.0003$ & 0.00844 \\
${ }^{56} \mathrm{Fe}(\mathrm{n}, \mathrm{p}){ }^{56} \mathrm{Mn}$ & 2.966 & - & 0.0000912 \\
${ }^{59} \mathrm{Co}(\mathrm{n}, \mathrm{p}){ }^{59} \mathrm{Fe}$ & 0.796 & $0.0123 \pm 0.0002$ & 0.000158 \\
${ }^{58} \mathrm{Ni}(\mathrm{n}, \mathrm{p}){ }^{58} \mathrm{Co}$ & 0.000 & 0.0116 \\
\hline
\end{tabular}

Table 14. Data Used in the MCNP Calculations for the (n,p) Activation Ratios

\begin{tabular}{lcccc}
\hline Reaction & ENDF/B-V & $\begin{array}{c}\text { ENDF/B-VI } \\
\text { Release 2 }\end{array}$ & $\begin{array}{c}\text { LLLDOS } \\
\text { (ACTL) }\end{array}$ & $\begin{array}{c}\text { ENDF/B-V } \\
\text { Dosimetry }\end{array}$ \\
\hline${ }^{27} \mathrm{Al}(\mathrm{n}, \mathrm{p})^{27} \mathrm{Mg}$ & $13027.50 \mathrm{c}$ & $13027.60 \mathrm{c}$ & $13027.30 \mathrm{y}$ & $13027.26 \mathrm{y}$ \\
${ }^{46} \mathrm{Ti}(\mathrm{n}, \mathrm{p}){ }^{46} \mathrm{Sc}$ & - & - & $22046.30 \mathrm{y}$ & $22046.26 \mathrm{y}$ \\
${ }^{47} \mathrm{Ti}(\mathrm{n}, \mathrm{p})^{47} \mathrm{Sc}$ & - & - & $22047.30 \mathrm{y}$ & $22047.26 \mathrm{y}$ \\
${ }^{48} \mathrm{Ti}(\mathrm{n}, \mathrm{p})^{48} \mathrm{Sc}$ & - & - & $22048.30 \mathrm{y}$ & $22048.26 \mathrm{y}$ \\
${ }^{54} \mathrm{Fe}(\mathrm{n}, \mathrm{p}){ }^{54} \mathrm{Mn}$ & - & $26054.60 \mathrm{c}$ & $26054.30 \mathrm{y}$ & $26054.26 \mathrm{y}$ \\
${ }^{56} \mathrm{Fe}(\mathrm{n}, \mathrm{p}){ }^{56} \mathrm{Mn}$ & - & $26056.60 \mathrm{c}$ & $26056.30 \mathrm{y}$ & $26056.26 \mathrm{y}$ \\
${ }^{59} \mathrm{Co}(\mathrm{n}, \mathrm{p}){ }^{59} \mathrm{Fe}$ & $27059.50 \mathrm{c}$ & $27059.60 \mathrm{c}$ & $27059.30 \mathrm{y}$ & - \\
${ }^{58} \mathrm{Ni}(\mathrm{n}, \mathrm{p}){ }^{58} \mathrm{Co}$ & - & $28058.60 \mathrm{c}$ & $28058.30 \mathrm{y}$ & $28058.26 \mathrm{y}$ \\
\hline
\end{tabular}


Table 15. Comparison of MCNP Calculations to Experiment for the (n,p) Activation Ratios

\begin{tabular}{|c|c|c|c|c|c|c|c|c|}
\hline \multirow[t]{2}{*}{ Reaction } & \multicolumn{2}{|c|}{ ENDF/B-V } & \multicolumn{2}{|c|}{$\begin{array}{c}\text { ENDF/B-VI } \\
\text { Release } 2\end{array}$} & \multicolumn{2}{|c|}{$\begin{array}{c}\text { LLLDOS } \\
\text { (ACTL) }\end{array}$} & \multicolumn{2}{|c|}{$\begin{array}{l}\text { ENDF/B-V } \\
\text { Dosimetry }\end{array}$} \\
\hline & $\mathrm{C} / \mathrm{E}$ & RE & $\mathrm{C} / \mathrm{E}$ & RE & $\mathrm{C} / \mathrm{E}$ & RE & $\mathrm{C} / \mathrm{E}$ & RE \\
\hline${ }^{27} \mathrm{Al}(\mathrm{n}, \mathrm{p}){ }^{27} \mathrm{Mg}$ & 1.271 & 0.067 & 1.271 & 0.067 & 1.298 & 0.066 & 1.271 & 0.067 \\
\hline${ }^{46} \mathrm{Ti}(\mathrm{n}, \mathrm{p}){ }^{46} \mathrm{Sc}$ & - & - & - & - & - & - & 1.011 & 0.071 \\
\hline${ }^{47} \mathrm{Ti}(\mathrm{n}, \mathrm{p}){ }^{47} \mathrm{Sc}$ & - & - & - & - & - & - & 1.296 & 0.055 \\
\hline${ }^{48} \mathrm{Ti}(\mathrm{n}, \mathrm{p}){ }^{48} \mathrm{Sc}$ & - & - & - & - & - & - & 0.738 & 0.153 \\
\hline${ }^{54} \mathrm{Fe}(\mathrm{n}, \mathrm{p}){ }^{54} \mathrm{Mn}$ & - & - & 1.087 & 0.054 & 1.144 & 0.052 & 1.085 & 0.053 \\
\hline${ }^{56} \mathrm{Fe}(\mathrm{n}, \mathrm{p}){ }^{56} \mathrm{Mn}$ & - & - & 1.168 & 0.117 & 1.306 & 0.111 & 1.169 & 0.118 \\
\hline${ }^{59} \mathrm{Co}(\mathrm{n}, \mathrm{p}){ }^{59} \mathrm{Fe}$ & 1.153 & 0.058 & 1.063 & 0.063 & 1.123 & 0.058 & - & - \\
\hline${ }^{58} \mathrm{Ni}(\mathrm{n}, \mathrm{p}){ }^{58} \mathrm{Co}$ & - & - & 1.066 & 0.042 & 1.051 & 0.043 & 1.042 & 0.043 \\
\hline
\end{tabular}

\section{4. (n,2n) Activation Measurements}

Measurements of the $(n, 2 n)$ reaction rate have been performed on the Jezebel, Flattop-25, Flattop-Pu, Bigten and Thor assemblies. With the exception of the Thor assembly, these measurements were all performed by CST-LANL. No error estimates have been given for the measurements from CST-LANL. As seen previously in the central-fission ratio measurements, the reaction rates for the Thor assembly are given with respect to nuclides and reactions other than ${ }^{235} \mathrm{U}$ fission. For these cases, the denominator in the reaction rate ratio is calculated using ENDF/B-VI-based data from the ENDF60 library. The experimental measurements are detailed in Table 16, along with the reaction threshold for the $(n, 2 n)$ reaction for each nuclide. Table 17 lists the available MCNP data, and Table 18 gives the calculated-to-experimental ratios and relative errors for each reaction. The $(n, 2 n)$ cross sections for each data library used in the calculations are shown in Appendix D.

The reaction rate measured for ${ }^{107} \mathrm{Ag}$ is ${ }^{107} \mathrm{Ag}(\mathrm{n}, 2 \mathrm{n}){ }^{106 \mathrm{~m}} \mathrm{Ag}$. The reaction rate measured for ${ }^{191}$ Ir is composed of the sum of the reaction rate to the ground state and the first metastable state $(\mathrm{m} 1)$ plus $5.6 \%$ to the second metastable state $(\mathrm{m} 2)$. Comparisons to the latest theoretical evaluation work indicate that the cross section given in the SUPER library is equivalent to $\mathrm{gs}+\mathrm{m} 1+5.6 \% \mathrm{~m} 2$. All other reaction rates are for the total $(\mathrm{n}, 2 \mathrm{n})$ reaction. Since the contribution of the second metastable state of ${ }^{190}$ Ir is only $5.72 \%$ of the total at an incident neutron energy of $10 \mathrm{MeV}$, using the total $(\mathrm{n}, 2 \mathrm{n})$ cross section will not greatly affect the results for the LLLDOS data. $^{32}$ 
Table 16. Experimental Data for the (n,2n) Activation Ratio Measurements

\begin{tabular}{|c|c|c|c|c|}
\hline Reaction & Threshold (MeV) & Assembly & CSEWG & CST-LANL \\
\hline${ }^{59} \mathrm{Co}(\mathrm{n}, 2 \mathrm{n})^{58} \mathrm{Co}$ & 10.632 & Bigten & - & 0.0000314 \\
\hline${ }^{89} Y(n, 2 n){ }^{88} Y$ & 11.607 & Bigten & - & 0.0000467 \\
\hline \multirow[t]{4}{*}{${ }^{169} \mathrm{Tm}(\mathrm{n}, 2 \mathrm{n}){ }^{168} \mathrm{Tm}$} & 8.081 & Jezebel & - & 0.00303 \\
\hline & & Bigten & - & 0.000545 \\
\hline & & Flattop-25 & - & 0.00142 \\
\hline & & Flattop-Pu & - & 0.00236 \\
\hline \multirow[t]{2}{*}{${ }^{197} \mathrm{Au}(\mathrm{n}, 2 \mathrm{n}){ }^{196} \mathrm{Au}$} & 8.112 & Bigten & - & 0.000352 \\
\hline & & Flattop-25 & - & 0.00162 \\
\hline \multirow[t]{2}{*}{${ }^{203} \mathrm{Tl}(\mathrm{n}, 2 \mathrm{n}){ }^{202} \mathrm{Tl}$} & 7.888 & Flattop-25 & - & 0.00157 \\
\hline & & Flattop-Pu & - & 0.00232 \\
\hline${ }^{238} U(n, 2 n){ }^{237} U$ & 6.180 & Bigten & - & 0.00174 \\
\hline${ }^{232} \mathrm{Th}(\mathrm{n}, 2 \mathrm{n})^{231} \mathrm{Th} /{ }^{238} \mathrm{U}(\mathrm{n}, 2 \mathrm{n}){ }^{237} \mathrm{U}$ & 6.466 & Thor & $1.04 \pm 0.03$ & - \\
\hline${ }^{238} \mathrm{U}(\mathrm{n}, 2 \mathrm{n}){ }^{237} \mathrm{U} /{ }^{238} \mathrm{U}(\mathrm{n}, \mathrm{f})$ & 6.180 & Thor & $0.053 \pm 0.003$ & - \\
\hline \multirow[t]{2}{*}{${ }^{107} \mathrm{Ag}(\mathrm{n}, 2 \mathrm{n}){ }^{106 \mathrm{~m}} \mathrm{Ag}$} & 9.627 & Flattop-25 & - & 0.000144 \\
\hline & & Flattop-Pu & _ & 0.000213 \\
\hline \multirow[t]{4}{*}{${ }^{191} \operatorname{Ir}(\mathrm{n}, 2 \mathrm{n}){ }^{190(\mathrm{gs}+\mathrm{ml}+5.6 \% \mathrm{~m} 2)} \mathrm{Ir}$} & 8.115 & Jezebel & - & 0.00303 \\
\hline & & Bigten & - & 0.000477 \\
\hline & & Flattop-25 & - & 0.00171 \\
\hline & & Flattop-Pu & - & 0.00268 \\
\hline
\end{tabular}

Table 17. Data Used in the MCNP Calculations for the (n,2n) Activation Ratios

\begin{tabular}{lccccc}
\hline $\begin{array}{c}\text { Target } \\
\text { Nuclide }\end{array}$ & ENDF/B-V & $\begin{array}{c}\text { ENDF/B-VI } \\
\text { Release 2 }\end{array}$ & ENDL92 & $\begin{array}{c}\text { LLLDOS } \\
\text { (ACTL) }\end{array}$ & SUPER \\
\hline${ }^{59} \mathrm{Co}$ & $27059.50 \mathrm{c}$ & $27059.60 \mathrm{c}$ & $27059.42 \mathrm{c}$ & $27059.30 \mathrm{y}(\mathrm{a})$ & - \\
${ }^{89} \mathrm{Y}$ & - & $39089.60 \mathrm{c}$ & $39089.42 \mathrm{c}$ & $39089.30 \mathrm{y}$ & $39089.71 \mathrm{y}(\mathrm{a})$ \\
${ }^{169} \mathrm{Tm}$ & $69169.55 \mathrm{c}(\mathrm{b})$ & - & - & - & - \\
${ }^{197} \mathrm{Au}$ & $79197.55 \mathrm{c}(\mathrm{b})$ & $79197.60 \mathrm{c}$ & - & $79197.30 \mathrm{y}(\mathrm{a})$ & - \\
${ }^{203} \mathrm{Tl}$ & - & - & - & $81203.30 \mathrm{y}$ & - \\
${ }^{232} \mathrm{Th}$ & $90232.50 \mathrm{c}$ & $90232.60 \mathrm{c}$ & $90232.42 \mathrm{c}$ & $90232.30 \mathrm{y}$ & - \\
${ }^{238} \mathrm{U}$ & $92238.50 \mathrm{c}$ & $92238.60 \mathrm{c}$ & $92238.42 \mathrm{c}$ & $92238.30 \mathrm{y}$ & - \\
${ }^{107} \mathrm{Ag}$ & - & - & - & $47107.30 \mathrm{y}$ & $77191.70 \mathrm{y}$ \\
${ }^{191} \mathrm{Ir}$ & - & - & & $77191.30 \mathrm{y}$ & \\
(a) This reaction is composed of more than one MT value. & & \\
(b) These evaluations are from LANL and are not part of ENDF/B-V. & &
\end{tabular}


Table 18. Comparison of MCNP Calculations-to-Experiment for the (n,2n) Activation Ratios

\begin{tabular}{|c|c|c|c|c|c|c|c|c|c|c|c|}
\hline \multirow[t]{2}{*}{$\begin{array}{c}\text { Target } \\
\text { Nuclide }\end{array}$} & \multirow[t]{2}{*}{ Assembly } & \multicolumn{2}{|c|}{ ENDF/B-V } & \multicolumn{2}{|c|}{$\begin{array}{c}\text { ENDF/B.VI } \\
\text { Release } 2\end{array}$} & \multicolumn{2}{|c|}{ ENDL92 } & \multicolumn{2}{|c|}{$\begin{array}{c}\text { LLLDOS } \\
\text { (ACTL) }\end{array}$} & \multicolumn{2}{|c|}{ SUPER } \\
\hline & & $\mathrm{C} / \mathrm{E}$ & $\mathbf{R E}$ & $\mathrm{C} / \mathrm{E}$ & $\mathbf{R E}$ & $\mathrm{C} / \mathrm{E}$ & $\mathbf{R E}$ & $\mathrm{C} / \mathrm{E}$ & $\mathbf{R E}$ & $\mathrm{C} / \mathrm{E}$ & $\mathbf{R E}$ \\
\hline \multirow{3}{*}{${ }^{169} \mathrm{Tm}$} & Jezebel & 1.177 & 0.041 & - & - & - & - & 1.127 & 0.043 & 1.160 & 0.042 \\
\hline & Flattop -25 & 1.600 & 0.056 & - & - & - & - & 1.548 & 0.058 & 1.586 & 0.057 \\
\hline & Flattop- $P u$ & 1.207 & 0.039 & - & - & _- & - & 1.163 & 0.040 & 1.198 & 0.039 \\
\hline${ }^{197} \mathrm{Au}$ & Flattop -25 & I.195 & 0.062 & 1.112 & 0.062 & - & - & 1.362 & 0.059 & - & - \\
\hline \multirow[t]{2}{*}{${ }^{203} \mathrm{Tl}$} & Flattop- 25 & - & - & - & - & - & - & 1.879 & 0.054 & - & - \\
\hline & Flattop-Pu & - & - & - & - & - & - & 1.605 & 0.037 & - & - \\
\hline${ }^{238} \mathrm{U}$ & Bigten & 0.839 & 0.176 & 0.781 & 0.179 & 0.906 & 0.181 & 0.908 & 0.181 & - & - \\
\hline \multirow{2}{*}{${ }^{232} \mathrm{Th} /{ }^{238} \mathrm{U}(\mathrm{n}, 2 \mathrm{n})$} & Thor & 1.054 & 0.040 & 1.054 & 0.040 & 1.120 & 0.040 & 1.120 & 0.040 & - & - \\
\hline & Thor & 1.125 & 0.060 & 1.056 & 0.060 & 1.207 & 0.060 & 1.209 & 0.060 & - & - \\
\hline \multirow{5}{*}{${ }^{{ }^{107} \mathrm{Ag}}$} & Flattop-25 & - & - & - & - & - & - & 0.837 & 0.106 & - & - \\
\hline & Flattop-Pu & - & - & - & - & - & - & 0.619 & 0.077 & - & - \\
\hline & Jezebel & - & - & - & - & - & - & 0.868 & 0.046 & 1.041 & 0.042 \\
\hline & Flattop-25 & - & - & - & - & - & - & 1.004 & 0.062 & 1.187 & 0.057 \\
\hline & Flattop-Pu & - & - & - & - & - & - & 0.791 & 0.043 & 0.943 & 0.039 \\
\hline
\end{tabular}

The results in Table 18 show that it is extremely difficult to calculate a reaction rate for the $(\mathrm{n}, 2 \mathrm{n})$ reaction in a critical assembly. The MCNP results for ${ }^{59} \mathrm{Co},{ }^{89} \mathrm{Y},{ }^{169} \mathrm{Tm},{ }^{191} \mathrm{Ir}$ and ${ }^{197} \mathrm{Au}$ for the Bigten assembly have not been included in Table 18 because of the very poor statistics. The neutron flux spectrum decreases greatly as a function of neutron energy, as shown in Figures 7-9 of Section III.A, and very few high-energy neutrons are produced. Therefore, using variance-reduction techniques such as weight windows are not effective for these types of problems. In some cases, the results may only be used to gauge general trends and cannot be relied upon to validate these reaction cross sections. The $(n, 2 n)$ reaction rate is overestimated for ${ }^{169} \mathrm{Tm},{ }^{197} \mathrm{Au}$, and ${ }^{203} \mathrm{Tl}$. The measurements performed on the Bigten assembly appear to consistently underestimate the reaction-rate for ${ }^{238} \mathrm{U}$, but the statistics are poor. The reaction rate calculations for the Thor assembly seem to be in better agreement with experiment, and are easier to calculate because the heaviest nuclides have the lowest $(n, 2 n)$ reaction threshold. For both ${ }^{232}$ Th and ${ }^{238} \mathrm{U}$, the ENDF/B-VI-based data appear to better match experiment for the Thor assembly. The reaction rates are underestimated by the LLLDOS data for the ${ }^{107} \mathrm{Ag}$. The (n, $2 \mathrm{n}$ ) reaction rates for ${ }^{191}$ Ir are close to the measured values for both the LLLDOS and SUPER libraries. 


\section{5. (n,n' $\gamma$ ) Activation Measurements}

Measurements for the $\left(\mathrm{n}, \mathrm{n}^{\prime} \gamma\right)$ reaction rate have been performed on the Jezebel, Flattop-25, Flattop-Pu and Bigten assemblies for two nuclides, ${ }^{115}$ In and ${ }^{193}$ Ir. For both nuclides, the reaction rate given is for the population of the metastable state and not the total (n, n' $\gamma)$ cross section. Hence, there are few data libraries that have these cross sections. Tables 19 and 20 detail the experimental measurements and available MCNP data libraries. Table 21 gives the results of the MCNP calculations. From the results in Table 21, it can be seen that we do an adequate job of matching experiment for the ${ }^{115}$ In measurement, but overpredict by a substantial amount the reaction rate for ${ }^{193} \mathrm{Ir}$.

Table 19. Experimental Data for the (n,n' $\gamma)$ Activation Ratio Measurements

\begin{tabular}{clcc}
\hline Reaction & Assembly & CSEWG & CST-LANL \\
\hline${ }^{115} \operatorname{In}\left(\mathrm{n}^{\prime} \mathrm{n}^{\prime} \gamma\right)^{115 \mathrm{~m} I \mathrm{In}}$ & Bigten & $0.0271 \pm 0.0006$ & 0.0246 \\
${ }^{193} \operatorname{Ir}\left(\mathrm{n}, \mathrm{n}^{\prime} \gamma\right)^{133 \mathrm{~m}} \mathrm{Ir}$ & Jezebel & - & 0.2144 \\
& Bigten & - & 0.0609 \\
& Flattop-25 & - & 0.155 \\
& Flattop-Pu & - & 0.182 \\
\hline
\end{tabular}

Table 20. Data Used in the MCNP Calculations for the $\left(\mathbf{n}, \mathbf{n}^{\prime} \gamma\right)$ Activation Ratios

\begin{tabular}{ccc}
\hline Reaction & ENDF/B-V Dosimetry & SUPER \\
\hline${ }^{115} \operatorname{In}\left(\mathrm{n}^{\prime} \mathbf{n}^{\prime} \gamma\right)^{115 \mathrm{~m}} \mathrm{In}$ & $49115.26 \mathrm{y}$ & - \\
${ }^{193} \operatorname{Ir}\left(\mathbf{n}, \mathbf{n}^{\prime} \gamma\right)^{193 \mathrm{~m}} \mathrm{Ir}$ & - & $77193.71 \mathrm{y}$ \\
\hline
\end{tabular}

Table 21. Comparison of MCNP Calculations to Experiment for the (n, n' $\gamma)$ Activation Ratios

\begin{tabular}{lllccc}
\hline \multicolumn{1}{c}{ Reaction } & Assembly & ENDF/B-V Dosimetry & \multicolumn{1}{c}{ SUPER } \\
\hline & & C/E & RE & C/E & RE \\
${ }^{115} \operatorname{In}\left(\mathbf{n}, \mathbf{n}^{\prime} \gamma\right)^{115 \mathrm{~m}} \mathrm{In}$ & Bigten & 1.008 & 0.033 & - & - \\
${ }^{193} \operatorname{Ir}\left(\mathbf{n}, \mathbf{n}^{\prime} \gamma\right)^{193 \mathrm{~m}} \mathrm{Ir}$ & Jezebel & - & - & 2.640 & 0.004 \\
& Bigten & - & - & 2.839 & 0.018 \\
& Flattop-25 & - & - & 2.808 & 0.004 \\
& Flattop-Pu & - & 2.720 & 0.003 \\
& & &
\end{tabular}


Because of experimental uncertainties in the detector efficiency and decay scheme data for the ${ }^{193} \operatorname{Ir}\left(n^{\prime} \gamma\right)^{193 m}$ Ir, it has been suggested that an adjustment factor of 2.319 be applied to the experimental measurement. If this adjustment is made, the experimental value becomes 0.422 and the calculated-to-experimental ratios become 1.138, 1.224, 1.211, and 1.173 for the Jezebel, Bigten, Flattop-25, and Flattop-Pu assemblies, respectively. More effort will be needed to fully understand the corrections that must be applied to the measured value and therefore the quality of the ${ }^{193} \operatorname{Ir}\left(\mathbf{n}^{\gamma} \gamma\right)^{193 \mathrm{~m}}$ Ir reaction cross section in the SUPER library.

\section{NIST Measurements}

A very careful set of experimental measurements were performed at the National Institute of Standards and Technology (NIST). A thin-encapsulated ${ }^{252} \mathrm{Cf}$ neutron source was suspended by a thin-walled stainless steel tube at the center of a spherical shell of stainless steel. A pair of double-fission chambers were positioned symmetrically on opposite sides of the container. Each chamber contained two foils positioned at the center of the chamber, generally within $0.03 \mathrm{~cm}$ of each other. Figure 13 shows an illustration of the experimental geometry. Measurements were performed with the stainless steel tube and spherical container, either dry or filled with very pure water. Measurements were performed with and without cadmium covering the fission chambers. Three sets of measurements utilizing different sized containers were performed for foils of ${ }^{235.238} \mathrm{U},{ }^{237} \mathrm{~Np}$, and ${ }^{239} \mathrm{Pu}$. The stainless steel containers for the three sets of measurements had radii of $3.81,5.08$, and $6.35 \mathrm{~cm}(1.5,2.0$, and 2.5 " radii), with corresponding average foil positions of $7.62,7.62$ and $9.525 \mathrm{~cm}$. Therefore, for each foil location and foil type, four measurements were made: no water or cadmium (Bare), no water with cadmium $(\mathrm{Cd})$, water and no cadmium $\left(\mathrm{H}_{2} \mathrm{O}\right)$, and water with cadmium $\left(\mathrm{H}_{2} \mathrm{O}+\mathrm{Cd}\right)$.

The MCNP geometry is quite detailed. Previous studies showed that the contributions from neutrons scattered by the laboratory floor and other structures were negligible and so were not included in these calculations. ${ }^{6,7}$ Various variance-reduction methods were employed for the different experimental geometries. To compare with the published experimental fission rates, the contributions from the near foil positions were summed and the contributions from the far foil positions were summed. These two sums were then averaged and multiplied by $4 \pi r^{2}$, where $r$ is the average radius of the foil positions in $\mathrm{cm}$. F2 tallies for the flux through a surface at each foil 
location were multiplied by the appropriate fission cross section as a function of neutron energy, using the FM tally option in MCNP.

For the current calculations, the ENDF60 neutron-data library was used for most of the material specifications for the transport calculations. Exceptions to this rule were the use of the ENDL92 data for Platinum, and the ENDF/B-V data of ENDF5U for Cadmium. Table 22 lists the specific data libraries used in the fission-rate calculations for each isotope of interest. Figure 14 shows the neutron-flux spectrum at the foil locations for the bare sphere (Bare), bare sphere with cadmium-covered fission chambers $(\mathrm{Cd})$, water-moderated sphere $\left(\mathrm{H}_{2} \mathrm{O}\right)$, and watermoderated sphere with cadmium-covered chambers $\left(\mathrm{H}_{2} \mathrm{O}+\mathrm{Cd}\right)$ for the 2 " radius sphere experiments. In Figure 14, the curves for the bare and cadmium-covered fission chambers overlap. The total absorption cross section for cadmium is shown in Figure 15.
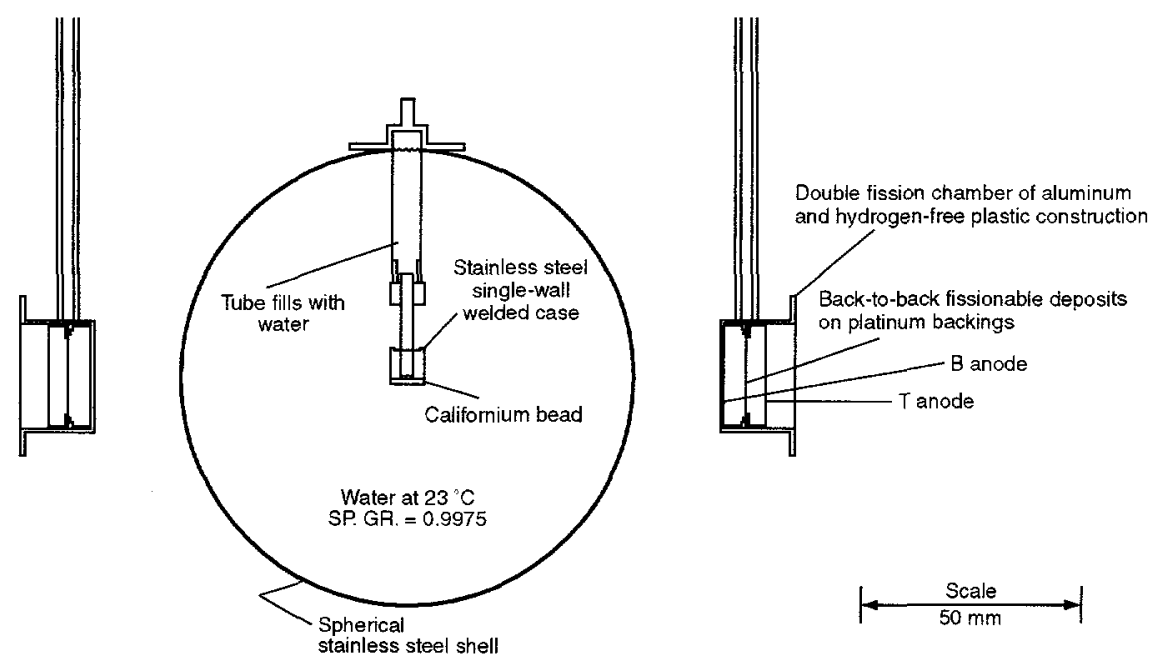

Figure 13. NIST experimental geometry for the $5.08 \mathrm{~cm}\left(2^{\prime \prime}\right)$ sphere.

Table 22. Data Used for the Fission Rate Calculations in MCNP

\begin{tabular}{ccccc}
\hline $\begin{array}{c}\text { Target } \\
\text { Nuclide }\end{array}$ & ENDF/B-V & $\begin{array}{c}\text { ENDF/B-VI } \\
\text { Release 2 }\end{array}$ & ENDL92 & $\begin{array}{c}\text { LLLDOS } \\
\text { (ACTL) }\end{array}$ \\
\hline${ }^{235} \mathrm{U}$ & $92235.50 \mathrm{c}$ & $92235.60 \mathrm{c}$ & $92235.30 \mathrm{y}$ \\
${ }^{238} \mathrm{U}$ & $92238.50 \mathrm{c}$ & $92238.60 \mathrm{c}$ & $92235.42 \mathrm{c}$ & $92238.30 \mathrm{y}$ \\
${ }^{237} \mathrm{~Np}$ & $93237.55 \mathrm{c}(\mathrm{a})$ & $93237.60 \mathrm{c}$ & $92238.42 \mathrm{c}$ & $93237.30 \mathrm{y}$ \\
${ }^{239} \mathrm{Pu}$ & $94239.55 \mathrm{c}$ & $94239.60 \mathrm{c}$ & $93237.42 \mathrm{c}$ & $94239.30 \mathrm{y}$ \\
\hline (a) LANL evaluation and not ENDF/B-V. & & $94239.42 \mathrm{c}$ & \\
\hline
\end{tabular}




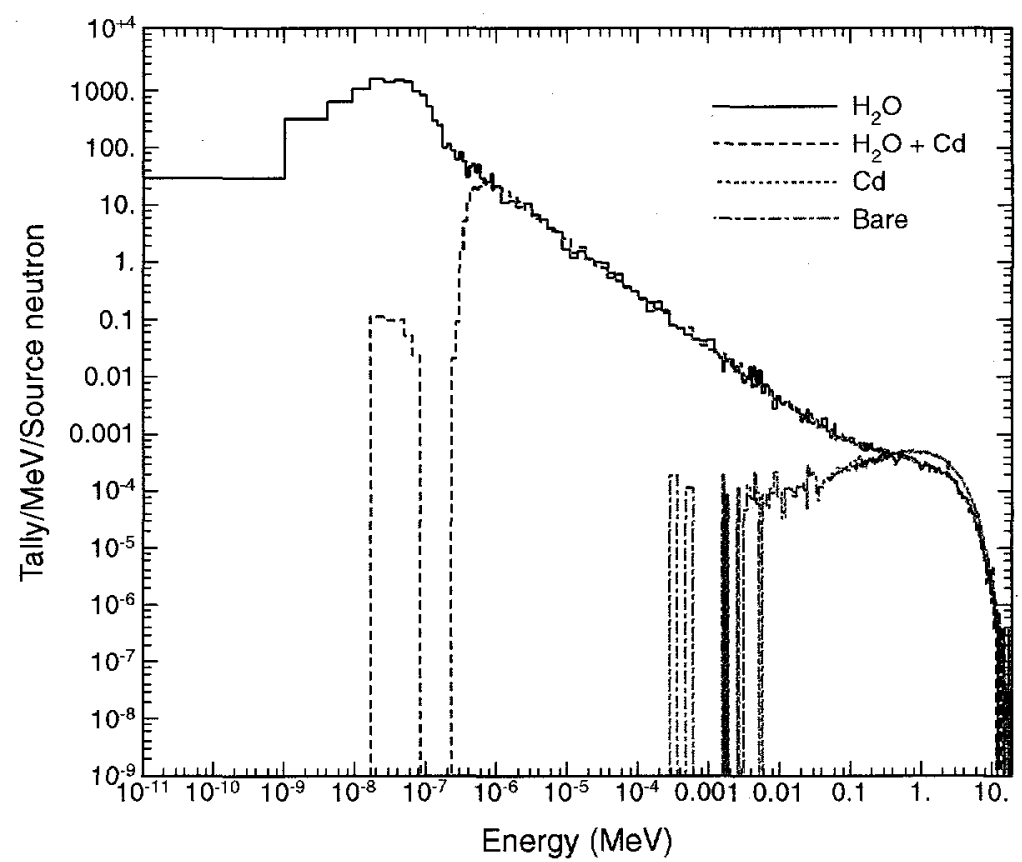

Figure 14. Neutron flux spectra for the $5.08 \mathrm{~cm}\left(2^{\prime \prime}\right)$ sphere experiments at the foil locations.

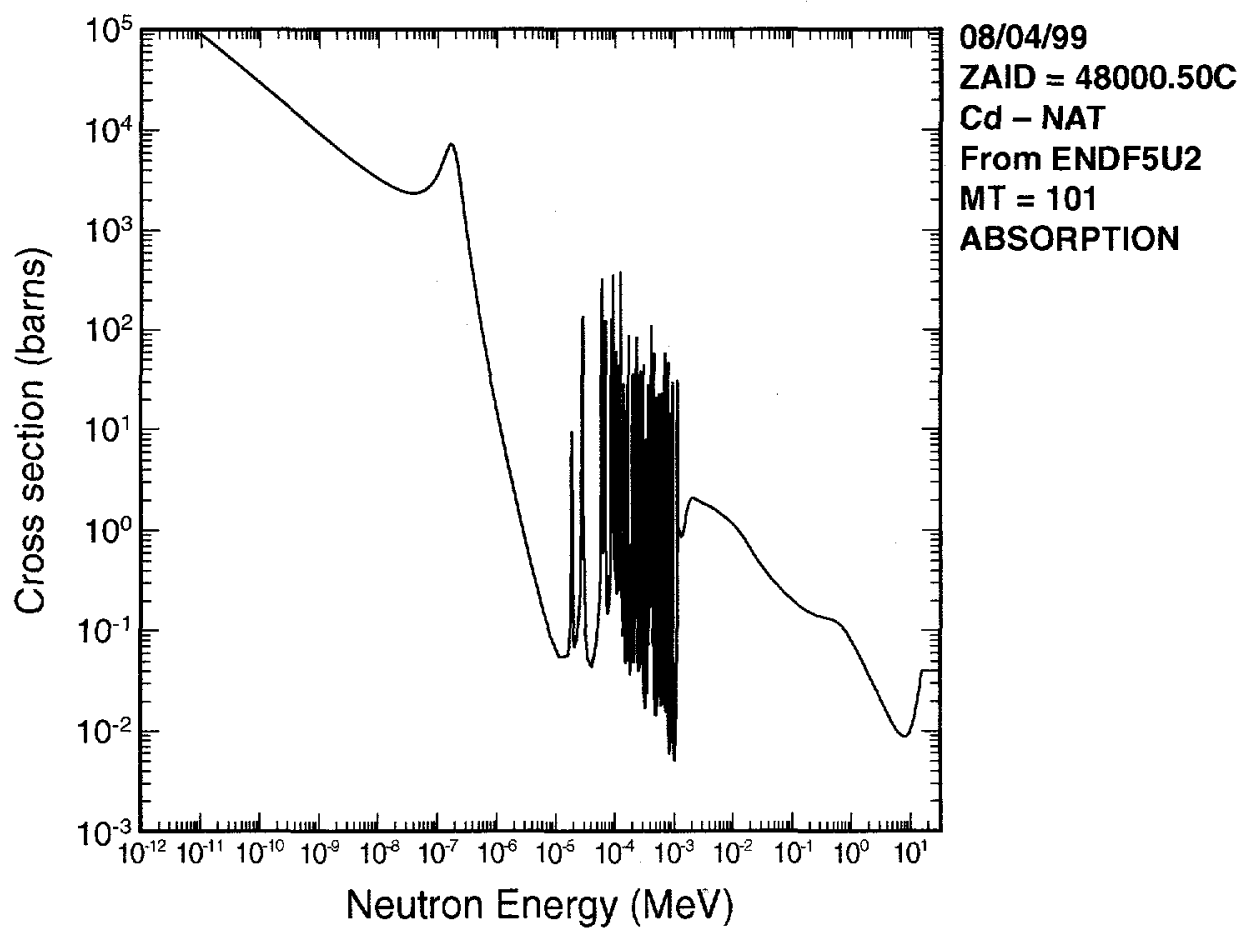

Figure 15. Total absorption cross section for Cadmium from ENDF/B-V. 


\section{A. Comparison to Previous ENDF/B-V Results}

First, the results from the experiments and original calculations are compared with the current results for the ENDF/B-V fission rates and are given in Table 23. The original calculations were performed using ENDF/B-V data for the neutron transport, with ENDL85 for Platinum. As described in the previous section, the current calculations are based mostly on ENDF/B-VI data for neutron transport. The results in Table 23 for both the original and current calculations use ENDF/B-V data for calculating the fission rates at the foil positions for ${ }^{235.238} \mathrm{U},{ }^{237} \mathrm{~Np}$, and ${ }^{239} \mathrm{Pu}$. The same source specifications were used for both MCNP calculations. From these results no clear pattern emerges. The average $\mathrm{C} / \mathrm{E}$ ratio for the original calculations was 0.977 , with an average deviation of 0.032 . The average $\mathrm{C} / \mathrm{E}$ ratio for the current calculations was also 0.977 , with an average deviation of 0.033 . Similar behavior was observed for each nuclide of interest; there were no appreciable differences between the original and current calculations. Experimental data were not available from NIST for the bare and cadmium-covered 2.5 " spheres. 
Table 23. Comparison of Original (ENDF/B-V) and Current (ENDF/B-VI) Transport Calculations with Experiment for the ENDF/B-V Fission Rates

\begin{tabular}{|c|c|c|c|c|c|c|c|c|c|}
\hline \multirow{2}{*}{$\begin{array}{c}\text { Target } \\
\text { Nuclide }\end{array}$} & \multirow[t]{2}{*}{ Experiment } & \multicolumn{2}{|c|}{ Radius } & \multicolumn{2}{|c|}{ NIST Experiment } & \multicolumn{2}{|c|}{ Original MCNP } & \multicolumn{2}{|c|}{ Current MCNP } \\
\hline & & $(\mathbf{m m})$ & (in.) & (barns) & RE & $\mathrm{C} / \mathrm{E}$ & RE & $\mathrm{C} / \mathrm{E}$ & RE \\
\hline \multirow{12}{*}{${ }^{235} \mathrm{U}$} & Bare & 38.1 & 1.5 & 1.278 & 0.016 & 1.009 & 0.019 & 1.006 & 0.017 \\
\hline & Bare & 50.8 & 2.0 & 1.279 & 0.016 & 1.009 & 0.019 & 1.006 & 0.017 \\
\hline & Bare & 63.5 & 2.5 & - & - & - & - & - & - \\
\hline & $\mathrm{Cd}$ & 38.1 & 1.5 & 1.288 & 0.018 & 1.004 & 0.021 & 1.004 & 0.019 \\
\hline & $\mathrm{Cd}$ & 50.8 & 2.0 & 1.291 & 0.018 & 1.002 & 0.020 & 1.003 & 0.019 \\
\hline & $\mathrm{Cd}$ & 63.5 & 2.5 & - & - & - & - & - & - \\
\hline & $\mathrm{H}_{2} \mathrm{O}$ & 38.1 & 1.5 & 19.6 & 0.017 & 1.010 & 0.023 & 1.046 & 0.019 \\
\hline & $\mathrm{H}_{2} \mathrm{O}$ & 50.8 & 2.0 & 45.7 & 0.017 & 1.044 & 0.020 & 1.020 & 0.023 \\
\hline & $\mathrm{H}_{2} \mathrm{O}$ & 63.5 & 2.5 & 72.2 & 0.017 & 1.022 & 0.023 & 1.042 & 0.028 \\
\hline & $\mathrm{H}_{2} \mathrm{O}+\mathrm{Cd}$ & 38.1 & 1.5 & 4.18 & 0.017 & 1.024 & 0.023 & 1.037 & 0.050 \\
\hline & $\mathrm{H}_{2} \mathrm{O}+\mathrm{Cd}$ & 50.8 & 2.0 & 5.51 & 0.017 & 1.049 & 0.029 & 1.022 & 0.034 \\
\hline & $\mathrm{H}_{2} \mathrm{O}+\mathrm{Cd}$ & 63.5 & 2.5 & 5.86 & 0.017 & 1.109 & 0.026 & 1.048 & 0.035 \\
\hline \multirow[t]{12}{*}{${ }^{238} \mathrm{U}$} & Bare & 38.1 & 1.5 & 0.332 & 0.017 & 0.946 & 0.021 & 0.945 & 0.018 \\
\hline & Bare & 50.8 & 2.0 & 0.334 & 0.017 & 0.940 & 0.020 & 0.940 & 0.018 \\
\hline & Bare & 63.5 & 2.5 & - & - & - & - & - & - \\
\hline & $\mathrm{Cd}$ & 38.1 & 1.5 & 0.333 & 0.018 & 0.940 & 0.022 & 0.936 & 0.019 \\
\hline & $\mathrm{Cd}$ & 50.8 & 2.0 & 0.334 & 0.018 & 0.937 & 0.021 & 0.934 & 0.019 \\
\hline & $\mathrm{Cd}$ & 63.5 & 2.5 & - & - & - & - & - & - \\
\hline & $\mathrm{H}_{2} \mathrm{O}$ & 38.1 & 1.5 & 0.228 & 0.018 & 0.961 & 0.025 & 0.945 & 0.018 \\
\hline & $\mathrm{H}_{2} \mathrm{O}$ & 50.8 & 2.0 & 0.199 & 0.018 & 0.935 & 0.020 & 0.944 & 0.019 \\
\hline & $\mathrm{H}_{2} \mathrm{O}$ & 63.5 & 2.5 & 0.172 & 0.018 & 0.942 & 0.021 & 0.950 & 0.020 \\
\hline & $\mathrm{H}_{2} \mathrm{O}+\mathrm{Cd}$ & 38.1 & 1.5 & 0.228 & 0.019 & 0.934 & 0.020 & 0.919 & 0.027 \\
\hline & $\mathrm{H}_{2} \mathrm{O}+\mathrm{Cd}$ & 50.8 & 2.0 & 0.199 & 0.019 & 0.930 & 0.027 & 0.928 & 0.029 \\
\hline & $\mathrm{H}_{2} \mathrm{O}+\mathrm{Cd}$ & 63.5 & 2.5 & 0.171 & 0.019 & 0.953 & 0.024 & 0.941 & 0.030 \\
\hline \multirow[t]{12}{*}{${ }^{237} \mathrm{~Np}$} & Bare & 38.1 & 1.5 & 1.419 & 0.018 & 0.968 & 0.021 & 0.969 & 0.019 \\
\hline & Bare & 50.8 & 2.0 & 1.420 & 0.018 & 0.968 & 0.020 & 0.969 & 0.019 \\
\hline & Bare & 63.5 & 2.5 & - & - & - & - & - & - \\
\hline & $\mathrm{Cd}$ & 38.1 & 1.5 & 1.427 & 0.019 & 0.961 & 0.022 & 0.962 & 0.020 \\
\hline & $\mathrm{Cd}$ & 50.8 & 2.0 & 1.427 & 0.019 & 0.963 & 0.021 & 0.962 & 0.020 \\
\hline & $\mathrm{Cd}$ & 63.5 & 2.5 & - & - & - & - & - & - \\
\hline & $\mathrm{H}_{2} \mathrm{O}$ & 38.1 & 1.5 & 0.987 & 0.018 & 0.977 & 0.019 & 0.967 & 0.018 \\
\hline & $\mathrm{H}_{2} \mathrm{O}$ & 50.8 & 2.0 & 0.873 & 0.018 & 0.953 & 0.020 & 0.954 & 0.019 \\
\hline & $\mathrm{H}_{2} \mathrm{O}$ & 63.5 & 2.5 & 0.761 & 0.018 & 0.930 & 0.021 & 0.938 & 0.020 \\
\hline & $\mathrm{H}_{2} \mathrm{O}+\mathrm{Cd}$ & 38.1 & 1.5 & 1.011 & 0.019 & 0.936 & 0.020 & 0.927 & 0.026 \\
\hline & $\mathrm{H}_{2} \mathrm{O}+\mathrm{Cd}$ & 50.8 & 2.0 & 0.877 & 0.019 & 0.932 & 0.024 & 0.936 & 0.025 \\
\hline & $\mathrm{H}_{2} \mathrm{O}+\mathrm{Cd}$ & 63.5 & 2.5 & 0.748 & 0.019 & 0.952 & 0.022 & 0.945 & 0.026 \\
\hline \multirow[t]{12}{*}{${ }^{239} \mathrm{Pu}$} & Bare & 38.1 & 1.5 & 1.916 & 0.015 & 0.970 & 0.018 & 0.969 & 0.016 \\
\hline & Bare & 50.8 & 2.0 & 1.924 & 0.015 & 0.967 & 0.017 & 0.965 & 0.016 \\
\hline & Bare & 63.5 & 2.5 & - & - & - & - & - & - \\
\hline & $\mathrm{Cd}$ & 38.1 & 1.5 & 1.934 & 0.018 & 0.964 & 0.021 & 0.964 & 0.019 \\
\hline & $\mathrm{Cd}$ & 50.8 & 2.0 & 1.931 & 0.018 & 0.966 & 0.020 & 0.966 & 0.019 \\
\hline & $\mathrm{Cd}$ & 63.5 & 2.5 & - & - & - & - & - & - \\
\hline & $\mathrm{H}_{2} \mathrm{O}$ & 38.1 & 1.5 & 36.7 & 0.015 & 1.011 & 0.027 & 1.019 & 0.019 \\
\hline & $\mathrm{H}_{2} \mathrm{O}$ & 50.8 & 2.0 & 82.3 & 0.015 & 1.038 & 0.020 & 1.007 & 0.022 \\
\hline & $\mathrm{H}_{2} \mathrm{O}$ & 63.5 & 2.5 & 125.5 & 0.015 & 1.010 & 0.021 & 1.029 & 0.027 \\
\hline & $\mathrm{H}_{2} \mathrm{O}+\mathrm{Cd}$ & 38.1 & 1.5 & 5.34 & 0.019 & 0.983 & 0.036 & 1.040 & 0.071 \\
\hline & $\mathrm{H}_{2} \mathrm{O}+\mathrm{Cd}$ & 50.8 & 2.0 & 7.04 & 0.019 & 0.959 & 0.034 & 0.984 & 0.040 \\
\hline & $\mathrm{H}_{2} \mathrm{O}+\mathrm{Cd}$ & 63.5 & 2.5 & 7.74 & 0.019 & 0.969 & 0.031 & 0.977 & 0.042 \\
\hline
\end{tabular}




\section{B. Current MCNP Calculations}

Simulations of the NIST experiments were performed using ENDF/B-V, ENDF/B-VI (ENDF60), ENDL92, and LLLDOS data to calculate the fission reaction rate for ${ }^{235,238} \mathrm{U},{ }^{237} \mathrm{~Np}$, and ${ }^{239} \mathrm{Pu}$. For these MCNP calculations, the ENDF/B-VI data of the ENDF60 neutron-data library (with ENDF/B-V for Cd and ENDL92 for Pt) were used for the neutron transport. The source specification was changed from a 45-group spectrum to a continuous Watt fission spectrum for ${ }^{252} \mathrm{Cf}$, described in Appendix $\mathrm{H}$ of the MCNP manual, having $\mathrm{a}=1.025 \mathrm{MeV}$ and $\mathrm{b}=2.926 \mathrm{MeV}^{-1}$. Tables $24-27$ list the results for ${ }^{235,238} \mathrm{U},{ }^{237} \mathrm{~Np}$, and ${ }^{239} \mathrm{Pu}$ respectively.

Table 24. Comparison of MCNP Calculations to NIST Experimental Measurements for ${ }^{235} \mathrm{U}$

\begin{tabular}{|c|c|c|c|c|c|c|c|c|c|c|}
\hline \multirow[t]{2}{*}{ Experiment } & \multicolumn{2}{|c|}{ Radius } & \multicolumn{2}{|c|}{ ENDF/B-V } & \multicolumn{2}{|c|}{$\begin{array}{c}\text { ENDF/B-VI } \\
\text { Release } 2\end{array}$} & \multicolumn{2}{|c|}{ ENDL92 } & \multicolumn{2}{|c|}{$\begin{array}{l}\text { LLLDOS } \\
\text { (ACTL) }\end{array}$} \\
\hline & $(\mathrm{mm})$ & (in.) & $\mathrm{C} / \mathrm{E}$ & RE & $\mathrm{C} / \mathrm{E}$ & $\mathbf{R E}$ & $\mathrm{C} / \mathrm{E}$ & RE & $\mathrm{C} / \mathrm{E}$ & RE \\
\hline Bare & 38.1 & 1.5 & 0.997 & 0.016 & 0.981 & 0.016 & 0.985 & 0.016 & 0.995 & 0.016 \\
\hline Bare & 50.8 & 2.0 & 0.996 & 0.016 & 0.981 & 0.016 & 0.985 & 0.016 & 0.994 & 0.016 \\
\hline Bare & 63.5 & 2.5 & - & - & - & - & - & - & - & - \\
\hline $\mathrm{Cd}$ & 38.1 & 1.5 & 0.994 & 0.018 & 0.978 & 0.018 & 0.982 & 0.018 & 0.991 & 0.018 \\
\hline $\mathrm{Cd}$ & 50.8 & 2.0 & 0.992 & 0.018 & 0.977 & 0.018 & 0.981 & 0.018 & 0.990 & 0.018 \\
\hline $\mathrm{Cd}$ & 63.5 & 2.5 & - & - & - & - & - & - & - & - \\
\hline $\mathrm{H}_{2} \mathrm{O}$ & 38.1 & 1.5 & 0.950 & 0.017 & 0.952 & 0.017 & 0.964 & 0.017 & 0.956 & 0.017 \\
\hline $\mathrm{H}_{2} \mathrm{O}$ & 50.8 & 2.0 & 0.944 & 0.018 & 0.947 & 0.018 & 0.960 & 0.018 & 0.957 & 0.018 \\
\hline $\mathrm{H}_{2} \mathrm{O}$ & 63.5 & 2.5 & 0.978 & 0.020 & 0.982 & 0.020 & 0.995 & 0.020 & 0.992 & 0.020 \\
\hline $\mathrm{H}_{2} \mathrm{O}+\mathrm{Cd}$ & 38.1 & 1.5 & 0.947 & 0.025 & 0.931 & 0.025 & 0.951 & 0.024 & 0.948 & 0.024 \\
\hline $\mathrm{H}_{2} \mathrm{O}+\mathrm{Cd}$ & 50.8 & 2.0 & 0.980 & 0.021 & 0.974 & 0.021 & 0.988 & 0.021 & 0.988 & 0.021 \\
\hline $\mathrm{H}_{2} \mathrm{O}+\mathrm{Cd}$ & 63.5 & 2.5 & 0.996 & 0.022 & 0.985 & 0.022 & 1.002 & 0.021 & 1.002 & 0.022 \\
\hline
\end{tabular}

Overall, the data libraries did well in matching experiment for ${ }^{235} \mathrm{U}$. The MCNP results for ENDF/B-VI consistently underpredict the experiment compared to the ENDF/B-V data for the Bare and Cd experiments. The same behavior is observed for the ENDL92 data relative to the LLLDOS data. The ENDF/B-V and B-VI data gave similar results for the water-moderated systems and underpredict the experiment relative to the LLNL-based data. The worst results relative to experiment are for the smaller, water-filled spheres and 1.5 " water $+\mathrm{Cd}$ sphere experiment. 
Table 25. Comparison of MCNP Calculations to NIST Experimental Measurements for ${ }^{238} \mathrm{U}$

\begin{tabular}{|c|c|c|c|c|c|c|c|c|c|c|}
\hline \multirow[t]{2}{*}{ Experiment } & \multicolumn{2}{|c|}{ Radius } & \multicolumn{2}{|c|}{ ENDF/B-V } & \multicolumn{2}{|c|}{$\begin{array}{c}\text { ENDF/B-VI } \\
\text { Release } 2\end{array}$} & \multicolumn{2}{|c|}{ ENDL92 } & \multicolumn{2}{|c|}{$\begin{array}{l}\text { LLLDOS } \\
\text { (ACTL) }\end{array}$} \\
\hline & $(\mathbf{m m})$ & (in.) & $\mathrm{C} / \mathrm{E}$ & RE & $\mathrm{C} / \mathrm{E}$ & $\mathbf{R E}$ & $\mathrm{C} / \mathrm{E}$ & RE & $\mathbf{C} / \mathbf{E}$ & RE \\
\hline Bare & 38.1 & 1.5 & 1.024 & 0.017 & 1.024 & 0.017 & 1.053 & 0.017 & 1.053 & 0.017 \\
\hline Bare & 50.8 & 2.0 & 1.017 & 0.017 & 1.018 & 0.017 & 1.047 & 0.017 & 1.047 & 0.017 \\
\hline Bare & 63.5 & 2.5 & - & - & - & - & - & - & - & - \\
\hline $\mathrm{Cd}$ & 38.1 & 1.5 & 1.015 & 0.018 & 1.016 & 0.018 & 1.045 & 0.018 & 1.045 & 0.018 \\
\hline $\mathrm{Cd}$ & 50.8 & 2.0 & 1.012 & 0.018 & 1.013 & 0.018 & 1.042 & 0.018 & 1.041 & 0.018 \\
\hline $\mathrm{Cd}$ & 63.5 & 2.5 & - & - & - & - & - & - & - & - \\
\hline $\mathrm{H}_{2} \mathrm{O}$ & 38.1 & 1.5 & 1.047 & 0.018 & 1.048 & 0.018 & 1.078 & 0.018 & 1.078 & 0.018 \\
\hline $\mathrm{H}_{2} \mathrm{O}$ & 50.8 & 2.0 & 1.054 & 0.018 & 1.054 & 0.018 & 1.083 & 0.018 & 1.083 & 0.018 \\
\hline $\mathrm{H}_{2} \mathrm{O}$ & 63.5 & 2.5 & 1.064 & 0.018 & 1.065 & 0.018 & 1.095 & 0.018 & 1.094 & 0.018 \\
\hline $\mathrm{H}_{2} \mathrm{O}+\mathrm{Cd}$ & 38.1 & 1.5 & 1.052 & 0.021 & 1.053 & 0.021 & 1.083 & 0.021 & 1.082 & 0.021 \\
\hline $\mathrm{H}_{2} \mathrm{O}+\mathrm{Cd}$ & 50.8 & 2.0 & 1.017 & 0.021 & 1.018 & 0.021 & 1.046 & 0.021 & 1.046 & 0.021 \\
\hline $\mathrm{H}_{2} \mathrm{O}+\mathrm{Cd}$ & 63.5 & 2.5 & 1.035 & 0.022 & 1.036 & 0.022 & 1.065 & 0.022 & 1.065 & 0.022 \\
\hline
\end{tabular}

The MCNP calculations consistently overpredict the fission rates for ${ }^{238} \mathrm{U}$ for all four data libraries. The new ENDF/B-VI evaluation for ${ }^{238} \mathrm{U}$ did not change the MCNP calculations relative to ENDF/B-V results. The LLNL-based data of ENDL92 and LLLDOS gave equivalent results. The ENDF-based data more closely matched experiment for all experimental configurations. The worst results are for the water-filled spheres.

Table 26. Comparison of MCNP Calculations to NIST Experimental Measurements for ${ }^{237} \mathrm{~Np}$

\begin{tabular}{|c|c|c|c|c|c|c|c|c|c|c|}
\hline \multirow[t]{2}{*}{ Experiment } & \multicolumn{2}{|c|}{ Radius } & \multicolumn{2}{|c|}{ ENDF/B-V } & \multicolumn{2}{|c|}{$\begin{array}{c}\text { ENDF/B-VI } \\
\text { Release } 2\end{array}$} & \multicolumn{2}{|c|}{ ENDL92 } & \multicolumn{2}{|c|}{$\begin{array}{c}\text { LLLDOS } \\
\text { (ACTL) }\end{array}$} \\
\hline & $(\mathbf{m m})$ & (in.) & $\mathrm{C} / \mathrm{E}$ & $\mathbf{R E}$ & $\mathrm{C} / \mathrm{E}$ & RE & $\mathrm{C} / \mathrm{E}$ & $\mathbf{R E}$ & $\mathrm{C} / \mathrm{E}$ & $\mathbf{R E}$ \\
\hline Bare & 38.1 & 1.5 & 1.000 & 0.018 & 0.986 & 0.018 & 0.967 & 0.018 & 0.968 & 0.018 \\
\hline Bare & 50.8 & 2.0 & 0.999 & 0.018 & 0.986 & 0.018 & 0.967 & 0.018 & 0.967 & 0.018 \\
\hline Bare & 63.5 & 2.5 & - & - & - & - & - & - & - & - \\
\hline $\mathrm{Cd}$ & 38.1 & 1.5 & 0.992 & 0.019 & 0.979 & 0.019 & 0.960 & 0.019 & 0.961 & 0.019 \\
\hline $\mathrm{Cd}$ & 50.8 & 2.0 & 0.993 & 0.019 & 0.979 & 0.019 & 0.961 & 0.019 & 0.962 & 0.019 \\
\hline $\mathrm{Cd}$ & 63.5 & 2.5 & - & - & - & - & - & - & - & - \\
\hline $\mathrm{H}_{2} \mathrm{O}$ & 38.1 & 1.5 & 1.029 & 0.018 & 1.015 & 0.018 & 1.012 & 0.018 & 1.013 & 0.018 \\
\hline $\mathrm{H}_{2} \mathrm{O}$ & 50.8 & 2.0 & 1.020 & 0.018 & 1.007 & 0.018 & 1.012 & 0.018 & 1.013 & 0.018 \\
\hline $\mathrm{H}_{2} \mathrm{O}$ & 63.5 & 2.5 & 1.020 & 0.018 & 1.006 & 0.018 & 1.017 & 0.019 & 1.018 & 0.019 \\
\hline $\mathrm{H}_{2} \mathrm{O}+\mathrm{Cd}$ & 38.1 & 1.5 & 1.007 & 0.021 & 0.994 & 0.021 & 0.990 & 0.021 & 0.991 & 0.021 \\
\hline $\mathrm{H}_{2} \mathrm{O}+\mathrm{Cd}$ & 50.8 & 2.0 & 0.996 & 0.020 & 0.982 & 0.020 & 0.990 & 0.020 & 0.991 & 0.020 \\
\hline $\mathrm{H}_{2} \mathrm{O}+\mathrm{Cd}$ & 63.5 & 2.5 & 1.014 & 0.020 & 1.001 & 0.020 & 1.012 & 0.020 & 1.013 & 0.020 \\
\hline
\end{tabular}

The ENDF/B-VI results for ${ }^{237} \mathrm{~Np}$ consistently underpredicted the experiment for the bare sphere and Cd measurements, and were consistently lower than the ENDF/B-V results. The ENDF/B-VI results for the water-moderated spheres more closely match experiment relative to 
the ENDF/B-V results. The ENDL92 and LLLDOS results were equivalent and farther from experiment for the Bare and $\mathrm{Cd}$ measurements relative to ENDF.

Table 27. Comparison of MCNP Calculations to NIST Experimental Measurements for ${ }^{239} \mathrm{Pu}$

\begin{tabular}{|c|c|c|c|c|c|c|c|c|c|c|}
\hline \multirow[t]{2}{*}{ Experiment } & \multicolumn{2}{|c|}{ Radius } & \multicolumn{2}{|c|}{ ENDF/B-V } & \multicolumn{2}{|c|}{$\begin{array}{c}\text { ENDF/B-VI } \\
\text { Release } 2\end{array}$} & \multicolumn{2}{|c|}{ ENDL92 } & \multicolumn{2}{|c|}{$\begin{array}{c}\text { LLLDOS } \\
\text { (ACTL) }\end{array}$} \\
\hline & $(\mathbf{m m})$ & (in.) & $\mathrm{C} / \mathrm{E}$ & RE & $\mathrm{C} / \mathrm{E}$ & RE & $\mathbf{C} / \mathbf{E}$ & RE & $\mathrm{C} / \mathrm{E}$ & RE \\
\hline Bare & 38.1 & 1.5 & 0.967 & 0.015 & 0.965 & 0.015 & 0.955 & 0.015 & 0.960 & 0.015 \\
\hline Bare & 50.8 & 2.0 & 0.963 & 0.015 & 0.961 & 0.015 & 0.951 & 0.015 & 0.956 & 0.015 \\
\hline Bare & 63.5 & 2.5 & - & - & - & - & - & - & - & - \\
\hline $\mathrm{Cd}$ & 38.1 & 1.5 & 0.961 & 0.018 & 0.959 & 0.018 & 0.949 & 0.018 & 0.954 & 0.018 \\
\hline $\mathrm{Ca}$ & 50.8 & 2.0 & 0.963 & 0.018 & 0.961 & 0.018 & 0.951 & 0.018 & 0.957 & 0.018 \\
\hline $\mathrm{Cd}$ & 63.5 & 2.5 & - & - & - & - & - & - & - & - \\
\hline $\mathrm{H}_{2} \mathrm{O}$ & 38.1 & 1.5 & 0.919 & 0.016 & 0.925 & 0.016 & 0.941 & 0.016 & 0.936 & 0.016 \\
\hline $\mathrm{H}_{2} \mathrm{O}$ & 50.8 & 2.0 & 0.926 & 0.017 & 0.932 & 0.017 & 0.952 & 0.017 & 0.956 & 0.017 \\
\hline $\mathrm{H}_{2} \mathrm{O}$ & 63.5 & 2.5 & 0.953 & 0.019 & 0.959 & 0.019 & 0.981 & 0.019 & 0.984 & 0.019 \\
\hline $\mathrm{H}_{2} \mathrm{O}+\mathrm{Cd}$ & 38.1 & 1.5 & 0.918 & 0.033 & 0.919 & 0.033 & 0.923 & 0.032 & 0.974 & 0.027 \\
\hline $\mathrm{H}_{2} \mathrm{O}+\mathrm{Cd}$ & 50.8 & 2.0 & 0.983 & 0.026 & 0.975 & 0.026 & 0.980 & 0.025 & 0.992 & 0.022 \\
\hline $\mathrm{H}_{2} \mathrm{O}+\mathrm{Cd}$ & 63.5 & 2.5 & 0.919 & 0.026 & 0.911 & 0.026 & 0.932 & 0.025 & 0.979 & 0.022 \\
\hline
\end{tabular}

The results for ${ }^{239} \mathrm{Pu}$ were remarkably similar for the four data libraries. The MCNP calculations consistently underpredict the measurements, particularly for the water-moderated spheres.

\section{Summary}

In addition to standard $\mathrm{k}_{\mathrm{eff}}$ measurements, a number of benchmarks also have had other experimental measurements performed on the assemblies. In particular, experimental data for neutron leakage and central-flux measurements, central-fission ratio measurements, and activation ratio measurements are available. Additionally, there exists another library of fission reaction-rate measurements performed at the National Institute of Standards and Technology (NIST), utilizing a ${ }^{252} \mathrm{Cf}$ source. This report first described the leakage and central-flux measurements and showed a comparison of experimental data to MCNP simulations performed using the ENDF/B-V and B-VI data libraries. There was good agreement between the MCNP simulations and experimental data for the neutron leakage spectrum in the Jezebel and Godiva assemblies. There was poor agreement in the lowest energy bins for the neutron-leakage spectrum of Jezebel-23 and the central-flux spectrum of Bigten. The improvements in the ${ }^{238} \mathrm{U}$ evaluation for ENDF/B-VI brought the calculated central-flux spectrum for Bigten closer to the experimental measurement, below $25 \mathrm{keV}$. 
In Section III central-fission and activation reaction rate measurements were described, and the comparison of experimental data to MCNP simulations using available data libraries for each reaction of interest was presented. Central-fission ratio measurements were available for ${ }^{232} \mathrm{Th},{ }^{232,238} \mathrm{U},{ }^{237} \mathrm{~Np}$ and ${ }^{239} \mathrm{Pu}$ in a number of fast critical assemblies. Central-fission ratios are available for ${ }^{232} \mathrm{Th}$ only in the Thor assembly. The ENDF- and LLNL-based data tended to underpredict the fission rate by $5 \%$ and $1.2 \%$, respectively, for ${ }^{232} \mathrm{Th}$.

The ENDF- and LLNL-based data for ${ }^{233} \mathrm{U}$ matched the experimental data within $1 \%$, with the exception of the LLNL-based data in the Bigten assembly, which overpredicted the fission rate by $2 \%$. On average the ${ }^{238} \mathrm{U}$ ENDF- and LLNL-based data matched the experimental measurements to within 3\%, with the exception of the Bigten measurements. The fission rate for ${ }^{238} \mathrm{U}$ is overpredicted by $11 \%$ for the ENDF-based data and by $14 \%$ for the LLNL-based data for Bigten. Similar results were obtained for ${ }^{237} \mathrm{~Np}$, where the calculated fission rate was within $3 \%$ for most assemblies. The LLNL-based data underpredicted the fission rate by $5 \%$ for the Jezebel assembly and by $7 \%$ for the Thor assembly. The ENDF-based data underpredicted the fission rate for the Thor assembly by $5-6 \%$ as well. All of the data libraries overpredicted the fission rate for ${ }^{237} \mathrm{~Np}$ in the Bigten assembly by $6-8 \%$. The ENDF- and LLNL-based data for ${ }^{239} \mathrm{Pu}$ matched the experimental data to within $3 \%$. As observed for ${ }^{238} \mathrm{U}$ and ${ }^{237} \mathrm{~Np}$, the fission rates were higher for the Bigten assembly, but this brought the calculated-to-experimental ratio closer to 1.0 for ${ }^{239} \mathrm{Pu}$.

There were 5 categories of activation measurements; $(n, \gamma),(n, \alpha),(n, p),(n, 2 n)$, and $\left(n, n^{\prime} \gamma\right)$. Often data are not available for calculating some of the measured reaction rates. For the $(\mathrm{n}, \gamma)$ reaction rates, most of the isotopes had differences of greater than $10 \%$ when compared to the measured values, indicating that the fast capture cross sections are not well known. The $(n, \alpha)$ reaction rates were underpredicted by the ENDF- and LLNL-based data libraries by $10-15 \%$. In general, the $(n, p)$ reaction rates were overpredicted by the various libraries by $4-30 \%$ with the exception of the ENDF/B-V dosimetry data for ${ }^{46} \mathrm{Ti}$, which matched the measured value to within $1 \%$, and the ENDF/B-V dosimetry data for ${ }^{48} \mathrm{Ti}$, which underpredicted the reaction rate by $26 \%$.

The $(n, 2 n)$ reaction rates could not be calculated with sufficient statistics for most of the Bigten measurements because of the high reaction thresholds for the lighter isotopes. The reaction rate for ${ }^{238} U(n, 2 n)$ in Bigten appears to be underpredicted, though the statistics are 
marginal. In the Thor assembly, the ${ }^{238} \mathrm{U}(\mathrm{n}, 2 \mathrm{n})$ rate is overpredicted, with the ENDF/B-VI data giving the best agreement, within $5 \%$, with the measurement. The $(n, 2 n)$ reaction rates for ${ }^{169} \mathrm{Tm}$, ${ }^{197} \mathrm{Au}$, and ${ }^{203} \mathrm{Tl}$ appear to be significantly overpredicted in a number of critical assemblies. The reaction rate for ${ }^{232} \mathrm{Th}(\mathrm{n}, 2 \mathrm{n})$ is within $5 \%$ for the ENDF-based data and $12 \%$ for the LLNL-based data for the Thor assembly. The ${ }^{107} \mathrm{Ag}(\mathrm{n}, 2 \mathrm{n}){ }^{106 \mathrm{~m}} \mathrm{Ag}$ rate is significantly underpredicted in both Flattop assemblies. The $(n, 2 n)$ reaction rates for ${ }^{191}$ Ir are close to the measured values for both the LLLDOS and SUPER libraries.

The ${ }^{115} \operatorname{In}\left(\mathrm{n}, \mathrm{n}^{\prime} \gamma\right)^{115 \mathrm{~m}}$ In reaction rate was accurately predicted by the ENDF/B-V dosimetry data in the Bigten assembly. The ${ }^{193} \operatorname{Ir}\left(\mathrm{n}, \mathrm{n}^{\prime} \gamma\right)^{193 \mathrm{~m}}$ Ir rate was substantially overpredicted, having an average calculated-to-experimental ratio of 2.75 for a number of assemblies. Because of uncertainties in the measurement for this reaction, an adjustment factor of 2.319 has been suggested for the measured value. Applying this adjustment would give an average calculated-toexperimental ratio of 1.186. More effort will be needed to fully understand the corrections that must be applied to the measured value and therefore the quality of the ${ }^{193} \operatorname{Ir}\left(\mathrm{n}, \mathrm{n}^{\prime} \gamma\right)^{193 \mathrm{~m}} \mathrm{Ir}$ reaction cross section data.

Finally, the NIST fission reaction-rate measurements were described in Section IV. A comparison of MCNP results published previously with the current MCNP simulations showed no appreciable differences between using the ENDF/B-V or ENDF/B-VI data for the neutron transport. For ${ }^{235} \mathrm{U}$, the water-moderated spheres underpredicted the fission rate more than the bare sphere experiments. For ${ }^{238} \mathrm{U}$, the water-moderated spheres overpredicted the fission rate more than the bare sphere experiments. The ENDF-based results were closer to the measured values by $3 \%$ than the LLNL-based results for ${ }^{238} \mathrm{U}$. The results for the bare sphere experiments for ${ }^{237} \mathrm{~Np}$ indicate that the ENDF/B-V data was closest to the measurement, followed by the ENDF/B-VI data. The LLNL-based data for ${ }^{237} \mathrm{~Np}$ underestimated the fission rate for the bare sphere experiments by the greatest amount, $\sim 3 \%$. All of the data libraries adequately matched the measured values for the water-moderated spheres for ${ }^{237} \mathrm{~Np}$. The bare sphere experiments were underestimated by all the data libraries for ${ }^{239} \mathrm{Pu}(4-5 \%)$, and the water-moderated sphere experiments were underestimated by a greater amount on average for ENDF-based and ENDL92 data. The LLNL dosimetry data only underestimated the fission rate an average of $3 \%$. 


\section{Acknowledgements}

The guidance and assistance of Bob Little and Harold Rogers are gratefully acknowledged. The information provided by Mike MacInnes and Tim Benjamin, regarding the CST-LANL data and measurement techniques, was very helpful in implementing many of these activation benchmarks.

This work was supported by Defense Programs and by the Nuclear Criticality Safety Program's Applicable Ranges of Bounding Curves and Data (AROBCAD) project of the Department of Energy.

\section{References}

${ }^{1}$ J. F. Briesmeister, Ed., "MCNP4B-A General Monte Carlo N-Particle Transport Code," Los Alamos National Laboratory report LA-12625-M (1997).

${ }^{2}$ S. C. Frankle, "A Suite of Criticality Benchmarks for Validating Nuclear Data," Los Alamos National Laboratory report LA-13594 (1999).

${ }^{3}$ S. C. Frankle, "Criticality Benchmark Results using Various MCNP Data Libraries," Los Alamos National Laboratory report LA-13627 (1999).

4 "Cross Section Evaluation Working Group Benchmark Specifications," ENDF-202, Brookhaven National Laboratory report BNL 19302 (revised 1991).

5 "International Handbook of Evaluated Criticality Safety Benchmark Experiments," NEA Nuclear Science Committee, NEA/NSC/DOC(95)03, 1998 ed. (http://wastenot.inel.gov/icsbep/handbook.html).

${ }^{6}$ D. M. Gilliam and J. F. Briesmeister, "Benchmark Measurements and Calculations of Neutron Leakage from Water Moderators," in Proceedings of the Int. Topical Mtg. on Adv. in Math, Comp., and Reactor Physics, Pittsburgh, PA, April 28-May 2, 1991.

${ }^{7}$ D. M. Gilliam and J. F. Briesmeister, "Neutron Leakage Benchmarks for Water Moderators," in Reactor Dosimetry, H. Farrar et al., Eds., $8^{\text {th }}$ Dosimetry meeting of ASTM-EURATOM, 1993 (ASTM, Philadelphia, 1994).

${ }^{8}$ G. A. Linenberger and L. L. Lowry, "Neutron Detector Traverses in the Topsy and Godiva Critical Assemblies," Los Alamos National Laboratory report LA-1653 (June 1953).

${ }^{9}$ C. I. Browne, "Radiochemical Experiments on the ${ }^{233} \mathrm{U}$ Jezebel Assembly," Los Alamos National Laboratory internal memorandum, September 5, 1961.

${ }^{10}$ C. I. Browne, "Radiochemical Experiments on the Flattop Assembly," Los Alamos National Laboratory internal memorandum, March 6, 1962.

${ }^{11}$ G. W. Knobeloch, "Pajarito Flattop Bombardment of Detectors," Los Alamos National Laboratory internal memorandum, May 8, 1962.

${ }^{12}$ G. W. Knobeloch, "Second Pajarito Flattop Bombardment of Detectors," Los Alamos National Laboratory internal memorandum, June 15, 1962.

${ }^{13}$ G. W. Knobeloch, "Pajarito Thor Bombardment of September 1961," Los Alamos National Laboratory internal memorandum, October 10, 1963.

${ }^{14}$ G. W. Knobeloch, "Interlaboratory Calibration Bombardment in Pajarito Flattop (Pu core)," Los Alamos National Laboratory internal memorandum, March 25, 1964.

${ }^{15}$ J. S. Hendricks, S. C. Frankle and J. D. Court, "ENDF/B-VI Data for MCNP," Los Alamos National Laboratory report LA-12891 (1994).

${ }^{16}$ L. Stewart, "Leakage Neutron Spectrum from a Bare ${ }^{239}$ Pu Critical Assembly," Nucl. Sci. and Eng. 8, 595-597 (1960). 
${ }^{17}$ S. C. Frankle, "Summary Documentation for the ENDL92 Continuous-energy Neutron Data Library," Los Alamos National Laboratory memorandum XTM:SCF-96-05 and LA-UR-96-327 (January 1996).

18 "FSX96: Collection of Continuous Energy Cross Section Libraries for MCNP based on JENDL," Radiation Safety Information Computational Center release, DLC-190 (1997).

${ }^{19}$ R. C. Greenwood et al., "Nonfission Reaction Rate Measurements," Nucl. Technol. 25, 274-288 (1975).

${ }^{20}$ R. C. Greenwood et al., "Radiometric Reaction Rate Measurement in CFRMF and Big-10," in Proceedings of the $2^{\text {nd }}$ ASTM-EURATOM Symposium Reactor Dosimetry: Dosimetry Methods for Fuels, Cladding, and Structural Materials, Palo Alto, California, October 1977 (NUREG/CP-0004), Vol. 3, pp. 1207-1221.

${ }^{21}$ J. A. Grundl et al., "Measurement of Absolute Fission Rates," Nucl. Technol. 25, 237-257 (1975).

${ }^{22}$ N. D. Dudey, "Fission-Product Rate Measurements and Yields," Nucl. Technol. 25, 294-304 (1975).

${ }^{23}$ R. G. Helmer and R. C. Greenwood, "Evaluated Decay Scheme Data," Nucl. Technol. 25, 258-273 (1975).

${ }^{24}$ R. B. Firestone et al., Table of Isotopes, $8^{\text {th }}$ ed. (John Wiley \& Sons, Inc., New York, 1998).

${ }^{25}$ T. Benjamin and M. MacInnes, private communications, Jan. 20, 1998.

${ }^{26}$ A. A. Adams, S. C. Frankle, and R. C. Little, "Revised Criticality Benchmarks for MCNP," X-Division Research Note XTM-RN(U)96-031, December 24, 1996.

${ }^{27}$ P. B. Bevington, Data Reduction and Error Analysis for the Physical Sciences (McGraw-Hill, 1969).

${ }^{28}$ R. C. Little and R. E. Seamon, "Dosimetry/Activation Cross Sections for MCNP," Los Alamos National Laboratory memorandum, March 13, 1984.

${ }^{29}$ M. A. Gardner and R. J. Howerton, "ACTL: Evaluated Neutron Activation Cross Section Library-Evaluation Techniques and Reaction Index," Lawrence Livermore National Laboratory Report UCRL-50400, Vol. 18 (Oct. 17. 1978).

${ }^{30}$ C. C. Byers, "Cross Sections of Various Materials in the Godiva and Jezebel Critical Assemblies," Nucl. Sci. and Eng. 8, 608-614 (1960).

${ }^{31}$ R. C. Little and R. E. Seamon, Los Alamos National Laboratory memorandum X-6:RCL:RES-87-172, March 17, 1987. The data library SUPER has not been publicly distributed.

${ }^{32}$ M. B. Chadwick and A. C. Hayes, "Iridium as a Radiochemical Detector for Neutron Spectroscopy," Los Alamos National Laboratory report LA-CP-99-226 (1999).

${ }^{33}$ H. Farrar IV, "Integral $(n, \alpha)$ Cross Sections by Helium Measurement," Interlaboratory Reaction Rate Program $11^{\text {th }}$ Progress Report, Vol. 1, Handford Engineering Development Laboratory report HEDL-TME 77-34 (1977).

${ }^{34}$ R. E. MacFarlane and D. W. Muir, "The NJOY Nuclear Data Processing System Version 91," Los Alamos National Laboratory report LA-12740-M (Manual), 1994.

${ }^{35}$ S. C. Frankle, "Total Charged-particle Production, GASPR," Los Alamos National Laboratory memorandum XTM:SCF-96-199 (May 22, 1996).

${ }^{36}$ R. C. Little, R. E. Seamon, and P. D. Soran, "ENDF/B-V Charged-Particle-Production Cross Sections," Los Alamos National Laboratory memorandum (July 7, 1981).

${ }^{37}$ R. C. Little, "Particle Production from ENDF/B-V Reactions," Los Alamos National Laboratory memorandum (January 20, 1981). 
Appendix A

Plots of Fission Cross Sections

A-1 
A-2 

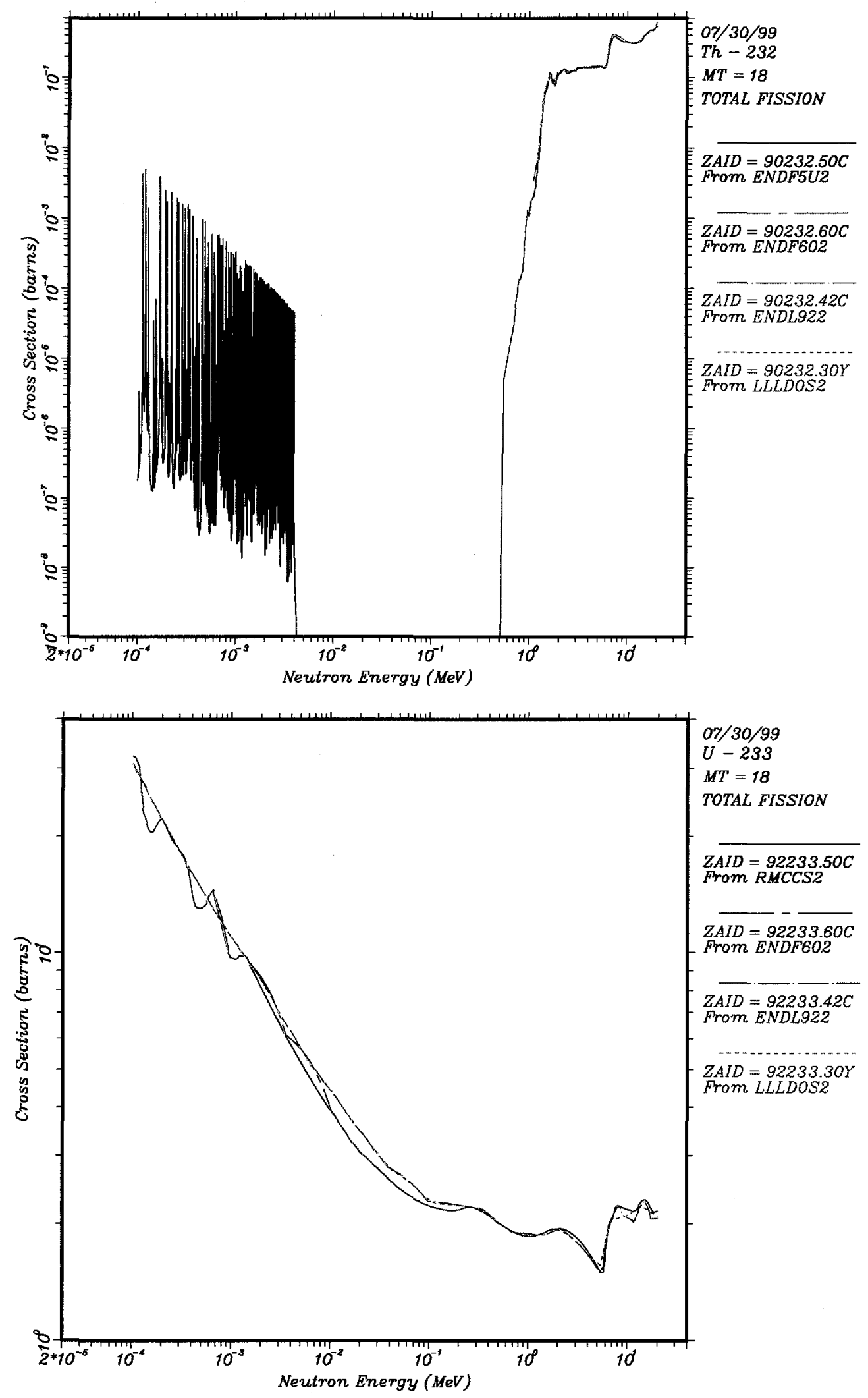

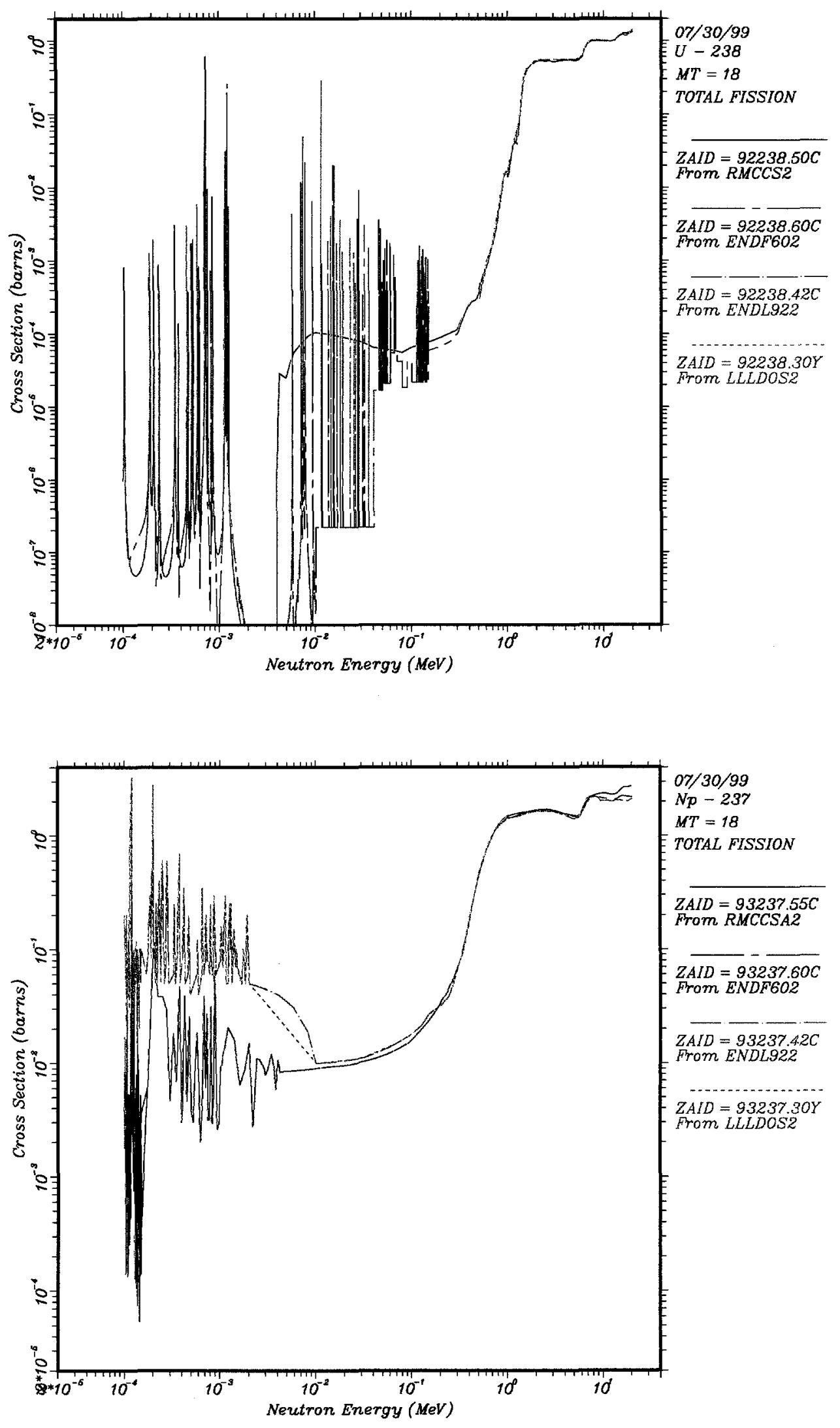


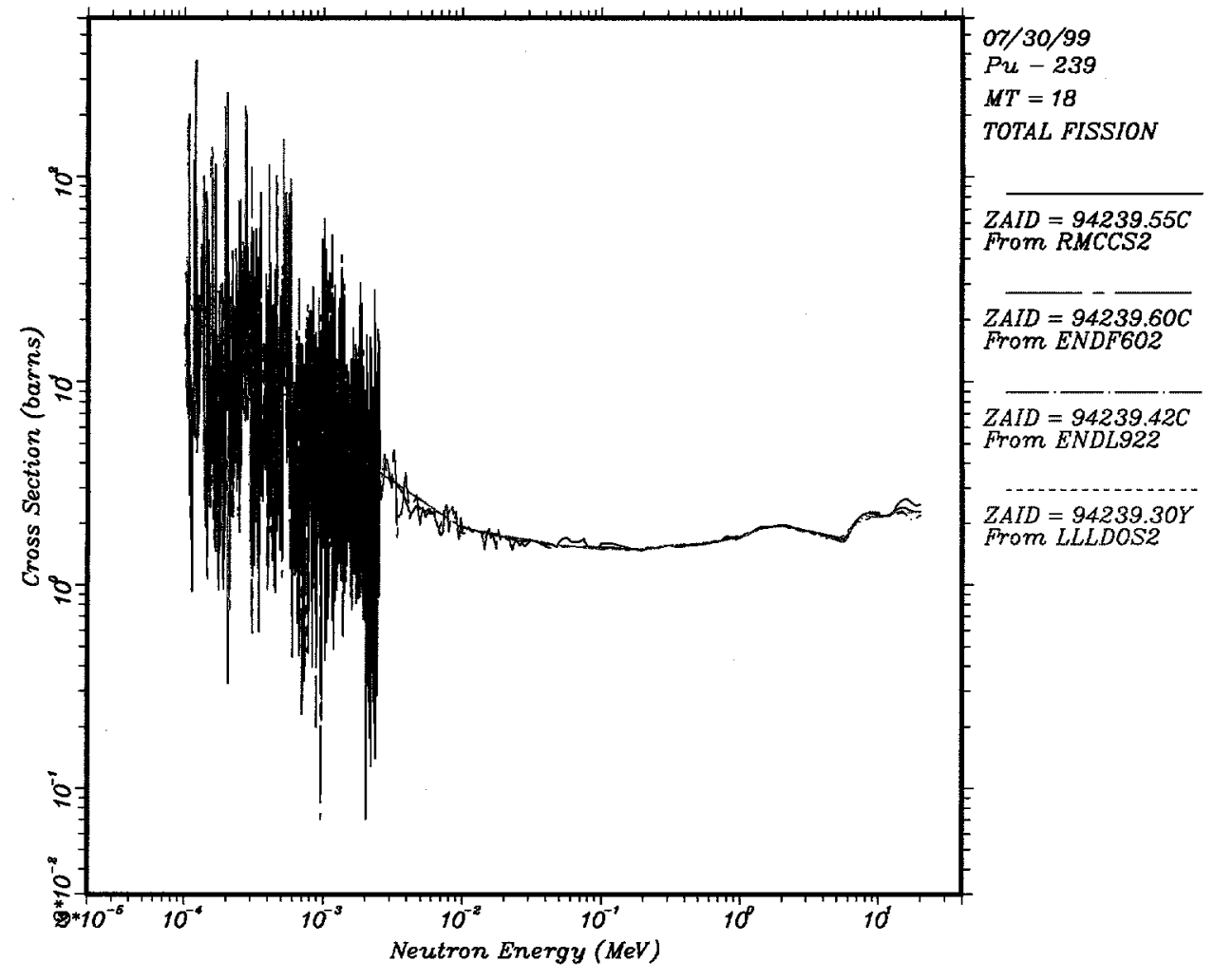


A- 6 
Appendix B

Plots of the $(n, \gamma)$ Cross Sections 
B-2 

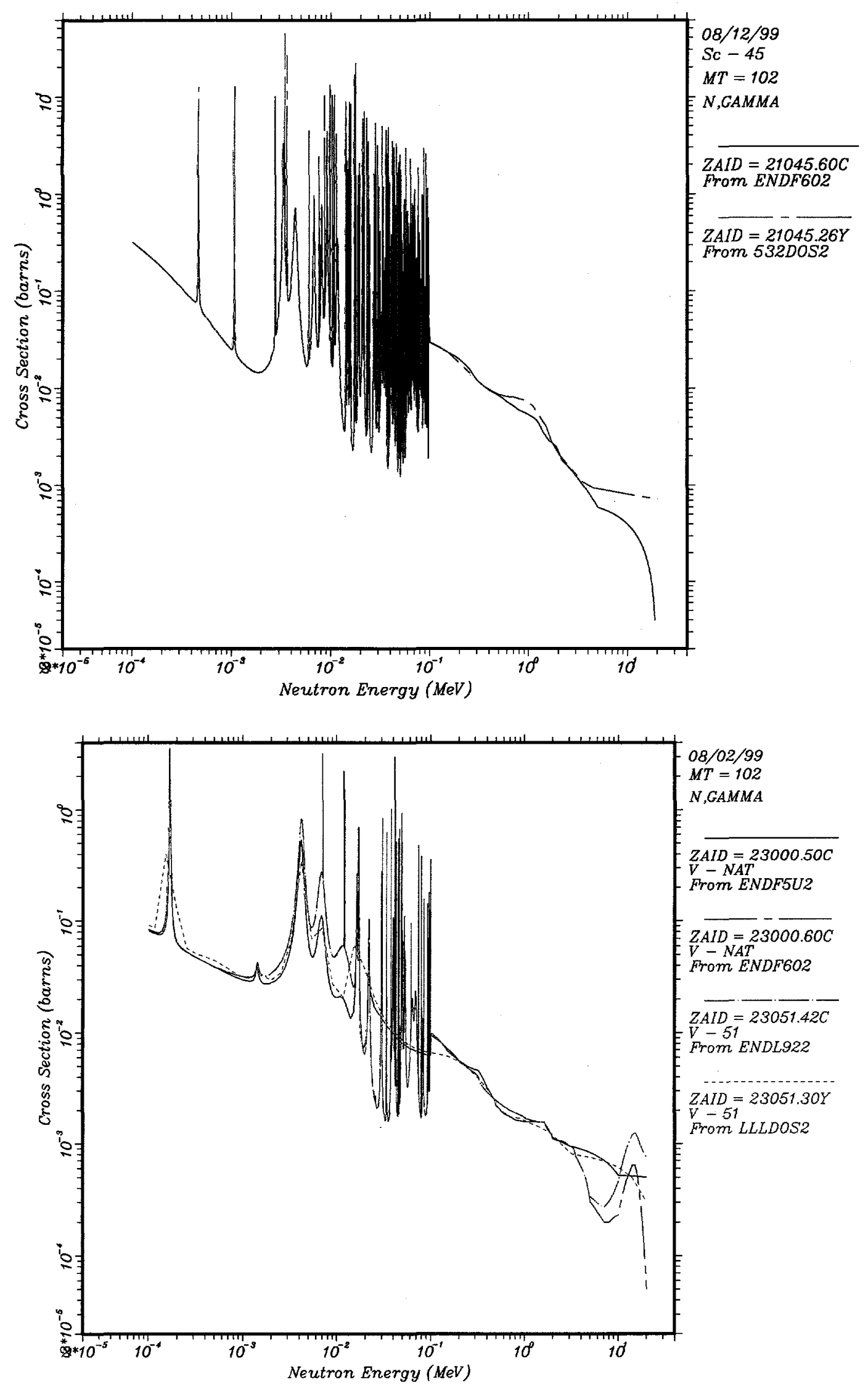

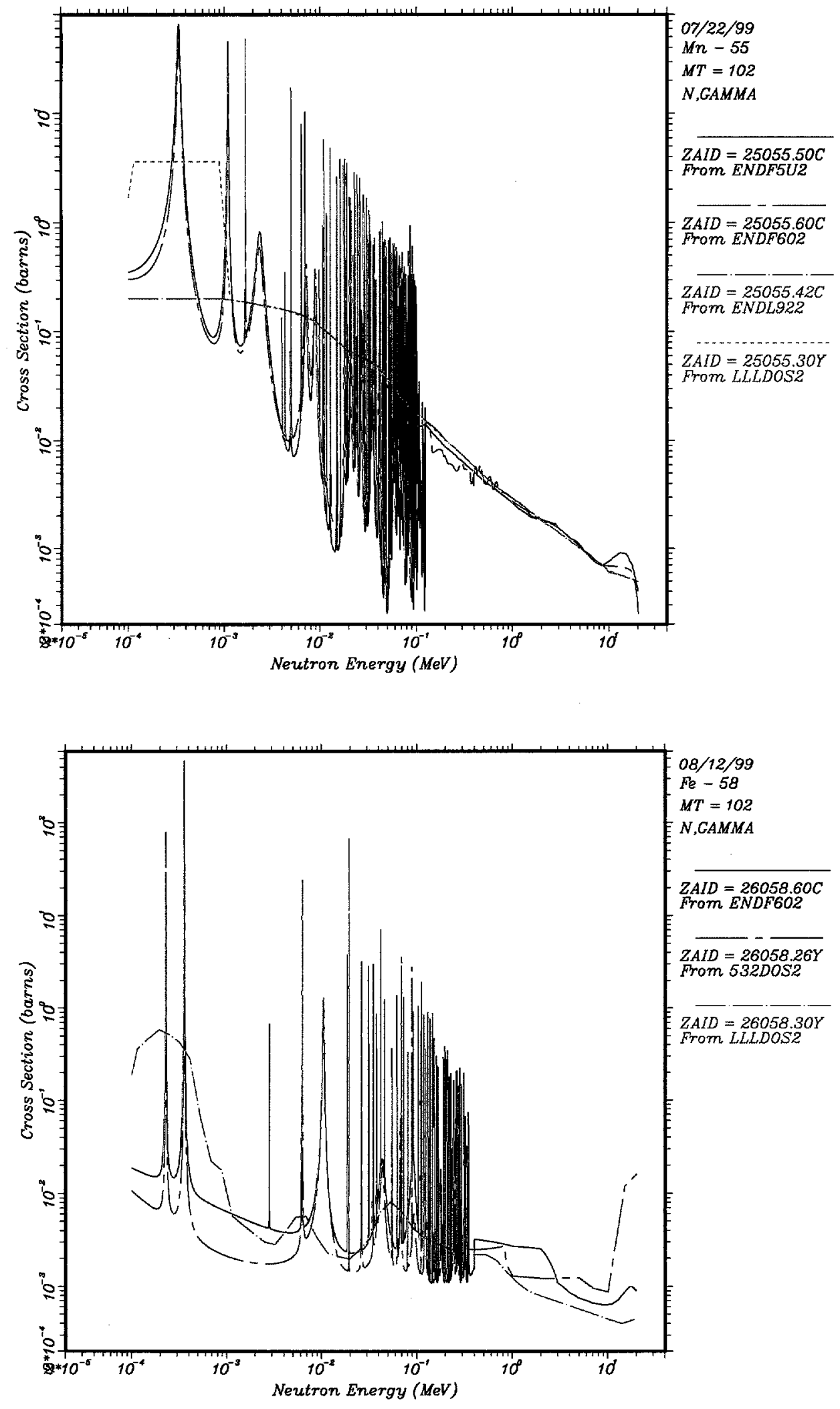

B-4 

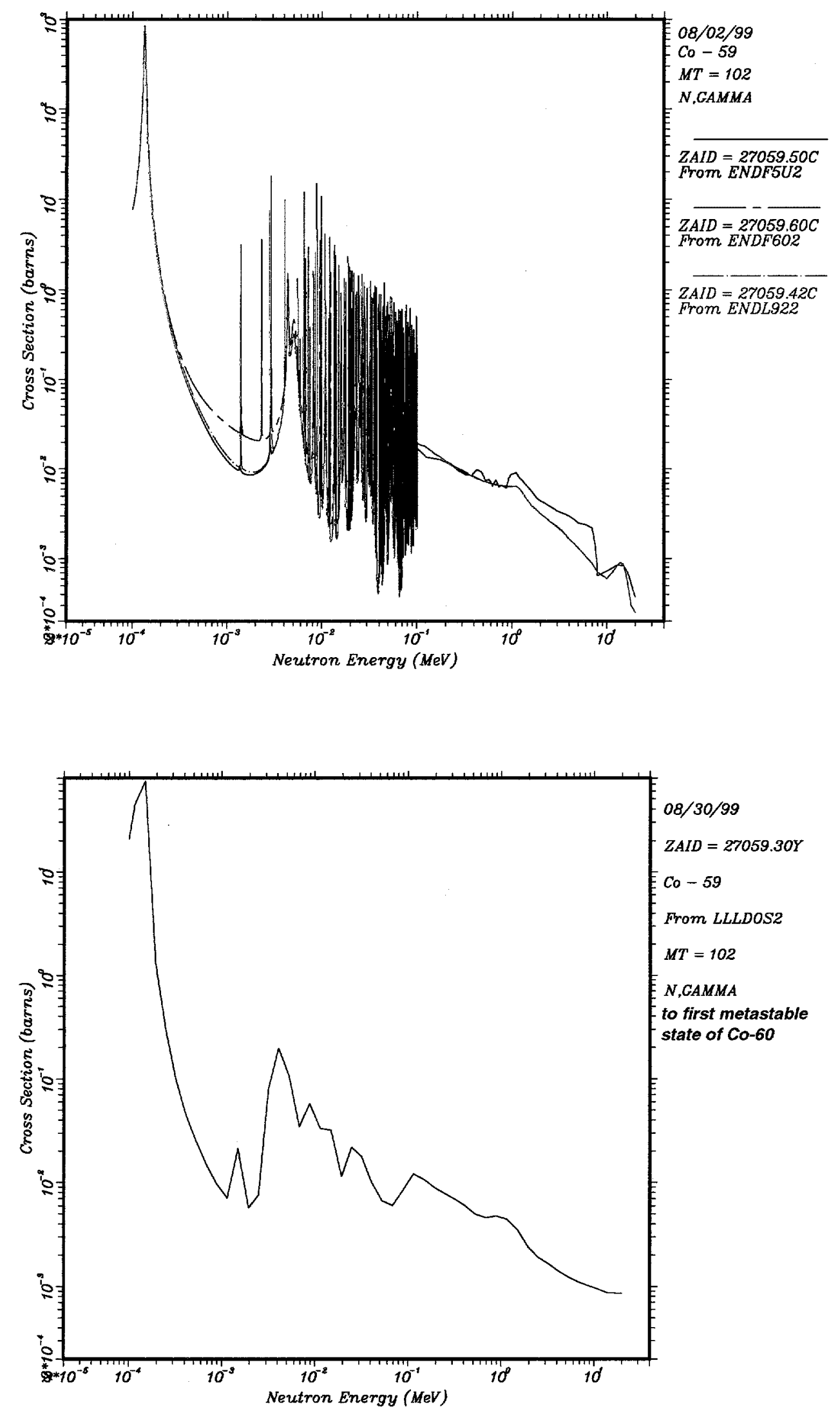

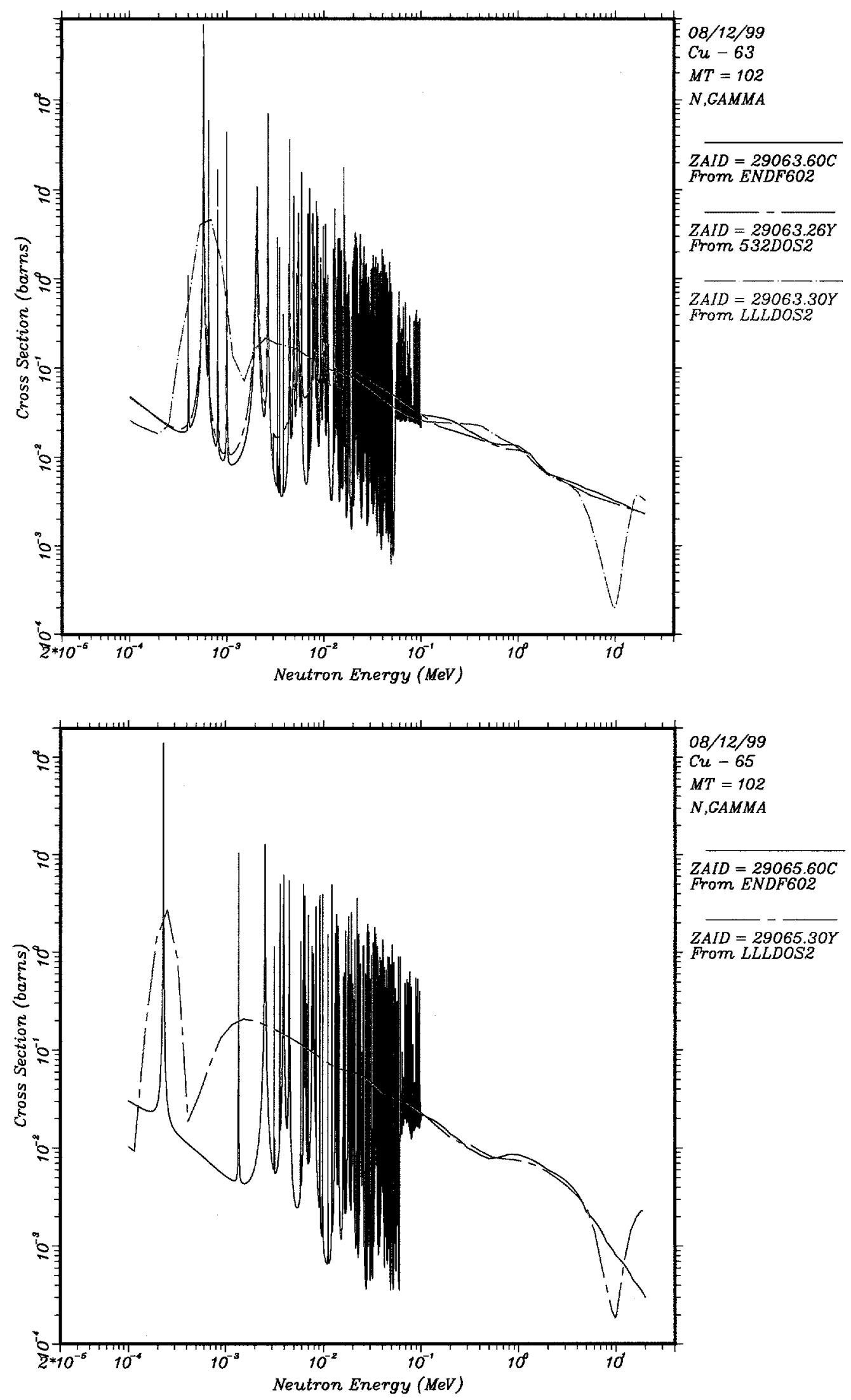

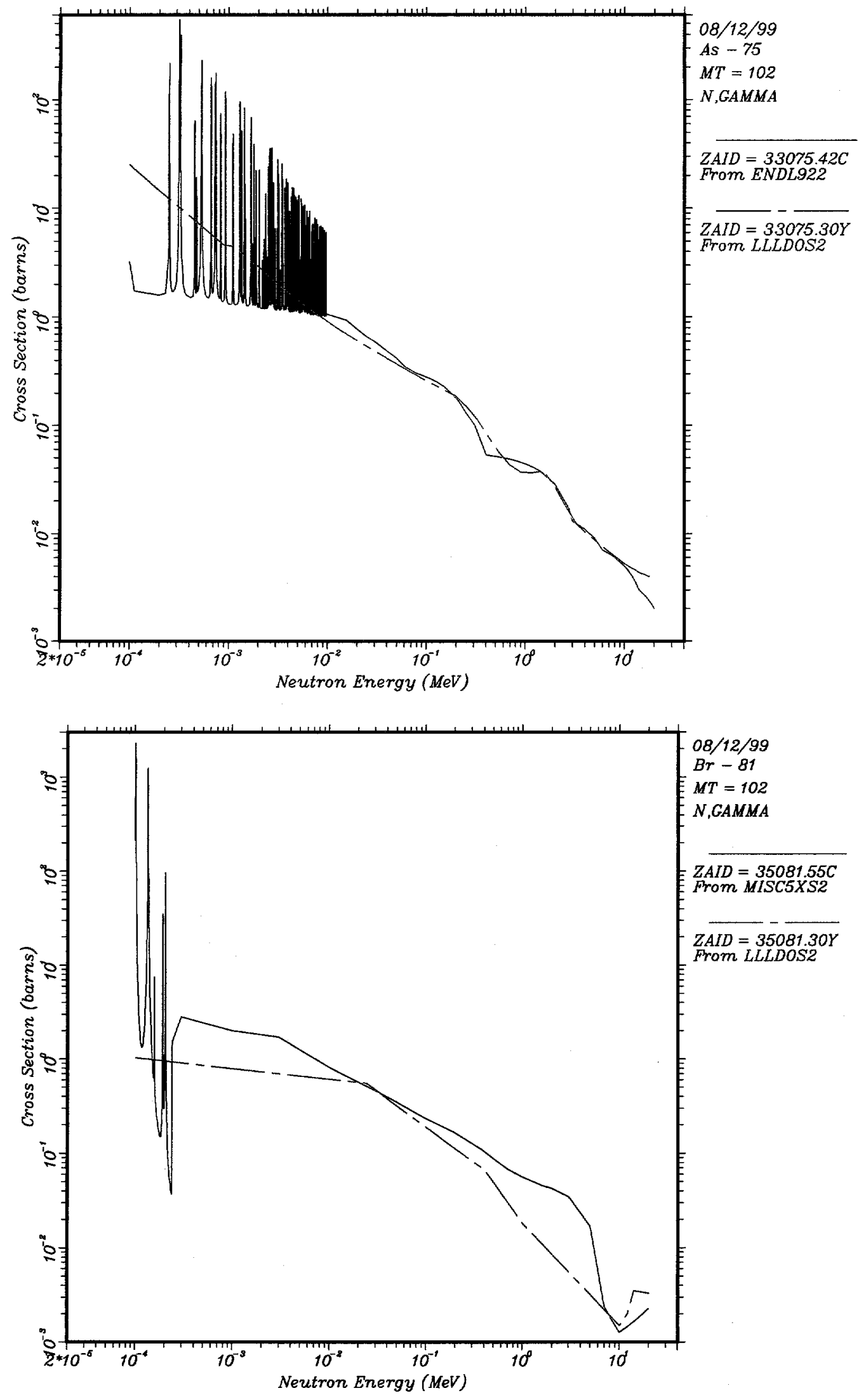

B-7 

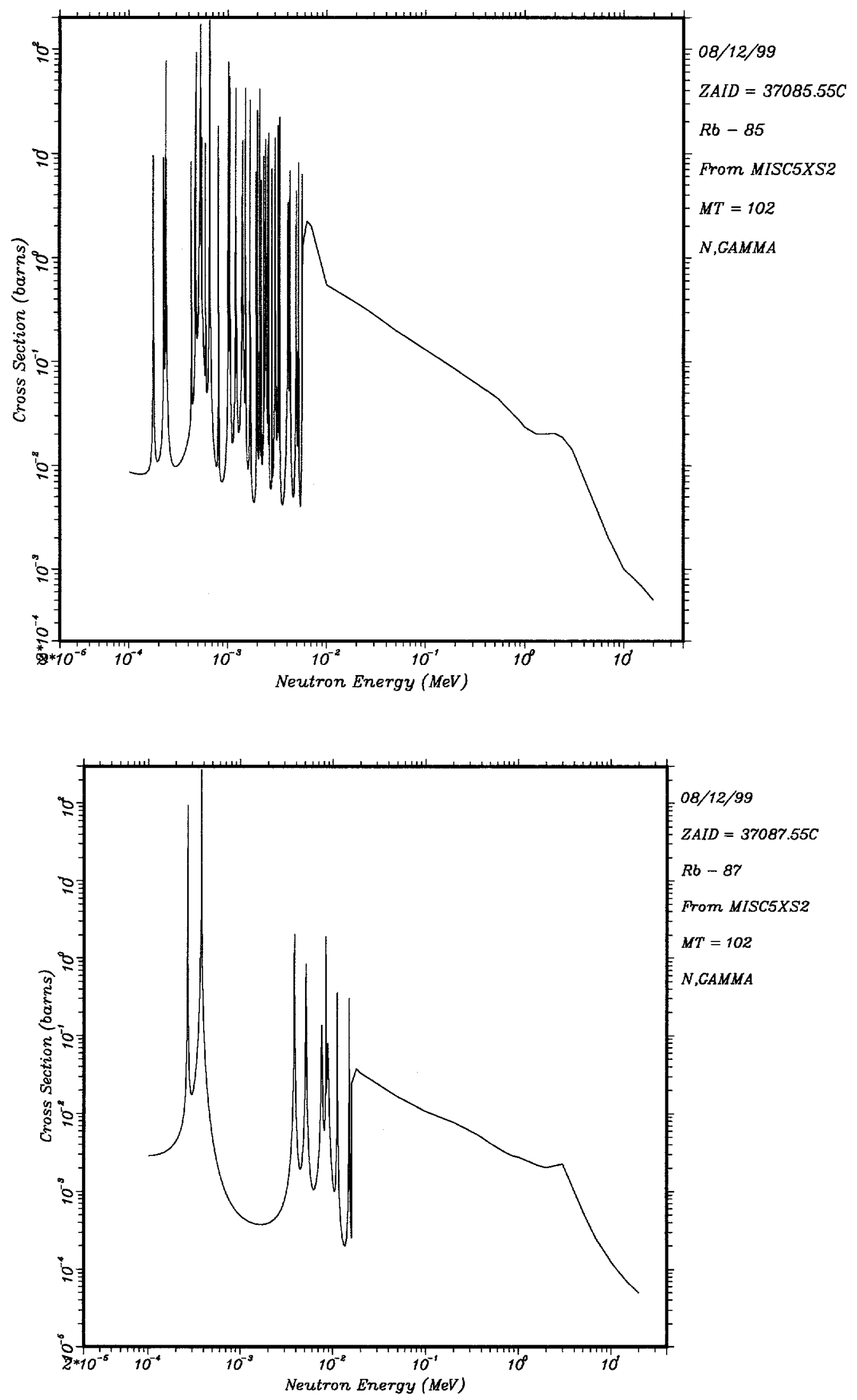

B-8 

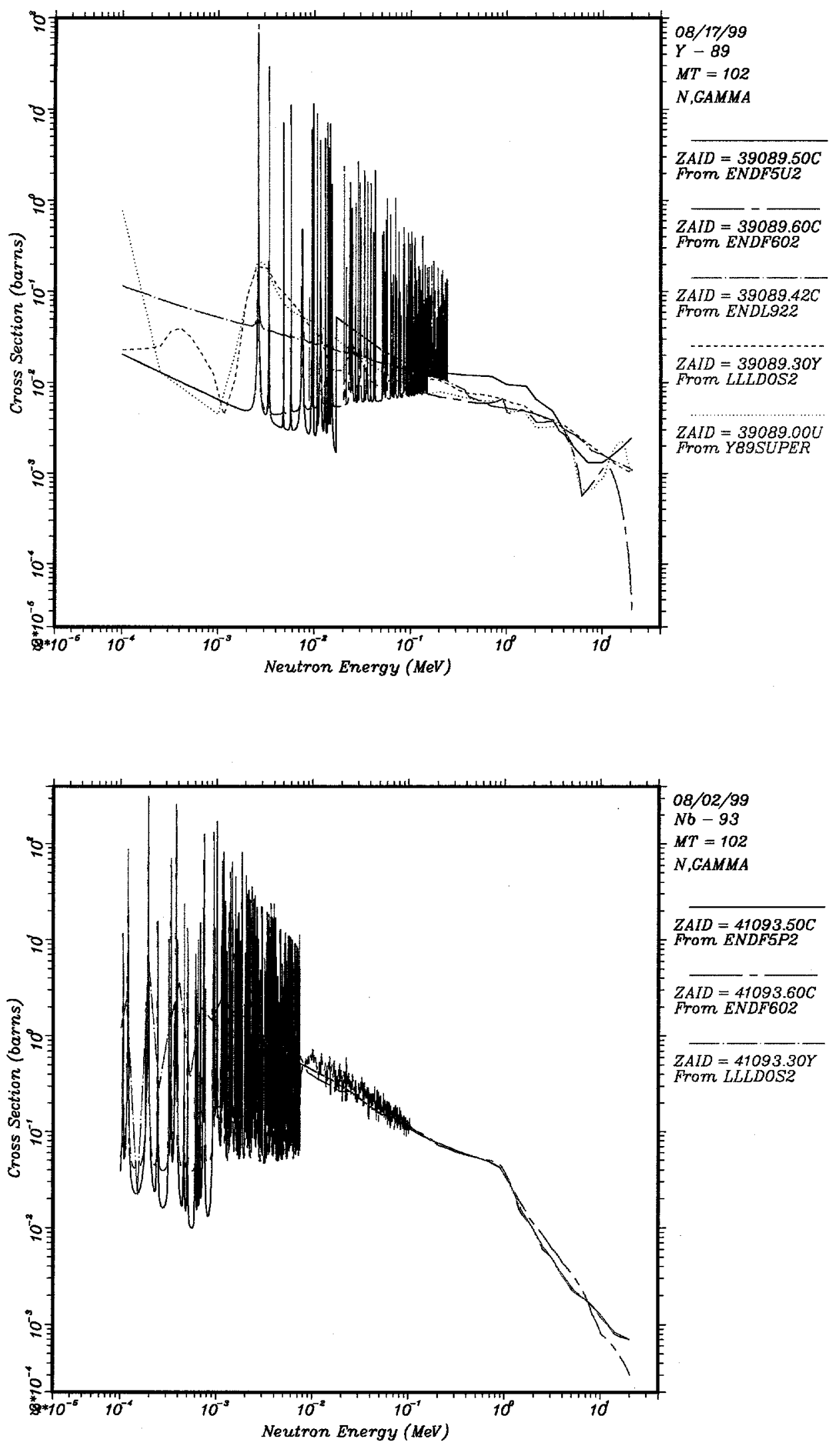

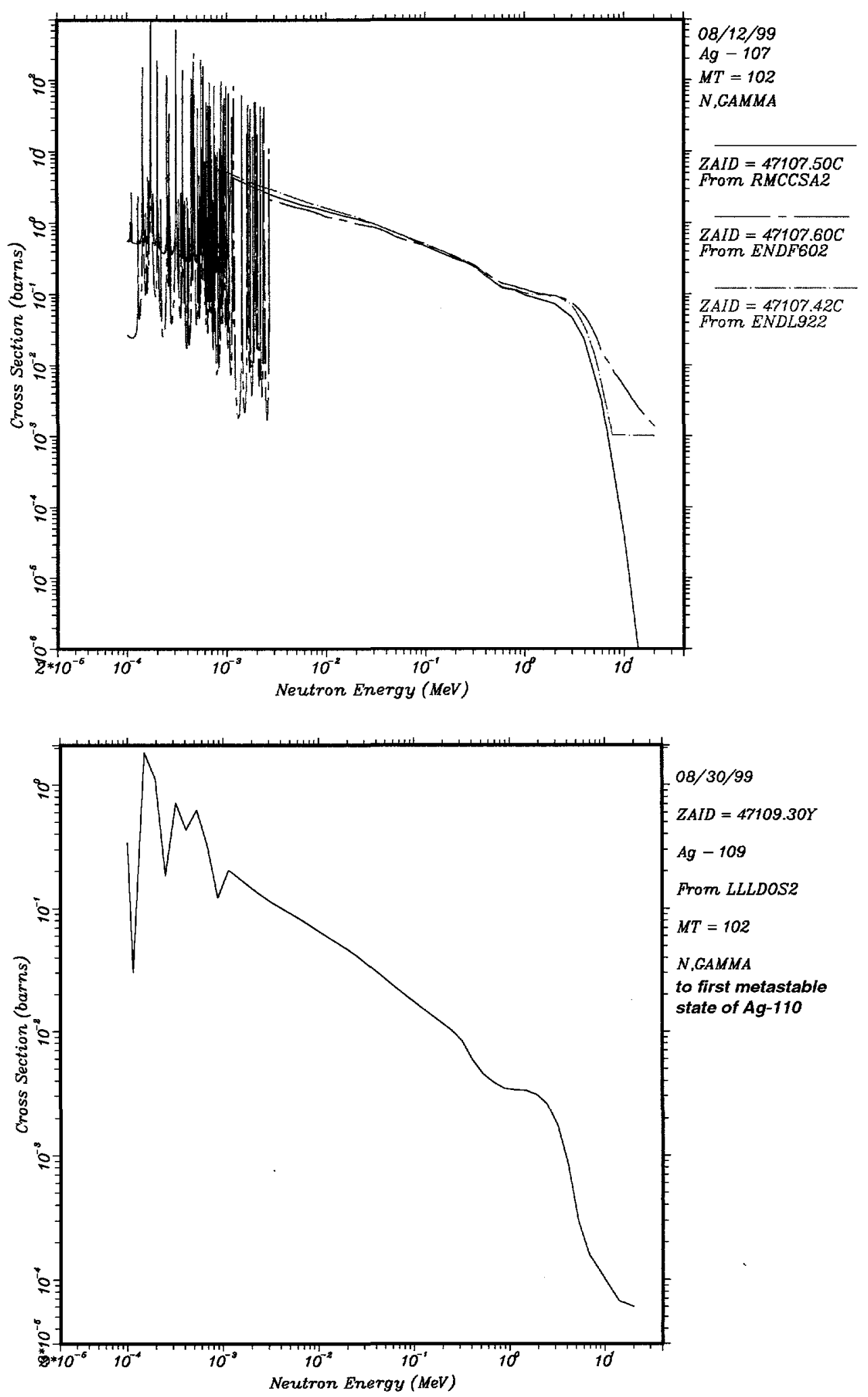

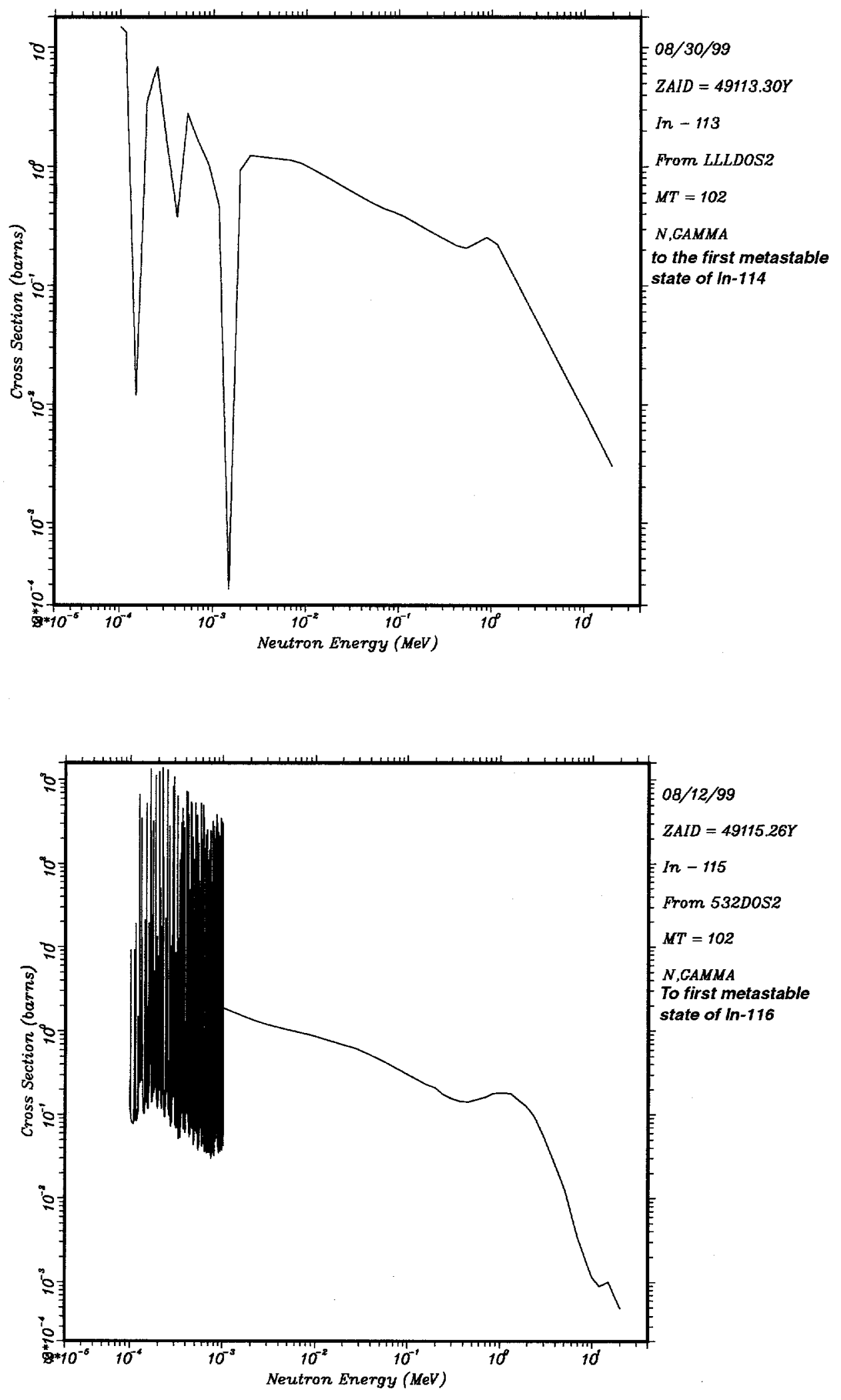

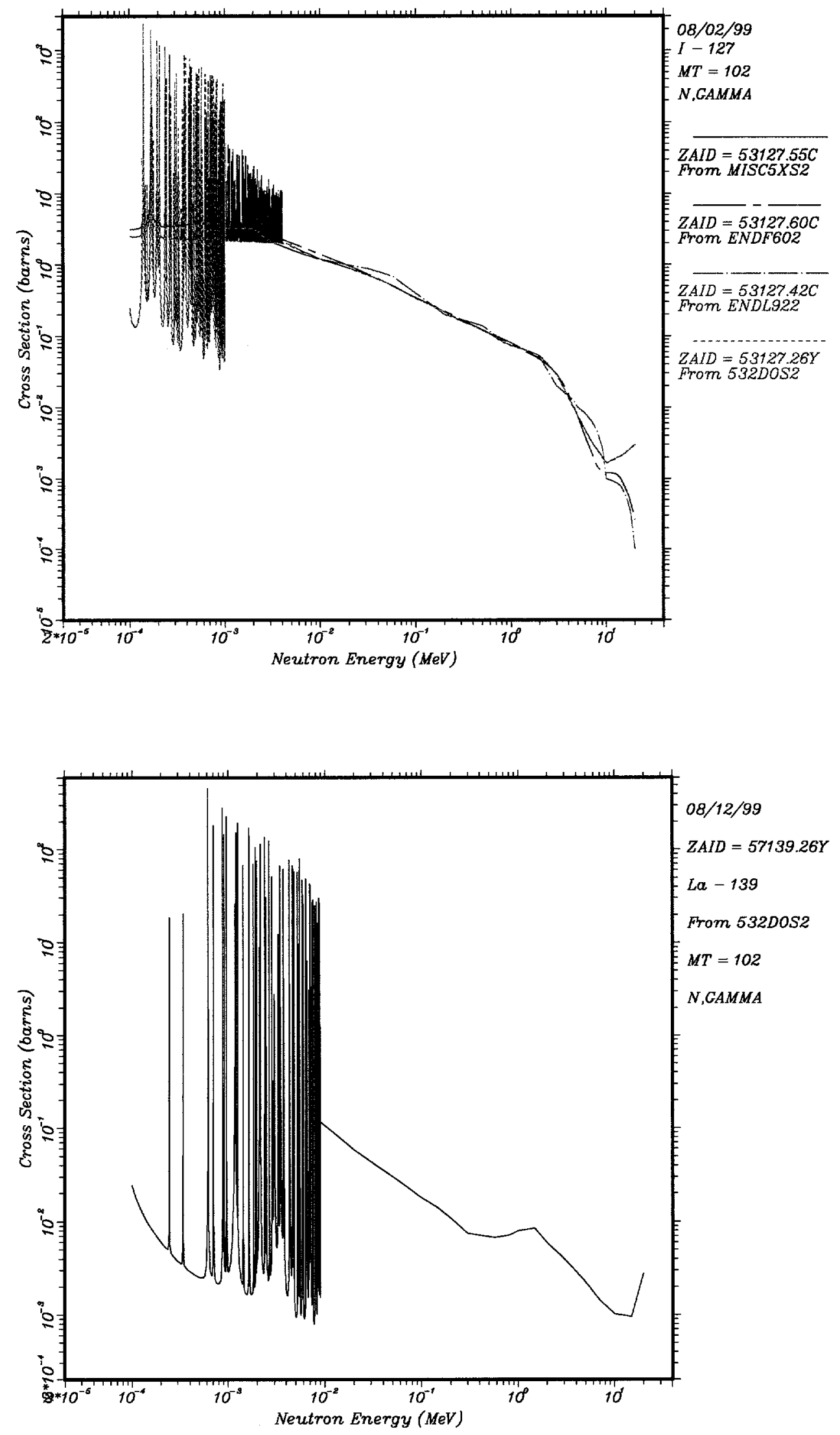

B-12 

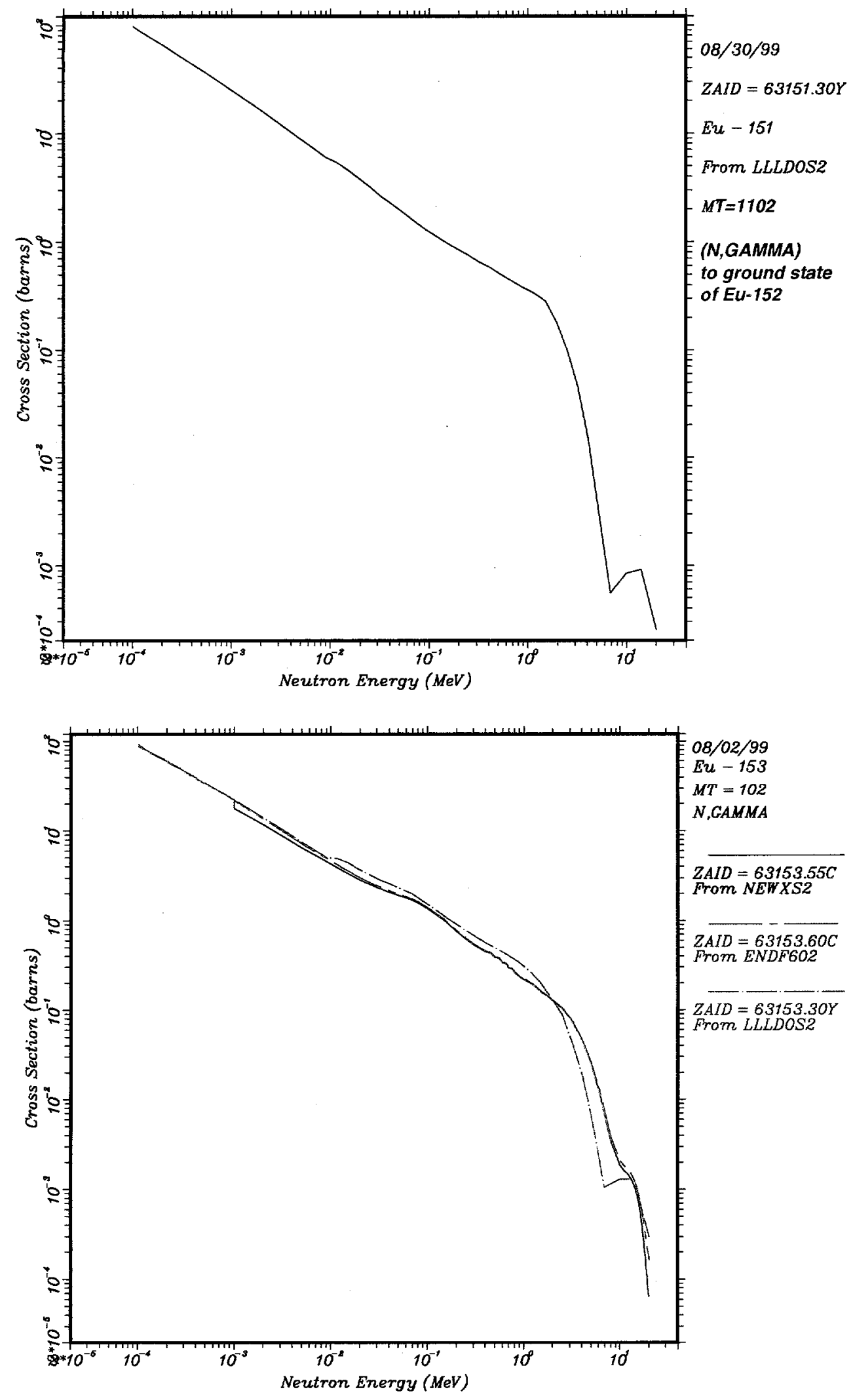

B-13 

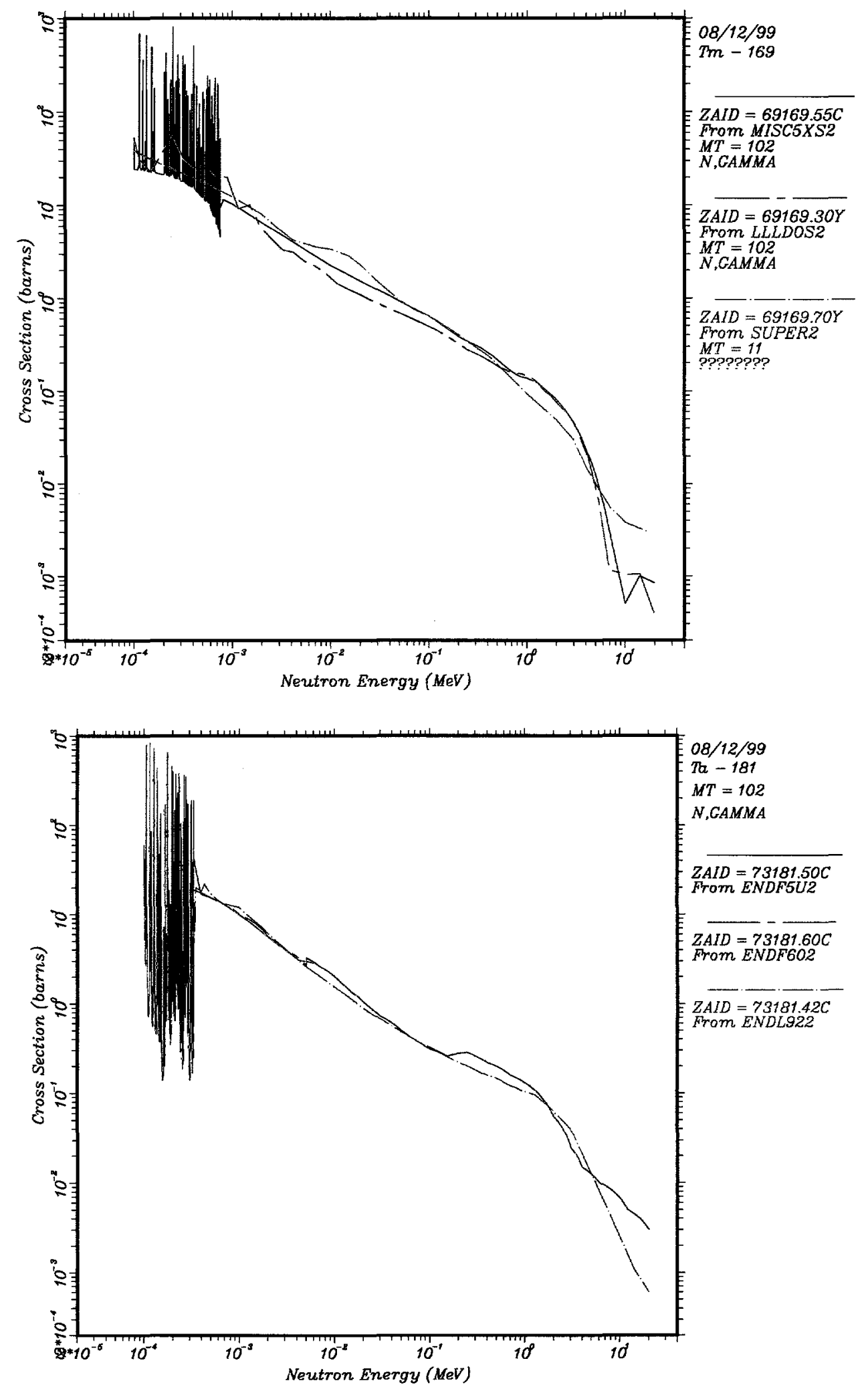

B-14 

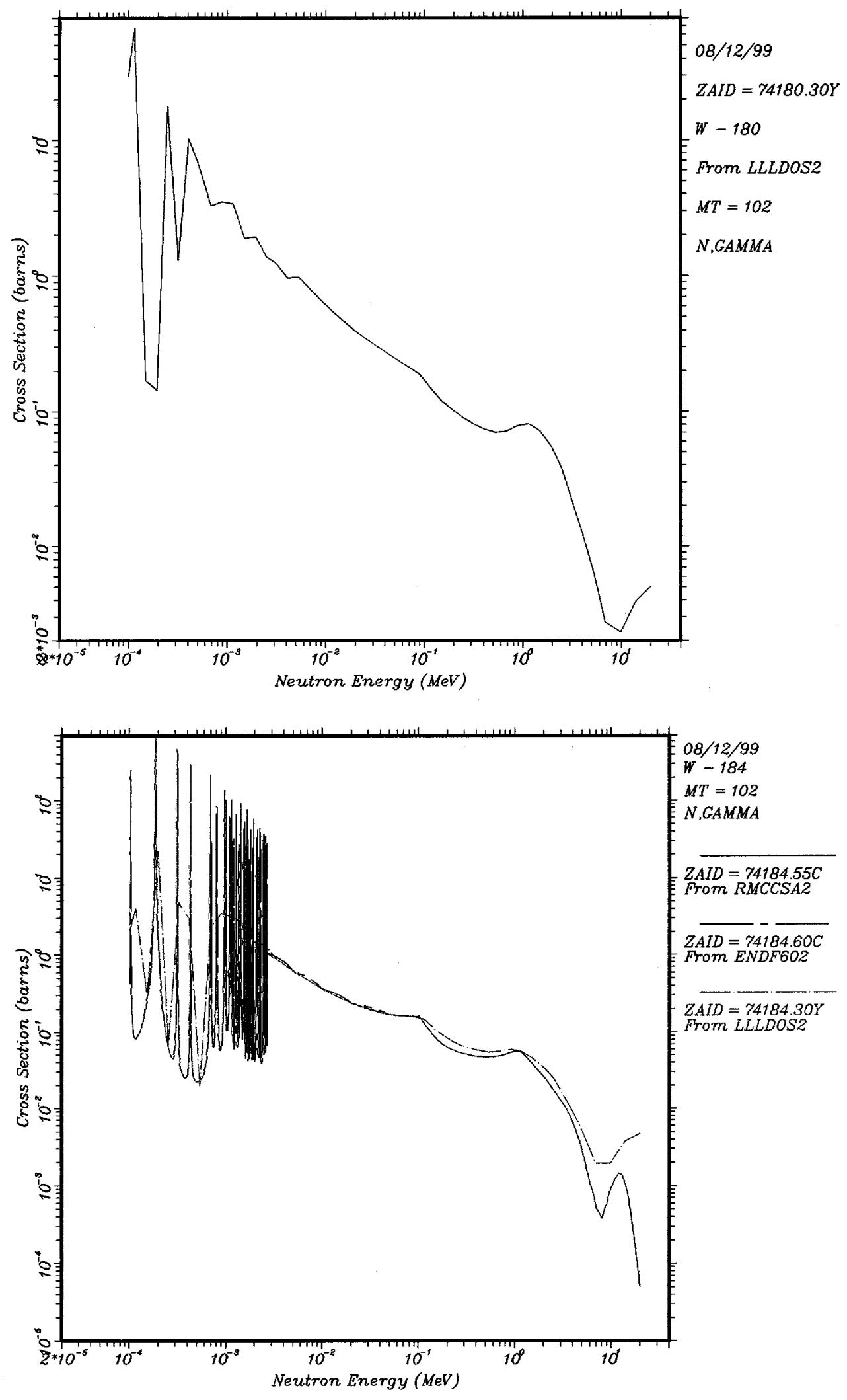

B-15 

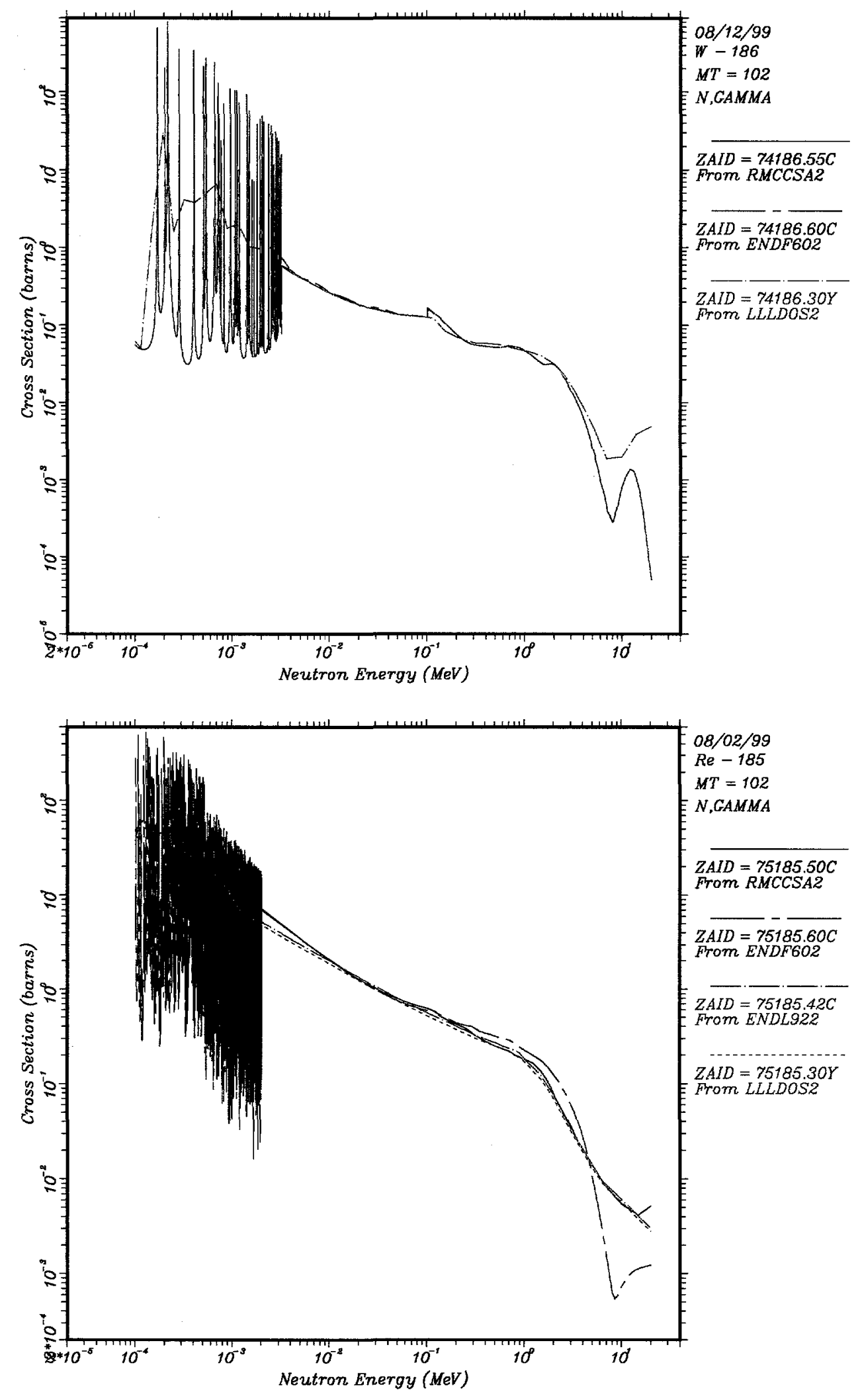

B-16 

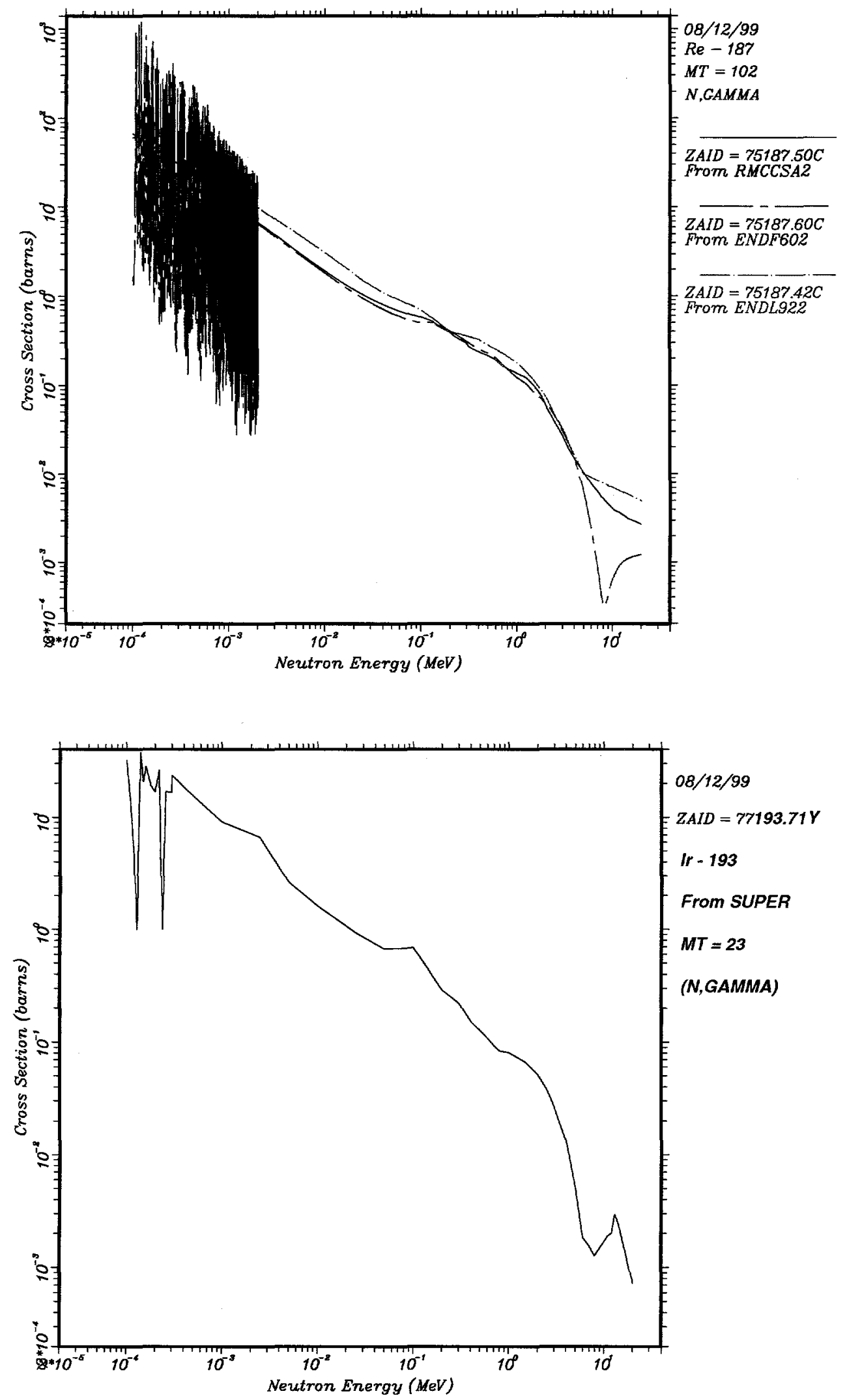

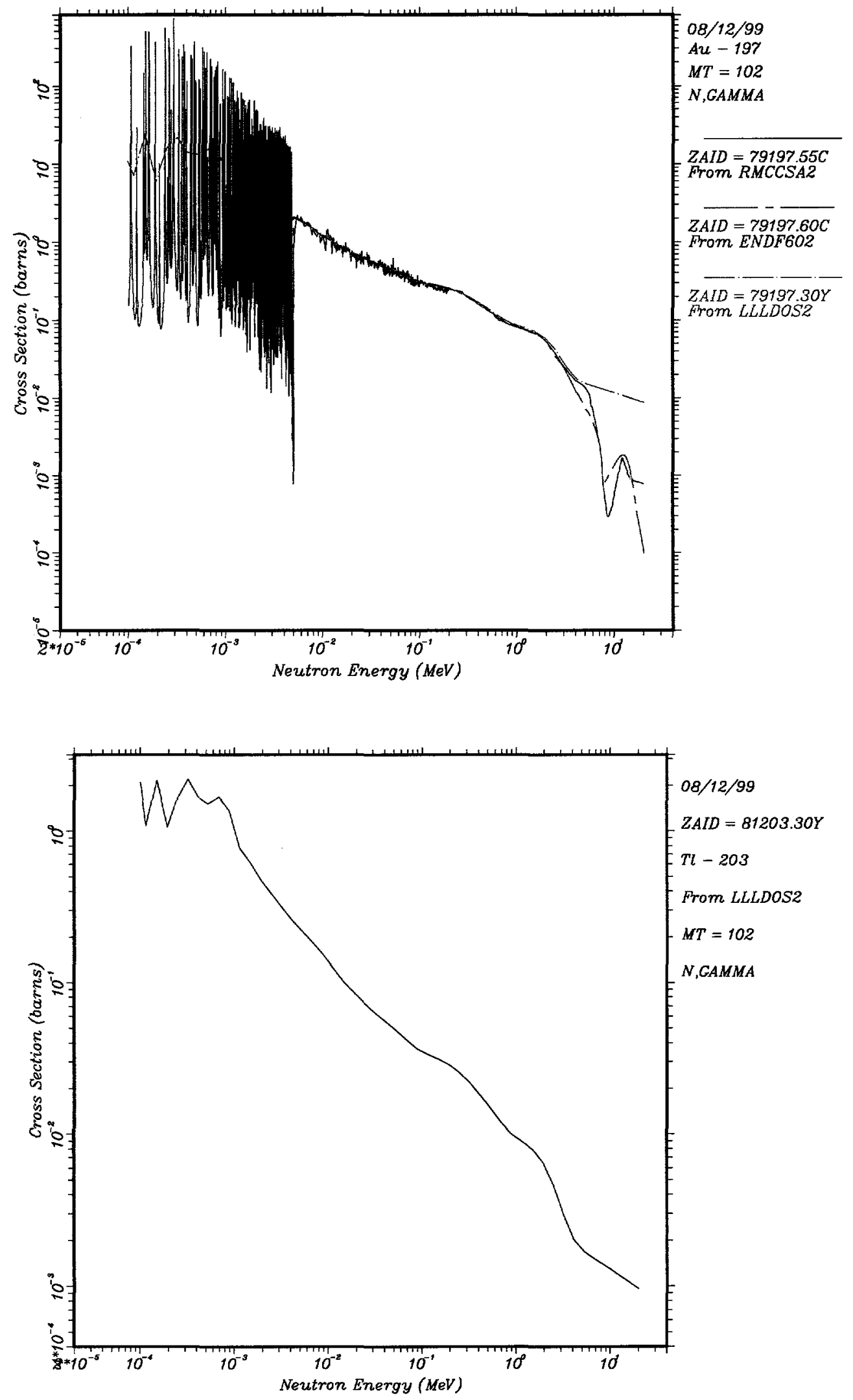

B-18 

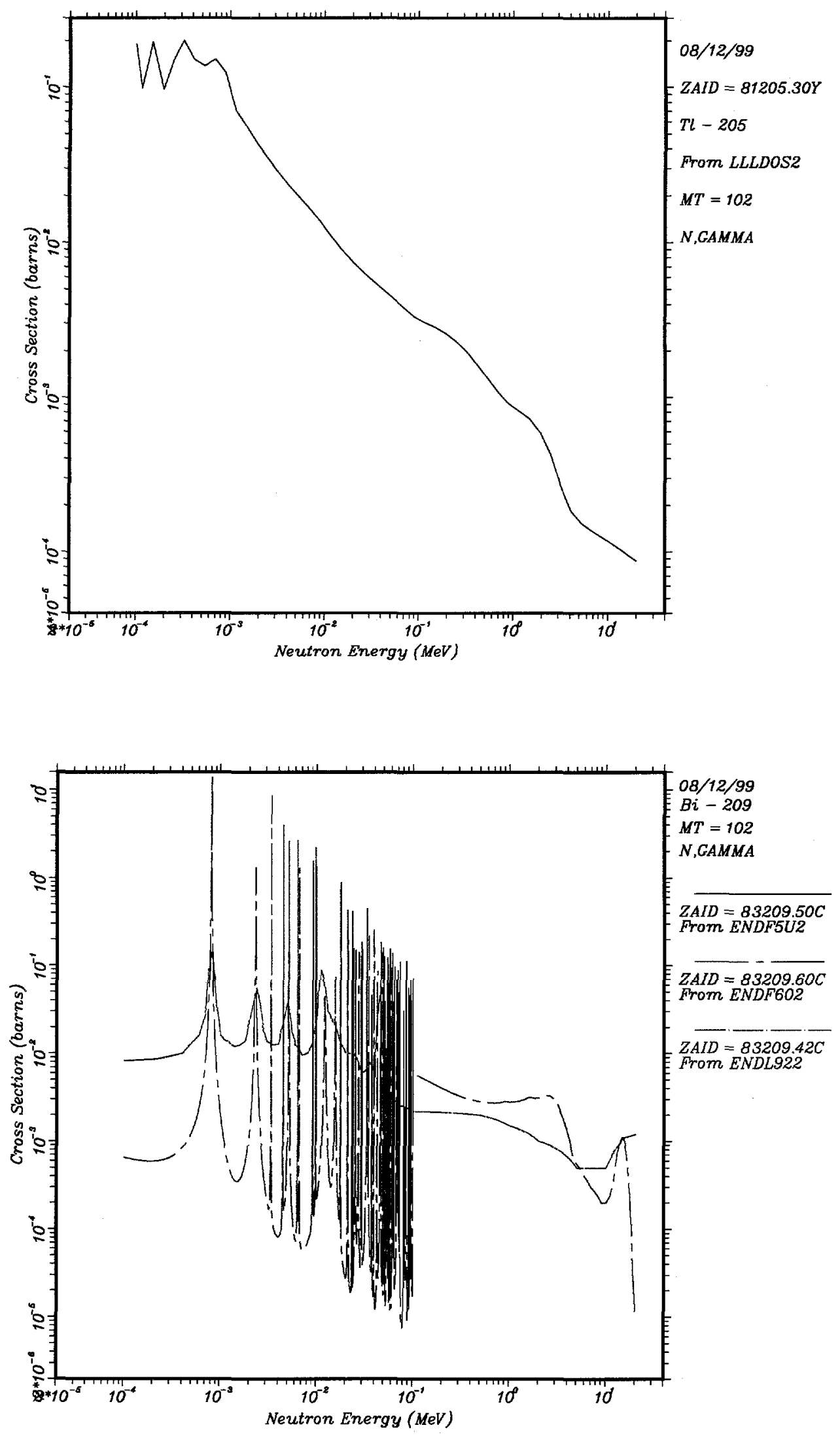

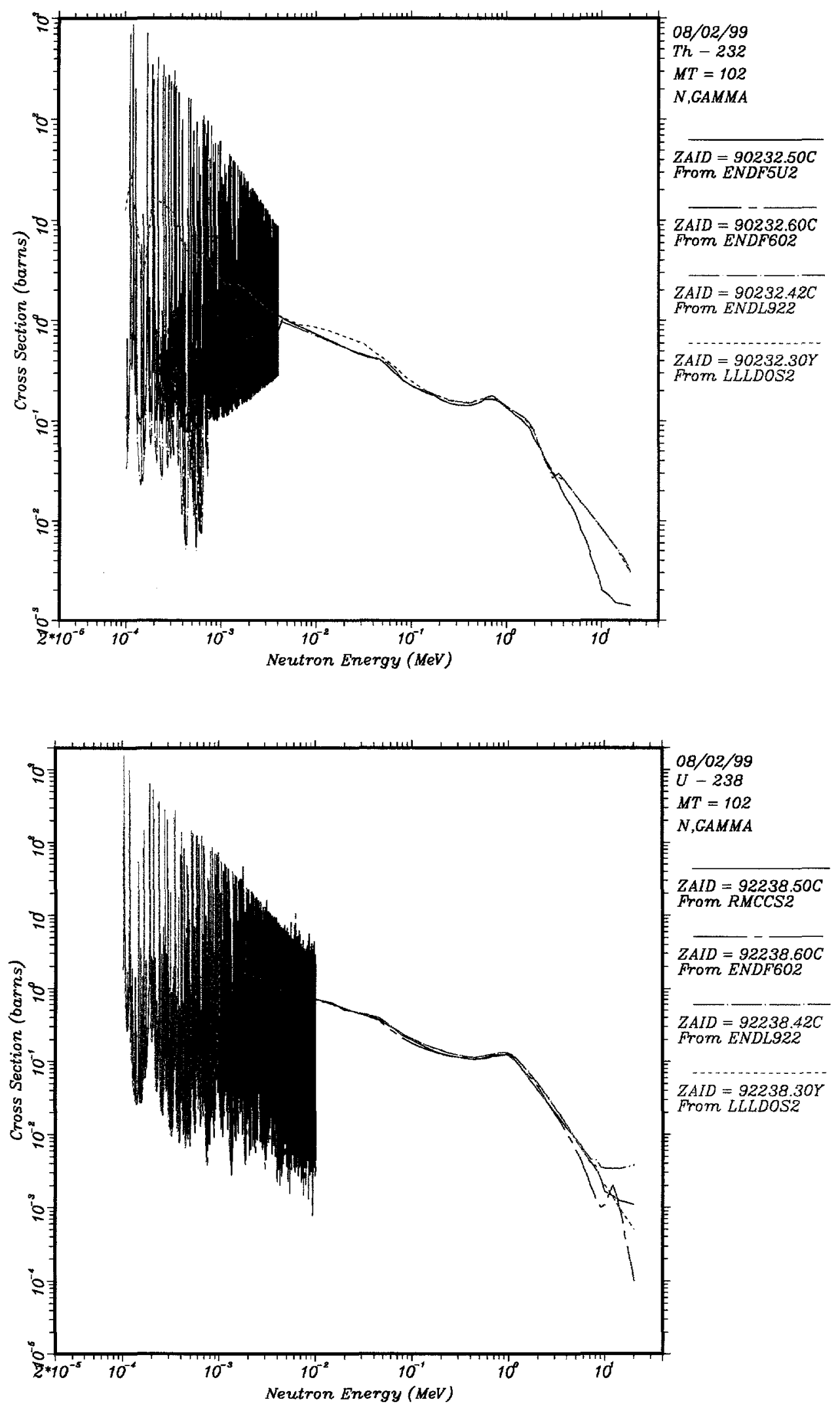


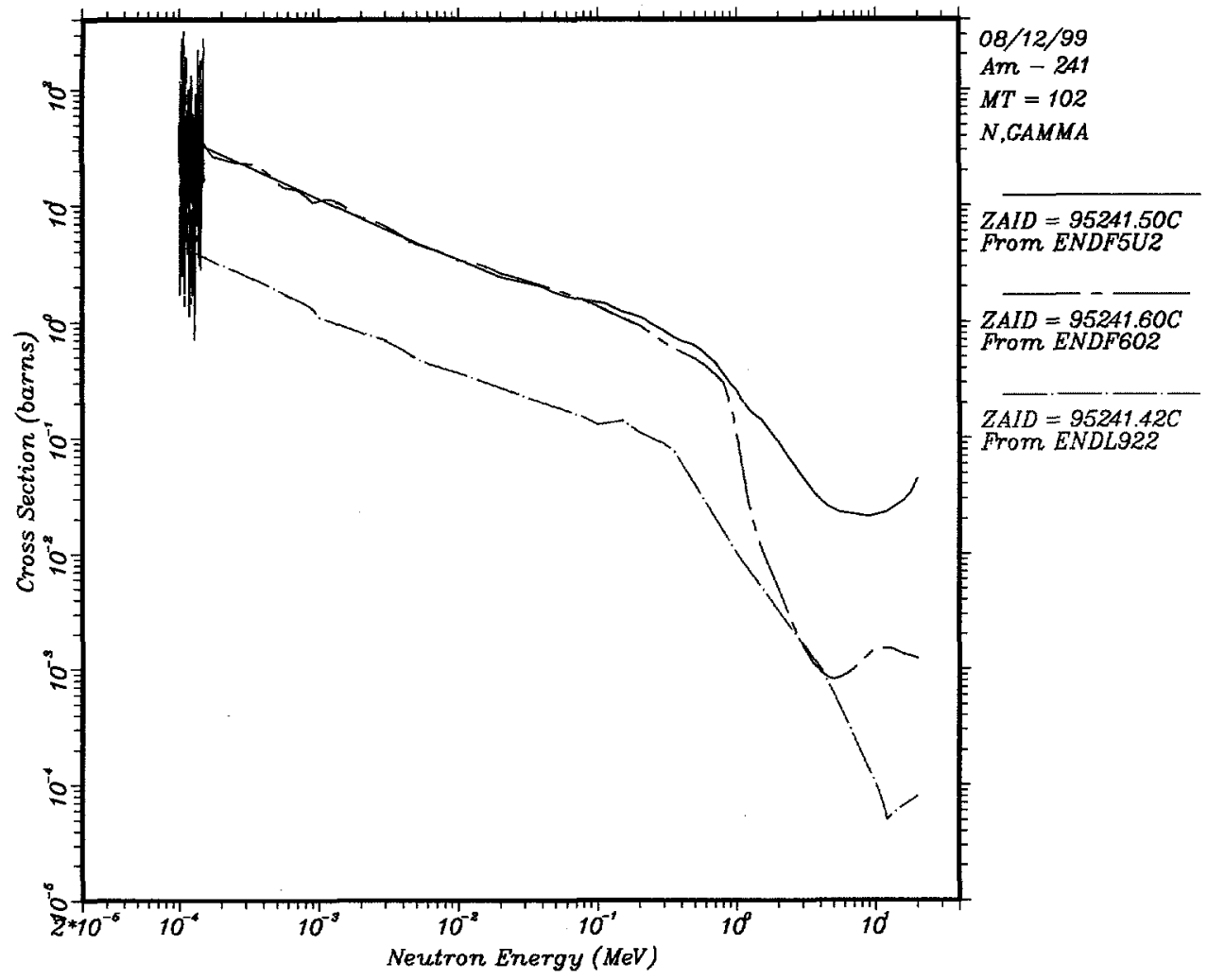


Appendix C

Plots of the (n,p) Cross Sections

C-1 
C-2 


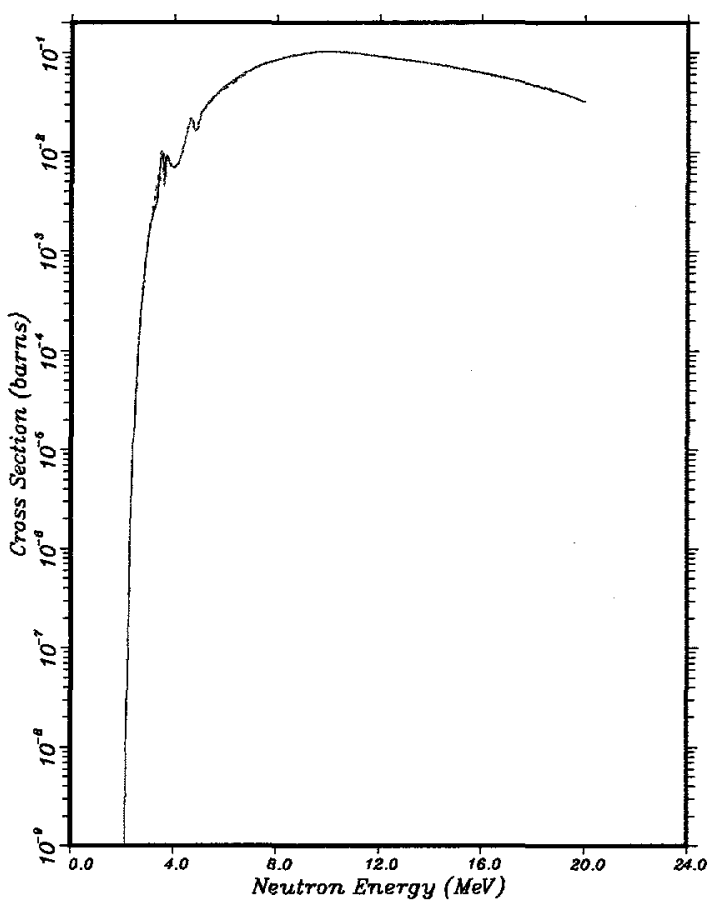

$07 / 30 / 99$

$M T=103$

$(N, P)$

ZAID $=13027.50 C$
From RMCCS2

$Z A I D=13027.60 \mathrm{C}$

From ENDF602

$Z A I D=13027.26 Y$

From 532DOS2

$Z A I D=13027.30 Y$

From LLLDOSZ

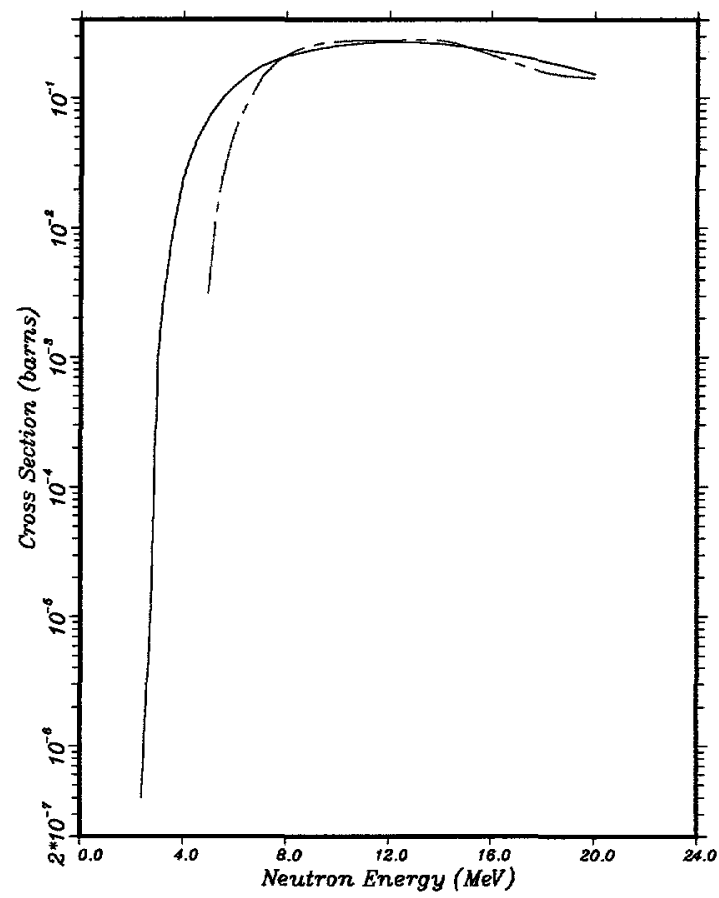

$07 / 30 / 99$

$\pi-46$

$M T=103$

$(N, P)$

$Z A I D=22046.26 Y$ From 532DOS2

$Z A I D=22046.30 Y$ From LLLDOSE 

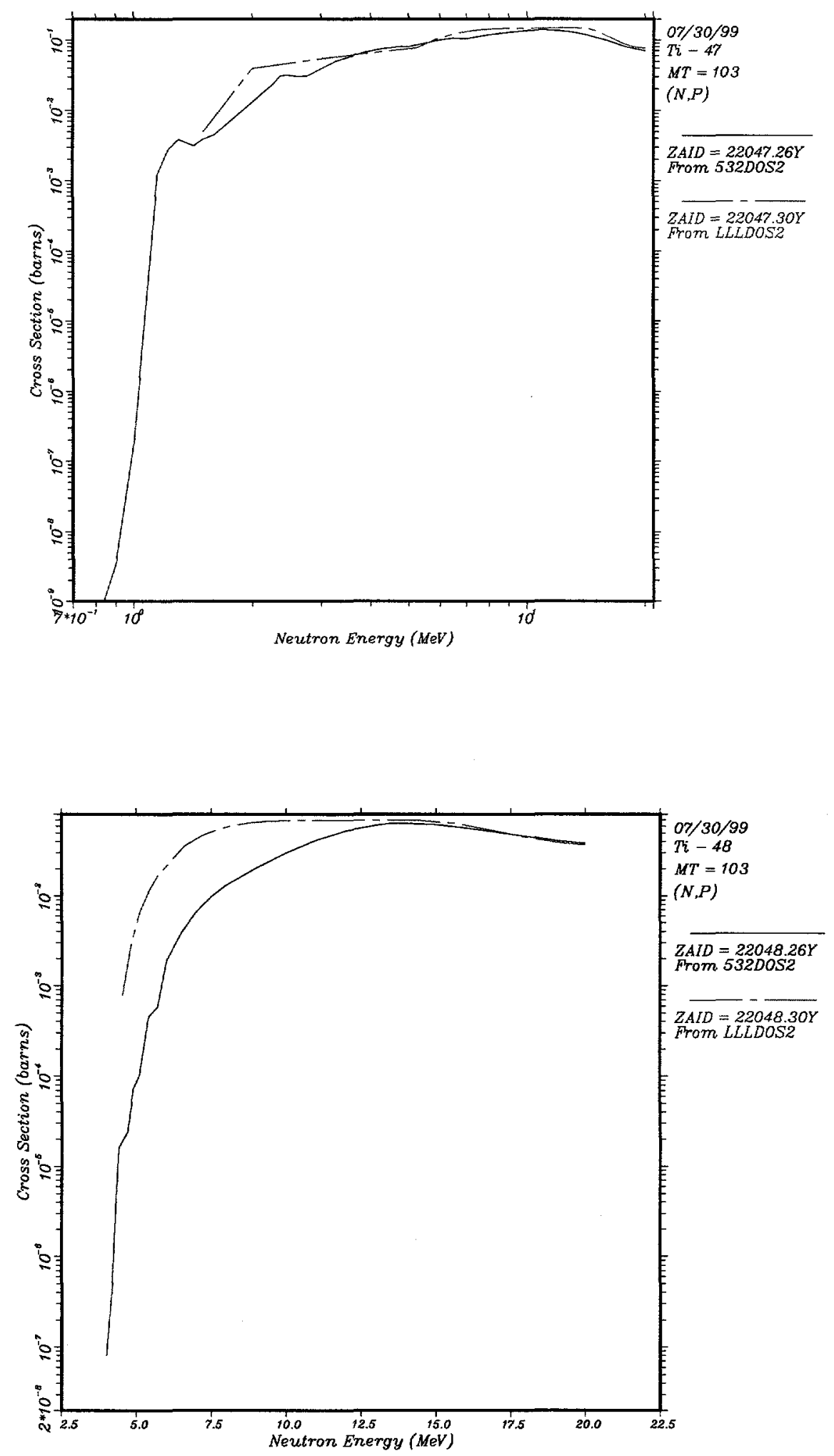

C-4 

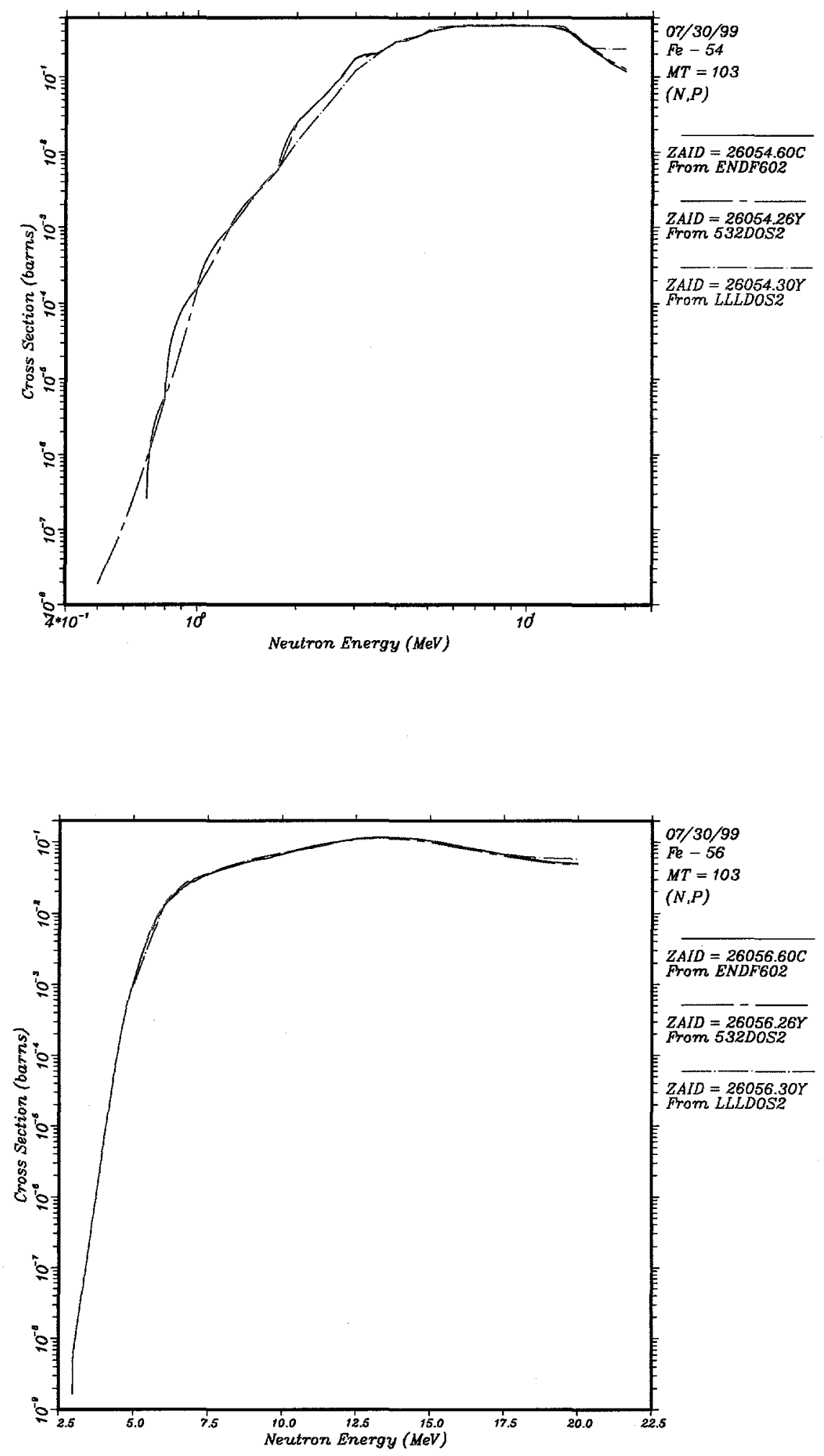

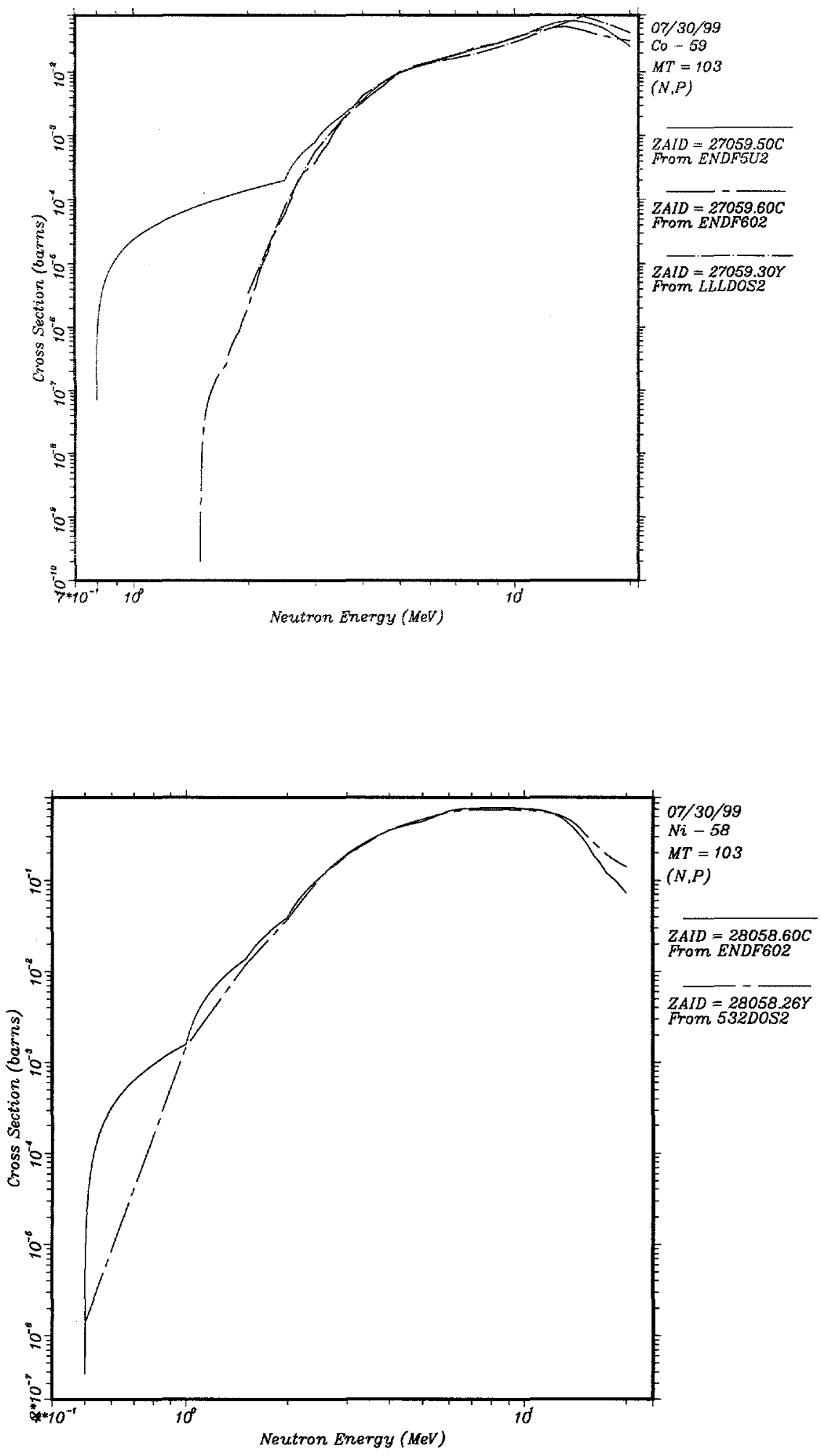
Appendix D

Plots of the (n,2n) Cross Sections

D-1 
D-2 


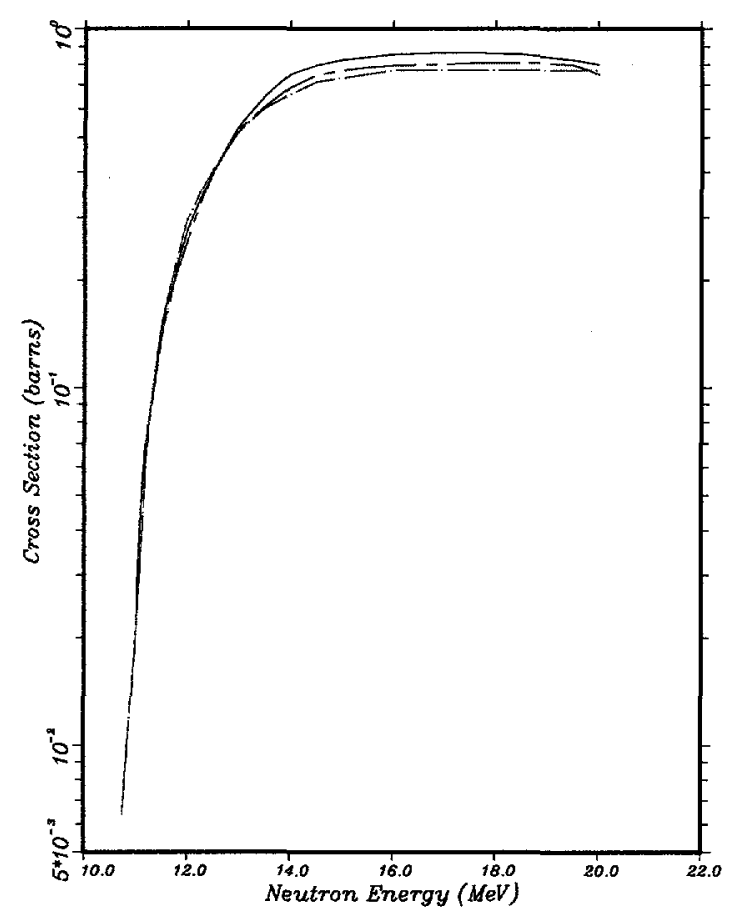

$07 / 30 / 99$

Co -59

$M T=16$

$(N, 2 N)$

$Z A I D=27059.50 C$ From ENDF5UZ

$Z A I D=27059.60 \mathrm{C}$

From ENDFGO2

$Z A I D=27059.42 \mathrm{C}$

From ENDL922

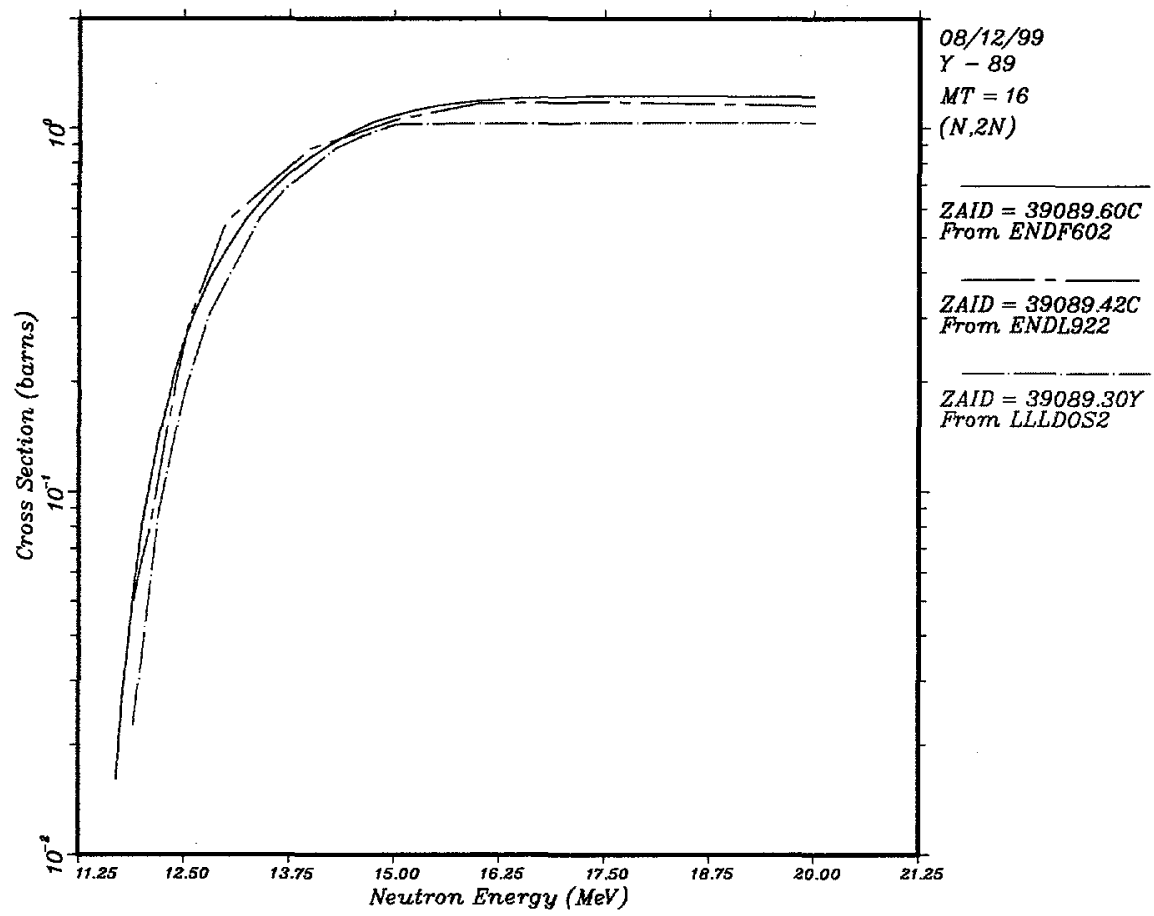



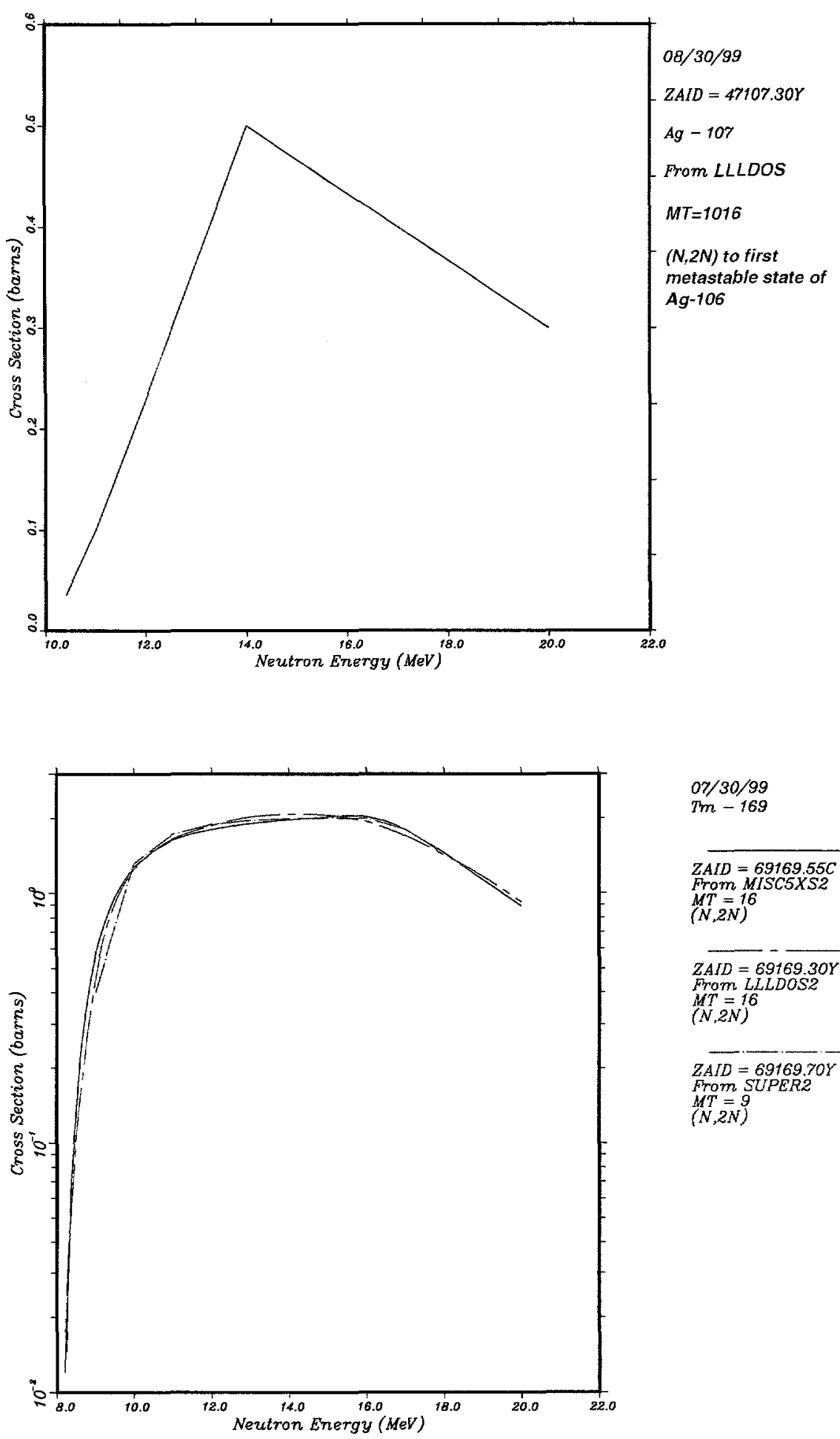

$07 / 30 / 99$

$7 m-169$

$Z A I D=69169.55 \mathrm{C}$ From MISCSXS2

$M T=16$

(N.2N)

$Z A I D=69169.30 Y$ From LLLDOSZ

$M T=16$
$(N, 2 N)$

$\overline{Z A D D}=6916970 \mathrm{r}$ ZAID

$M T=9$

$(N, 2 N)$ 

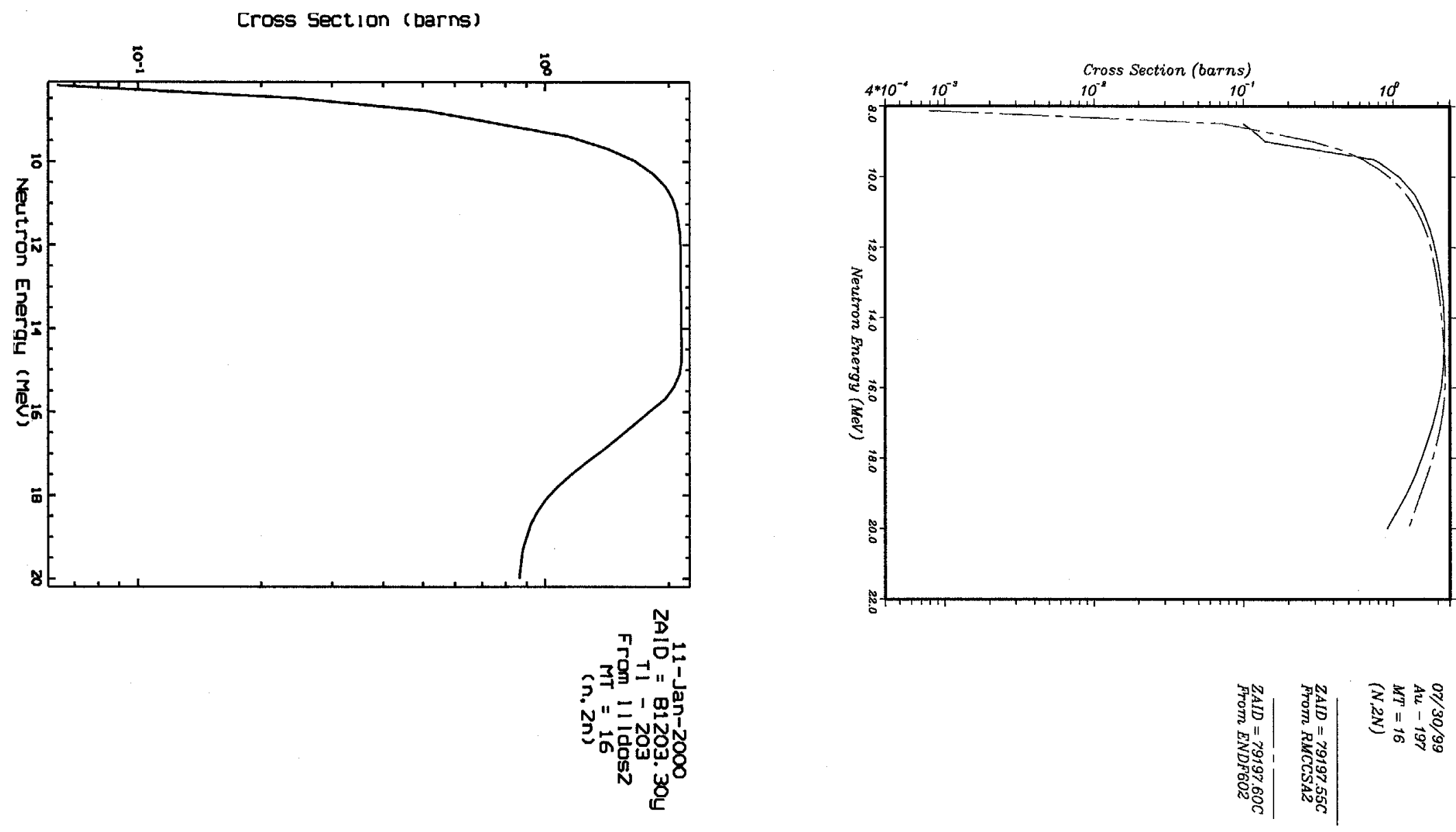

沜 

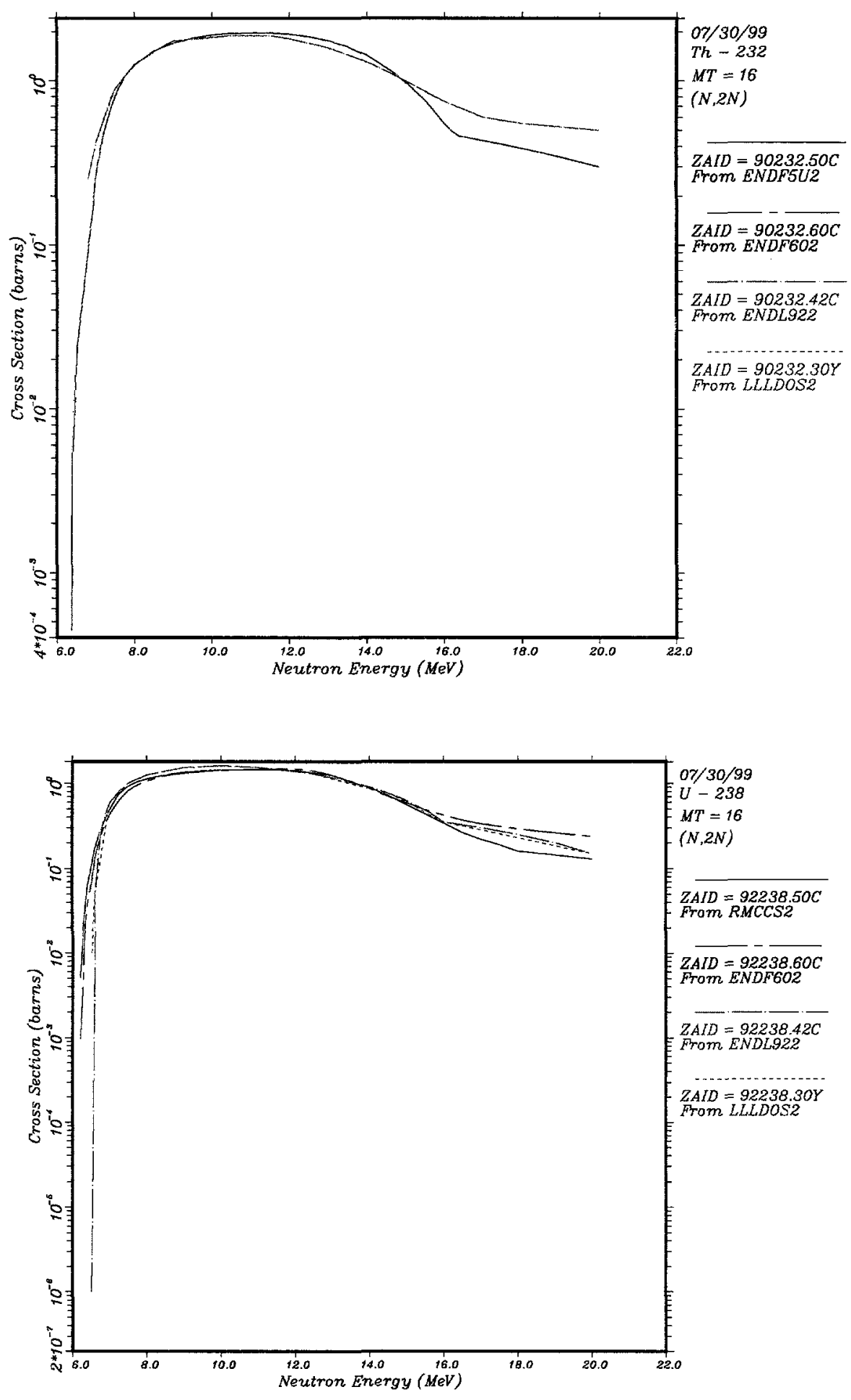
Appendix E

Plots of Other Cross Sections

E-1 
E-2 

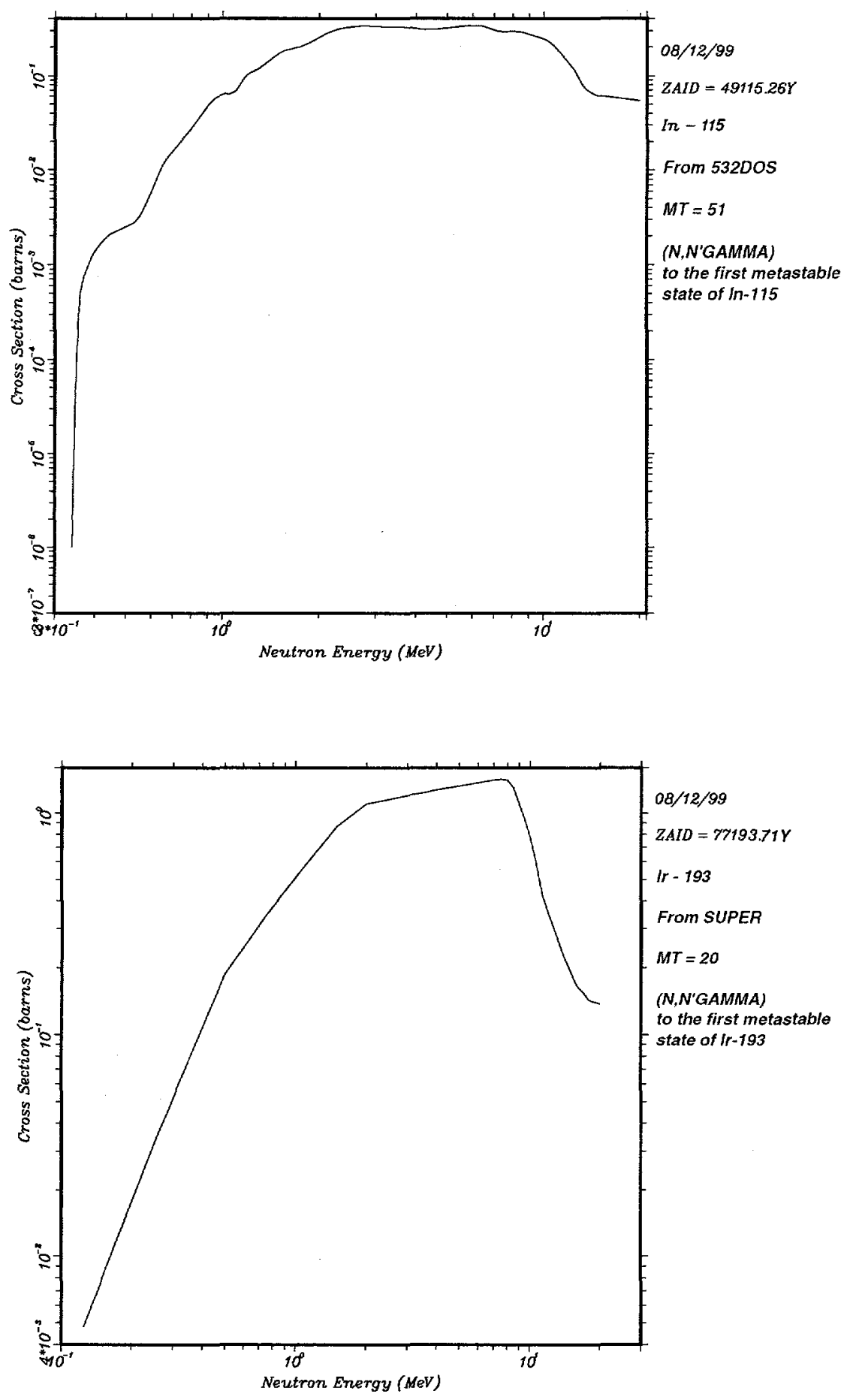